\title{
The Wind-to-Hydrogen Project: Operational Experience, Performance Testing, and Systems Integration
}

K.W. Harrison, G.D. Martin, T.G. Ramsden, and W.E. Kramer National Renewable Energy Laboratory

F.J. Novachek Xcel Energy

Technical Report NREL/TP-550-44082 March 2009 


\section{The Wind-to-Hydrogen Project: Operational Experience, Performance Testing, and Systems Integration}

K.W. Harrison, G.D. Martin, T.G. Ramsden, and W.E. Kramer

National Renewable Energy Laboratory

F.J. Novachek

Xcel Energy

Prepared under Task No. H271.3730

National Renewable Energy Laboratory

1617 Cole Boulevard, Golden, Colorado 80401-3393

303-275-3000 • www.nrel.gov

NREL is a national laboratory of the U.S. Department of Energy

Office of Energy Efficiency and Renewable Energy

Operated by the Alliance for Sustainable Energy, LLC

Contract No. DE-AC36-08-GO28308

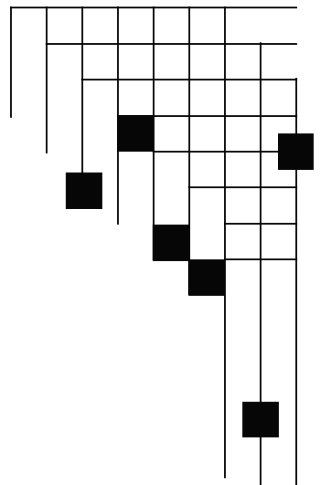




\section{NOTICE}

This report was prepared as an account of work sponsored by an agency of the United States government. Neither the United States government nor any agency thereof, nor any of their employees, makes any warranty, express or implied, or assumes any legal liability or responsibility for the accuracy, completeness, or usefulness of any information, apparatus, product, or process disclosed, or represents that its use would not infringe privately owned rights. Reference herein to any specific commercial product, process, or service by trade name, trademark, manufacturer, or otherwise does not necessarily constitute or imply its endorsement, recommendation, or favoring by the United States government or any agency thereof. The views and opinions of authors expressed herein do not necessarily state or reflect those of the United States government or any agency thereof.

Available electronically at http://www.osti.gov/bridge

Available for a processing fee to U.S. Department of Energy and its contractors, in paper, from:

U.S. Department of Energy

Office of Scientific and Technical Information

P.O. Box 62

Oak Ridge, TN 37831-0062

phone: 865.576 .8401

fax: 865.576 .5728

email: mailto:reports@adonis.osti.gov

Available for sale to the public, in paper, from:

U.S. Department of Commerce

National Technical Information Service

5285 Port Royal Road

Springfield, VA 22161

phone: 800.553.6847

fax: 703.605.6900

email: orders@ntis.fedworld.gov

online ordering: http://www.ntis.gov/ordering.htm 


\section{Acknowledgments}

The authors would like to recognize Rick Farmer, Roxanne Garland, and Jamie Holladay of the U.S. Department of Energy for funding this work. George Sverdrup of the National Renewable Energy Laboratory (NREL) and Vicki McCarl of Xcel Energy were both very helpful in scoping and defining the Wind2 $\mathrm{H} 2$ project and have provided excellent feedback throughout the project. Brad Hollenbaugh and Curtis Perry of Xcel Energy were instrumental in helping design and configure the Wind2H2 system and in participating in the readiness verification review. The authors would like to acknowledge John Cornish of EPC and Marc Mann of Spectrum Automation for their work installing and programming the Wind2H2 system. The authors would like to thank Connie Komomua for her assistance in editing the work. Finally, the authors would like to thank Robert Remick, Dave Mooney, Ben Kroposki, Mike Stewart, and Genevieve Saur of NREL for their technical assistance throughout the project. 


\section{List of Acronyms}

\begin{tabular}{|c|c|}
\hline $\mathrm{AC}$ & alternating current \\
\hline $\mathrm{AC} / \mathrm{DC}$ & AC-to-DC \\
\hline ASME & American Society of Mechanical Engineers \\
\hline atm & atmosphere \\
\hline $\mathrm{CG}$ & combustible gas \\
\hline $\mathrm{DC}$ & direct current \\
\hline $\mathrm{DC} / \mathrm{DC}$ & DC-to-DC \\
\hline DERTF & Distributed Energy Resources Test Facility \\
\hline DI & de-ionized \\
\hline DOE & U.S. Department of Energy \\
\hline EPC & Engineering Procurement \& Construction \\
\hline E-Stop & Emergency Stop \\
\hline FPGA & field programmable gate array \\
\hline GUI & graphical user interface \\
\hline $\mathrm{H}_{2}$ & hydrogen \\
\hline $\mathrm{HHV}$ & higher heating value \\
\hline hr & hour \\
\hline $\mathrm{I}-\mathrm{V}$ & current versus voltage \\
\hline $\mathrm{ICE}$ & internal combustion engine \\
\hline IGBT & insolated gate bipolar transistor \\
\hline IR & ohmic losses \\
\hline $\mathrm{I}_{\mathrm{SC}}$ & short circuit current \\
\hline $\mathrm{kg}$ & kilograms \\
\hline $\mathrm{kHz}$ & kiloHertz \\
\hline $\mathrm{KOH}$ & potassium hydroxide \\
\hline LFL & lower flammability limit \\
\hline LHV & lower heating value \\
\hline $\mathrm{m} / \mathrm{s}$ & meters per second \\
\hline $\mathrm{mA} \mathrm{cm} \mathrm{cm}^{-2}$ & milliamps per centimeter squared \\
\hline $\mathrm{mH}$ & milliHenry \\
\hline MIDC & Measurement and Instrumentation Data Center \\
\hline $\mathrm{MPH}$ & miles per hour \\
\hline MPP & maximum power point \\
\hline MPPT & maximum power point tracking \\
\hline MW & megawatts \\
\hline $\mathrm{M} \Omega-\mathrm{cm}$ & mega ohm-centimeter \\
\hline NEC & National Electric Code \\
\hline $\mathrm{Nm}^{3} / \mathrm{hr}$ & normal cubic meters per hour \\
\hline NREL & National Renewable Energy Laboratory \\
\hline NWTC & National Wind Technology Center \\
\hline $\mathrm{PE}$ & power electronics \\
\hline PEM & polymer electrolyte membrane \\
\hline PLC & programmable logic controller \\
\hline
\end{tabular}




$\begin{array}{ll}\text { ppmv } & \text { parts per million by volume } \\ \text { psig } & \text { pounds per square inch gauge } \\ \text { Pt } & \text { platinum } \\ \text { PV } & \text { photovoltaic } \\ \text { RE } & \text { renewable energy } \\ \text { RMS } & \text { root-mean-squared } \\ \text { RTD } & \text { resistive temperature device } \\ \text { RV } & \text { readiness verification } \\ \text { SCFH } & \text { standard cubic feet per hour } \\ \text { SLTS } & \text { soft-load transfer switch } \\ \text { STC } & \text { standard test conditions } \\ \text { UV/IR } & \text { ultraviolet/infrared } \\ \text { V-I } & \text { voltage versus current } \\ \mathrm{V}_{\text {OC }} & \text { open circuit voltage } \\ \text { Y } & \text { wye } \\ \eta_{\text {stack }} & \text { stack efficiency } \\ \mu J & \text { microjoules }\end{array}$




\section{Executive Summary}

Xcel Energy and the U.S. Department of Energy's (DOE) National Renewable Energy Laboratory (NREL) have collaborated to design, install, and operate the Wind-toHydrogen (Wind2H2) project. As the largest provider of wind generated electricity in the United States, Xcel Energy is working proactively with NREL to establish and understand state-of-the-art renewable electrolysis equipment and the operation of a renewable hydrogen production facility. Hosted at NREL's National Wind Technology Center (NWTC), the Wind2H2 system was approved for initial operation in March 2007 and is enjoying success as a demonstration project, producing hydrogen directly from renewable energy sources. This unique research-oriented project uses solar and wind energy to produce and store hydrogen. The stored hydrogen can be used both as a transportation fuel and as an energy storage medium, effectively allowing renewable energy to be stored and converted back to electricity at a later time.

The Wind $2 \mathrm{H} 2$ project is helping researchers understand the hurdles and potential areas for improvement in emerging renewable electrolysis technologies. By allowing engineers to operate and configure an integrated electrolysis facility, this project has enabled the investigation and analysis of hydrogen production, compression, storage, and electricity generation that is providing valuable data that are being used to improve the designs of future renewable electrolysis systems. This first report on the Wind2 2 project provides important guidance to industry and key stakeholders for development of future renewable electrolysis systems.

The Wind2H2 project is the only renewable hydrogen production facility in the world that can operate multiple electrolyzers in any of the following configurations:

1. Grid connected

2. Directly connected from the output of a photovoltaic array to the electrolyzer stack

3. Real-time electrolyzer stack current control based on a power signal from a wind turbine

4. Closely coupled photovoltaic (PV) and wind energy sources to the electrolyzer stack with custom designed and built power electronics.

NREL and Xcel Energy have undertaken the Wind2H2 project with several key objectives in mind. First and foremost, the Wind $2 \mathrm{H} 2$ project is being used to demonstrate operation of a renewable electrolysis system, allowing researchers to evaluate actual system performance and costs and to identify areas for cost and efficiency improvements. Additionally, the project provides operational experience with a renewable electrolysis hydrogen production facility, enabling project engineers to investigate operational challenges and to explore system-level integration issues and opportunities for performance and cost improvements resulting from system-level optimization. The project also seeks to investigate how to maximize the use of renewable energy resources in renewable hydrogen production systems by optimizing energy transfer from PV arrays and wind turbines to the stacks of commercial electrolyzers. Finally, the project is designed to explore operational challenges and opportunities related to energy storage 
systems and their potential for addressing electric system integration issues inherent with high penetrations of variable renewable energy resources.

To help enable greater penetration of renewable energy sources, hydrogen production from renewable electrolysis must be cost-competitive. DOE has a target of reducing the cost of central production of hydrogen from wind-based water electrolysis to $\$ 3.10 / \mathrm{kg}$ by 2012; by 2017 DOE seeks to reduce this cost to under $\$ 2 / \mathrm{kg}^{1}{ }^{1}$ Electrolyzer manufacturers are improving performance and reducing the capital cost of electrolyzer systems. At the same time, the complete renewable electrolysis system, including the renewable power source, electrolyzer, and interfacing power electronics, must be integrated and optimized to improve system performance and lower costs. The Wind2H2 project presents an excellent research platform to investigate these integration and optimization opportunities.

To achieve the objectives of the Wind2H2 project, NREL engineers have been working to complete a number of project tasks. These tasks include:

- Designing, building, and testing dedicated wind- and PV-to-electrolyzer stack power electronics to more closely integrate the renewable energy resources and electrolyzer stacks

- Modeling and simulating renewable electrolysis system performance to enable improved hydrogen production system designs

- Characterizing renewable energy system impacts on commercial electrolyzer technology and their ability to accommodate the varying energy input from wind and PV sources

- Sequencing multiple electrolyzer systems to improve overall system efficiency, responsiveness, and performance with varying renewable energy sources.

The challenge of renewable electrolysis is designing and implementing systems that can cost-effectively produce hydrogen from renewable sources using streamlined, robust, and efficient processes. When the wind turbine or solar array is co-located with the electrolysis system, more direct connection between the source and the electrolyzer stack is possible. This close-coupling eliminates the need for long distance transportation of electricity and reduces the number of electrical conversions resulting in a more efficient, cost-effective system.

In this report, specifications of the Wind2H2 equipment (electrolyzers, compressor, hydrogen storage tanks, and the hydrogen fueled generator) are summarized. System operational experience and lessons learned are discussed. Valuable operational experience is shared through running, testing, daily operations, and troubleshooting the Wind2H2 system and equipment errors are being logged to help evaluate the reliability of

\footnotetext{
${ }^{1}$ U.S. Department of Energy, (October 2007). Hydrogen, Fuel Cells \& Infrastructure Technologies Program: Multi-Year Research, Development and Demonstration Plan. Office of Energy Efficiency and Renewable Energy.
} 
the system. Project engineers have learned a number of valuable lessons from this system operational experience that will lead to improved design, implementation, and operational plans of renewable electrolysis systems. For example, integrated renewable electrolysis systems require that system components from different manufacturers be configured to function smoothly together. In light of this, programmable logic control systems need to be able to communicate with all major elements of the system (e.g., electrolyzers, compressors, power converters, and load transfer switches).

As another primary goal of the project, NREL engineers have investigated how to maximize renewable energy use and optimize energy transfer within the system. These types of system optimization efforts can significantly reduce the cost of renewable hydrogen. In an analysis of the potential improvements to a wind electrolysis system, project engineers estimated that optimized power electronics would result in a cost improvement of seven percent, reducing the cost of hydrogen produced from wind to $\$ 5.83 / \mathrm{kg}$ from a baseline of $\$ 6.25 / \mathrm{kg}^{2}$. For reference, DOE has a target for reducing the cost of central production of hydrogen from wind-based electrolysis to $\$ 3.10 / \mathrm{kg}$ by 2012 . To investigate such optimization opportunities, NREL developed multiple power electronics configurations that convert varying electricity from a solar PV array and wind turbines into the electricity used by the electrolyzer stacks directly. These power converters have the added benefit of executing maximum power point tracking (MPPT) from the wind turbine or PV array to enable higher energy transfer to the electrolyzer stack than a simple, unoptimized, direct connect configuration.

Two electrolyzer technologies are being tested and characterized - namely, polymer electrolyte membrane (PEM) and alkaline electrolyzer systems. Efficiencies of the PEM and alkaline electrolyzers were calculated using experimental data from system operation. Electrolyzer system and stack efficiency is reported on both the higher heating value (HHV) basis of hydrogen $(39.4 \mathrm{kWh} / \mathrm{kg})$ and the lower heating value (LHV) basis $(33.3 \mathrm{kWh} / \mathrm{kg})$. Table 1 summarizes the results of electrolyzer stack and electrolyzer system efficiency measurements. Stack efficiency peaks at low current while the overall electrolyzer system efficiency is greatest when operating at rated stack current.

Table 1: Electrolyzer system and stack efficiency

\begin{tabular}{ccccc}
\hline \multirow{2}{*}{ Efficiency } & \multicolumn{2}{c}{ PEM Electrolyzer } & \multicolumn{2}{c}{ Alkaline Electrolyzer } \\
& LHV & HHV & LHV & HHV \\
\hline Stack Efficiency & & & & \\
\hline Low Current & $80 \%(5 \mathrm{~A})$ & $95 \%(5 \mathrm{~A})$ & $78 \%(30 \mathrm{~A})$ & $92 \%(30 \mathrm{~A})$ \\
Rated Current & $63 \%(5 \mathrm{~A})$ & $75 \%(135 \mathrm{~A})$ & $59 \%(220 \mathrm{~A})$ & $70 \%(220 \mathrm{~A})$ \\
System Efficiency & & & & \\
Low Current & $0 \%(15 \mathrm{~A})$ & $0 \%(15 \mathrm{~A})$ & $0 \%(35 \mathrm{~A})$ & $0 \%(35 \mathrm{~A})$ \\
Rated Current & $49 \%(135 \mathrm{~A})$ & $57 \%(135 \mathrm{~A})$ & $35 \%(220 \mathrm{~A})$ & $41 \%(220 \mathrm{~A})$ \\
\hline
\end{tabular}

\footnotetext{
${ }^{2}$ See Section 5.2 for the full description and assumptions of this analysis.
} 
Voltage-current (V-I) characteristic curves were obtained by sweeping direct current (DC) to the electrolyzer stack. These V-I curves are compared with the theoretical stack voltage $(1.48 \mathrm{~V}$ per cell) adjusted for the nominal electrolyzer operating gas pressure to determine stack efficiency. System efficiency is determined by summing the electrolyzer stack load plus all ancillary electrical loads divided by the amount of hydrogen produced in kilograms $(\mathrm{kg})$ compared with the HHV of hydrogen.

The PV array connected to the electrolyzer stack with and without an intermediary power converter was tested and analyzed. The PV array was configured to supply different input voltages to a step-down, DC-to-DC (DC/DC) power converter over many days of testing. We found that the use of the power converter increases the energy delivered to the electrolyzer stack by $10 \%-20 \%$, depending on the PV array input voltage to the power converter. The efficiency of the power converter decreased as the input voltage from the PV array increased. Still, the highest input voltage from the PV array to the power converter provided the maximum energy capture to the electrolyzer stack. In other words, while suffering from the largest difference between PV voltage and electrolyzer stack voltage $(\Delta \mathrm{V})$, the configuration provided the largest amount of energy to the stack over a given day.

A $10 \mathrm{~kW}$ wind turbine was connected to one of the PEM electrolyzer stacks through an MPPT-alternating current (AC)-to-DC power converter. This configuration represents a non-grid-tied (i.e., stand-alone) configuration closely coupling a wind turbine to the electrolyzer stack. Testing and analysis shows that the AC-to-DC (AC/DC) converter has the ability to both maintain optimal operation of the turbine while delivering power to the electrolyzer stack without a battery link. It eliminates several power electronics conversions inherent in grid-tied electrolyzer configurations as well as a battery and associated maintenance. This $\mathrm{AC} / \mathrm{DC}$ power converter is undergoing upgrades that are expected to further increase the energy capture from the wind turbine.

Operation of the Wind2H2 system will continue with a focus on achieving project objectives. Future work includes the continued design and testing of optimization strategies and hardware, along with performance evaluation of these improved systems. This includes maximizing the transfer of wind and solar energy by better integrating system components and developing optimized power electronics packages. Improved sequencing of electrolyzer stacks to maximize hydrogen output will be designed, implemented, and tested and these optimized system configurations will be analyzed to determine the performance of the revised systems. Finally, a virtual connection between the $100 \mathrm{~kW}$ wind turbine power signal and $30 \mathrm{~kW}$ alkaline stack power controller will vary stack current and enable the characterization of the system performance under highly varying conditions.

One of the major tasks going forward will be to determine how the findings of the Wind2H2 project can improve performance and reduce the cost of renewable electrolysis production systems. The results of system optimization efforts, performance

measurements, and evaluation data will be used in economic models to better understand how these system improvements can lower the cost of hydrogen produced via renewable electrolysis. 


\section{KEY FINDINGS AND LESSONS LEARNED TO DATE}

- System Integration: More research and engineering design related to renewable electrolysis system integration will improve energy transfer and overall system efficiency and reduce system complexity and capital costs.

- Development of optimized power electronics packages in particular is a promising area for system-level improvements.

- Development of open architecture communication protocols between different component manufacturers would greatly simplify system integration efforts.

- Codes and Standards: Development of clear and consistent codes and standards will expedite implementation and reduce the cost of renewable electrolysis projects

- Efficiency Measurements: Based on the testing of the Wind2H2 project's small electrolyzer systems, PEM electrolyzers were found to be more efficient than the alkaline electrolyzer; counter to expectations.

- Energy Transfer Optimization:

- Analysis shows a potential 7\% reduction in the cost of hydrogen if the wind turbine inverters are replaced with DC/DC converters that feed directly to the electrolyzer stacks.

- For solar PV systems, NREL determined that the use of an optimized power electronics package (called a maximum power point tracking system - MPPT) captured between $10 \%$ and $20 \%$ more energy than a direct connection to the electrolyzer stack.

\section{IMPLICATIONS FOR ELECTRIC UTILITIES' COMPONENT SUPPLIERS AND HYDROGEN-BASED ENERGY STORAGE SYSTEMS INTEGRATORS}

Notwithstanding the previously identified issue that hydrogen-based energy storage system component capital costs and efficiencies must continue to improve to become competitive with other electric utility production and storage options, the following needs must also be addressed:

- Establish open architecture and communication protocols

- Design wind turbines and electrolyzers with each other in mind, to be part of an energy storage system

- Simplify and standardize codes and standards for electrolysis-based energy storage systems

- Optimize energy transfer within the system and eliminate redundant components

- Standardize system sizes and match component sizes. Until standardized designs and component sizes are developed, system integrators need to determine appropriate component sizes to meet the needs of electrolysis-based energy storage projects on a case-by-case basis. 


\section{Table of Contents}

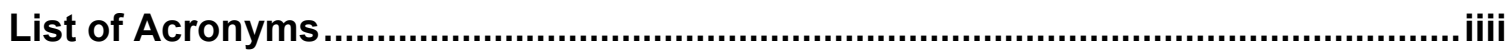

Executive Summary …............................................................................................vi

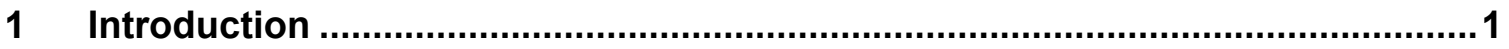

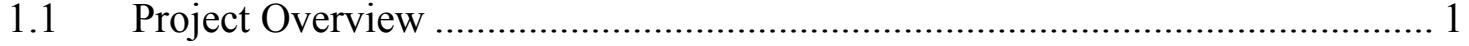

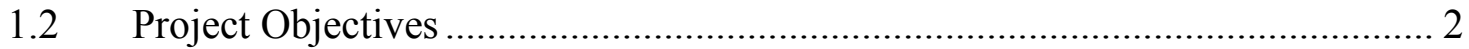

1.3 Hydrogen Production and Renewable Electrolysis............................................. 4

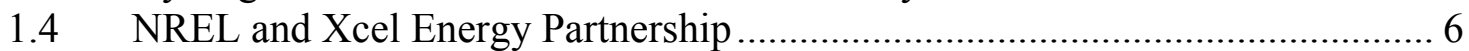

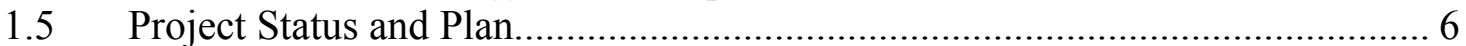

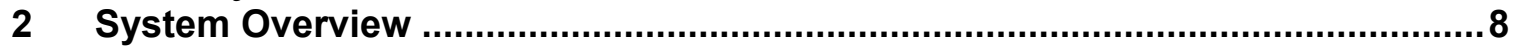

$2.1 \quad$ Hydrogen System...................................................................................... 13

2.1.1 PEM Electrolyzers (E-120 and E-130) ………...................................... 13

2.1.2 Alkaline Electrolyzer (E-110) ............................................................ 15

2.1.3 Compressor (C-200)......................................................................... 16

2.1.4 Hydrogen Storage Tanks..................................................................... 16

2.1.5 Internal Combustion Generator (G-400).................................................... 17

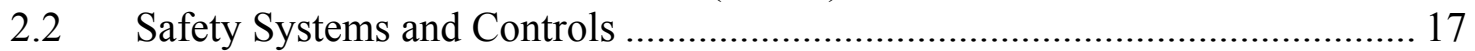

2.2.1 Production and Compression Building …………....................................... 17

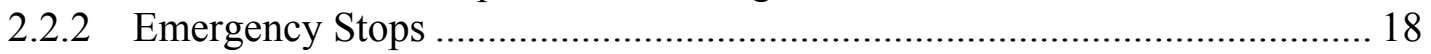

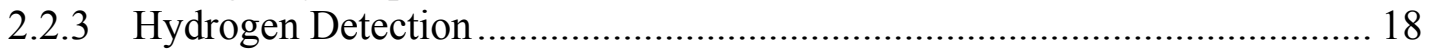

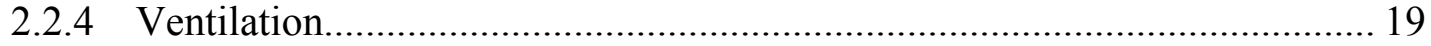

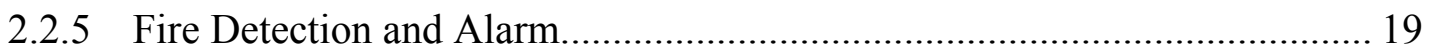

2.2.6 Hydrogen Vent Flare Monitor ................................................................ 19

2.2.7 High Pressure Isolation ....................................................................... 19

2.3 Renewable Energy Sources........................................................................ 19

2.3.1 Photovoltaic Solar Array........................................................................ 19

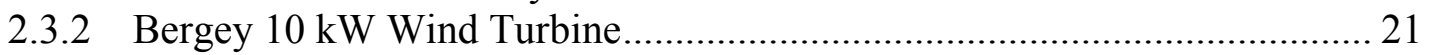

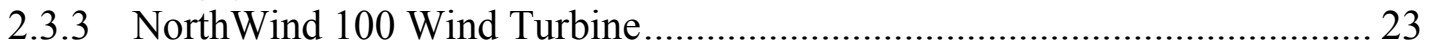

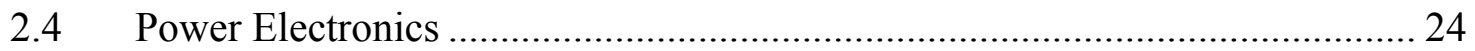

2.4.1 DC-to-DC Buck Converter with MPPT ...................................................... 24

2.4.2 AC-to-DC Turbine MPPT Converter...................................................... 25

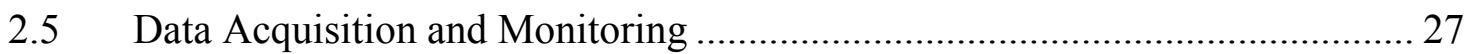

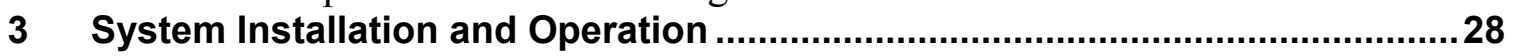

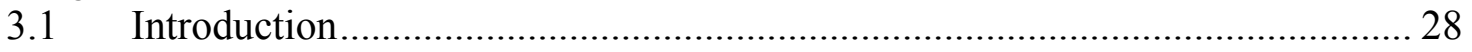

3.2 System Installation and Configuration............................................................. 29

3.3 Safety, Hazardous Operations Review, and Readiness Verification ................. 30

3.4 System Operational Experience.................................................................... 32

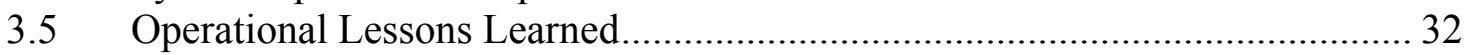

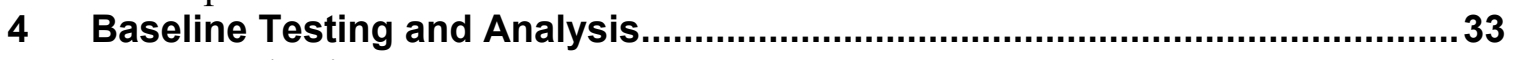

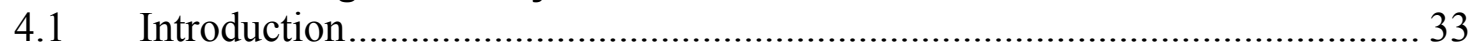

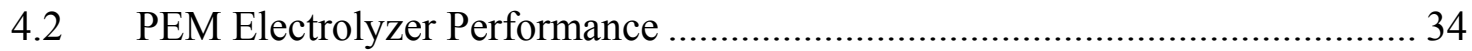

4.2.1 E-130 Stack Polarization Curves .............................................................. 34 


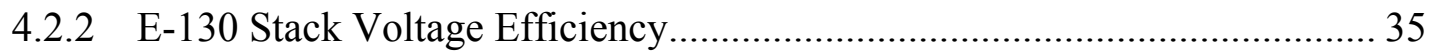

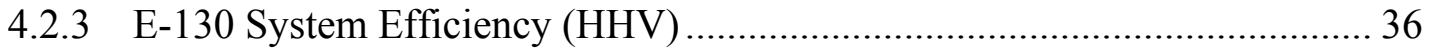

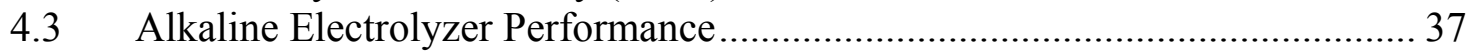

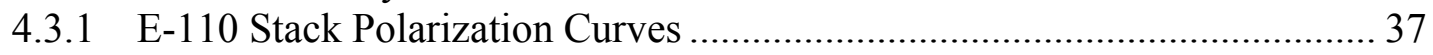

4.3.2 E-110 Stack Voltage Efficiency............................................................. 38

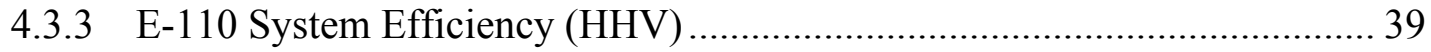

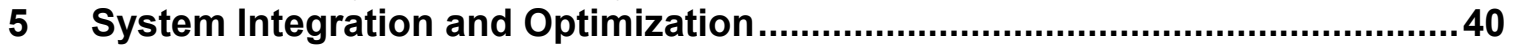

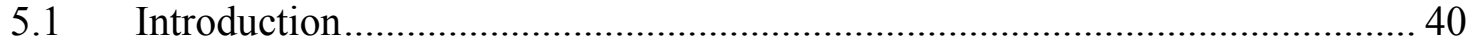

5.2 Economic Analysis of System Integration Opportunities............................... 41

5.3 Small Wind Powered Electrolysis Testing and Analysis................................ 43

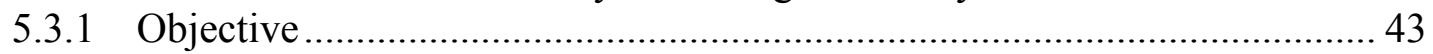

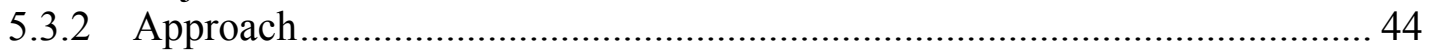

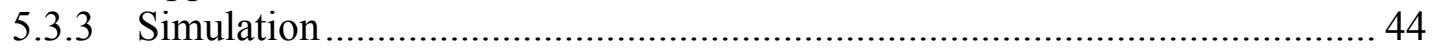

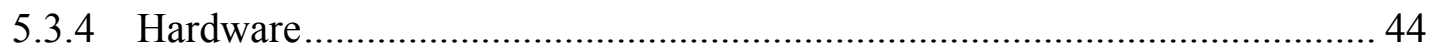

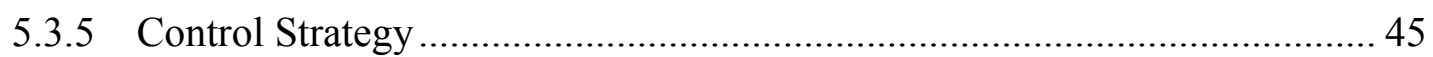

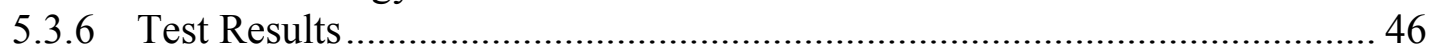

$5.4 \quad$ Solar-Powered Electrolysis Testing and Analysis ...................................... 50

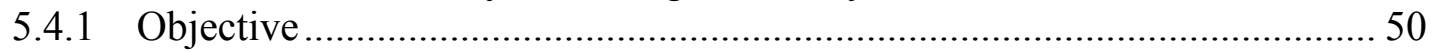

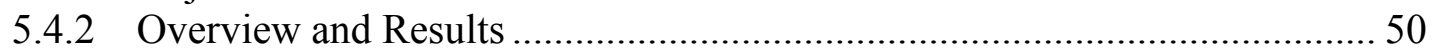

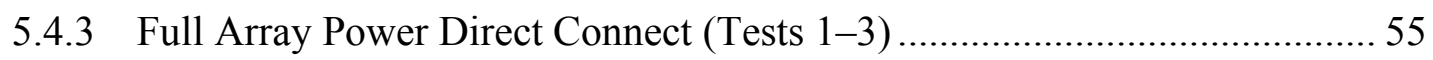

5.4.4 Full Array-Power MPPT Electronics (Tests 4-11)........................................ 58

5.4.5 Split Array Direct and MPPT Comparison (Tests 12-15)............................62

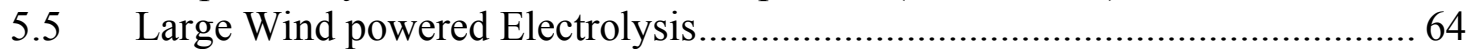

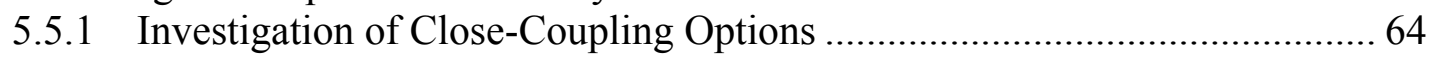

5.5.2 Real-Time Electrolyzer Operation Linked to Wind Turbine Output............ 67

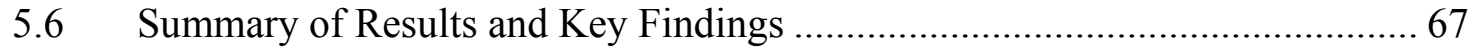

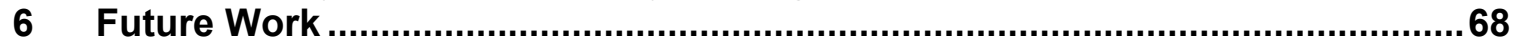

6.1 Renewable Electrolysis Cost Analysis and Modeling ................................. 68

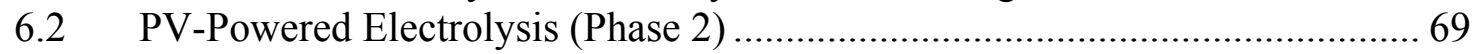

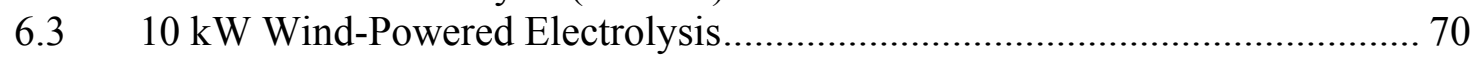

$6.4 \quad 100 \mathrm{~kW}$ Wind-Powered Electrolysis........................................................... 71

6.5 Electrolyzer Sequencing and Autonomous Operation ................................... 72

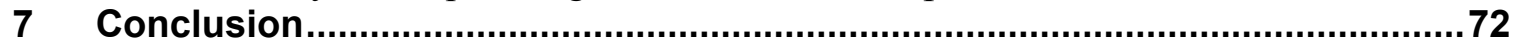

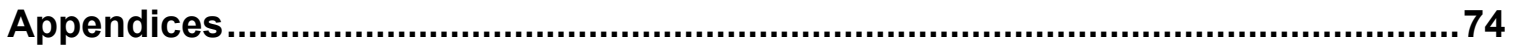




\section{List of Figures}

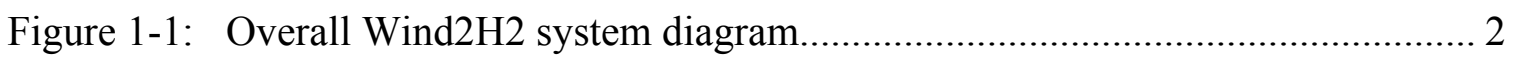

Figure 1-2: Wind2H2 project timeline............................................................... 7

Figure 2-1: Aerial photograph of Wind2H2 site and equipment .................................... 8

Figure 2-2: Baseline grid connected (AC) system configuration .................................... 9

Figure 2-3: $\mathrm{PV}$-powered electrolysis system configuration with DC/DC power converter to PEM electrolyzer stack ..................................................................... 10

Figure 2-4: $10 \mathrm{~kW}$ wind powered electrolysis system configuration with AC/DC power converter to PEM electrolyzer stack ........................................................ 10

Figure 2-5: $100 \mathrm{~kW}$ wind powered electrolysis system configuration using real-time power signal to vary stack current .......................................................... 11

Figure 2-6: $100 \mathrm{~kW}$ wind powered electrolysis system with PE interface to stack........ 11

Figure 2-7: PEM electrolyzer enclosure and internal components................................ 14

Figure 2-8: Alkaline hydrogen generator system components ...................................... 15

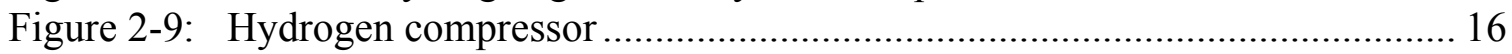

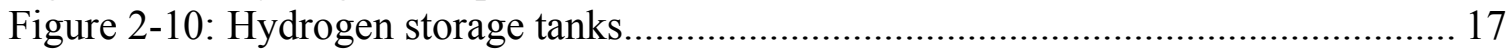

Figure 2-11: Hydrogen-fueled internal-combustion generator ......................................... 17

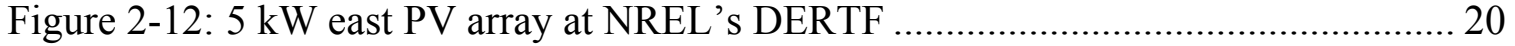

Figure 2-13: SX-120s solar panel I-V characteristic ................................................... 20

Figure 2-14: $10 \mathrm{~kW}$ Bergey Excel-S wind turbine at the NWTC .................................. 21

Figure 2-15: Enhanced wind-to-hydrogen system................................................. 22

Figure 2-16: Bergey Excel-S experimental power data.................................................. 22

Figure 2-17: $100 \mathrm{~kW}$ NorthWind 100 turbine located at NREL's NWTC ..................... 23

Figure 2-18: Manufacturer-provided power curve for NorthWind 100 turbine at standard (sea level) air density.......................................................................... 23

Figure 2-19: DC/DC step-down (buck) converter circuit................................................ 24

Figure 2-20: DC/DC step-down converter components and filter elements .................... 25

Figure 2-21: AC/DC controlled rectifier circuit …………………………………..... 26

Figure 2-22: AC/DC converter internal components (bottom) and filter elements (top .. 27

Figure 2-23: GUI system monitoring and controls interface ………………………….... 28

Figure 4-1: PEM E-130 stack polarization curves at $35^{\circ} \mathrm{C}$ and $55^{\circ} \mathrm{C}$........................... 35

Figure 4-2: Stack-efficiency data at $55^{\circ} \mathrm{C}, 195 \mathrm{psi}$ cathode, and $30 \mathrm{psi}$ anode for PEM

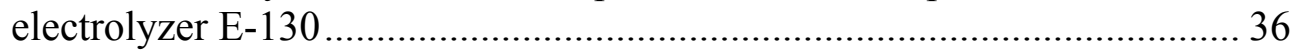

Figure 4-3: Alkaline E-110 stack polarization curves at $46^{\circ} \mathrm{C}$ and $72^{\circ} \mathrm{C}$...................... 38

Figure 4-4: Stack efficiency data at $72^{\circ} \mathrm{C}$, cathode pressure of $137 \mathrm{psi}$, and anode pressure of $137 \mathrm{psi}$ for alkaline electrolyzer E-110 …………………....... 39

Figure 4-5: E-110 resulting hydrogen flow for different stack-current levels................ 40

Figure 5-1: General model control block diagram......................................................... 44

Figure 5-2: Anemometer wind-speed data-acquisition system for Bergey turbine ........ 46

Figure 5-3: Wind velocity as a function of time …………………………………...... 47

Figure 5-4: Hydrogen production and stack current as a function of time..................... 47

Figure 5-5: Stack resistance as function of current....................................................... 48 
Figure 5-6: Hydrogen flow rate as a function of current for actual wind input.

Figure 5-7: Realized and planned increase in energy capture from generation 1 through $3 \mathrm{AC} / \mathrm{DC}$ power converters.

Figure 5-8: System efficiency illustration for direct connect configuration................... 52

Figure 5-9: System efficiency illustration for MPPT electronics configuration ............ 52

Figure 5-10: PE efficiency measurements and calculations for all tests ........................ 54

Figure 5-11: Solar array I-V and power characteristic for configuration A-1 ............... 56

Figure 5-12: Direct connection test results from test 3 ......................................... 57

Figure 5-13: Detail of hydrogen flow output cycling from PEM electrolyzer ................. 58

Figure 5-14: PV array I-V characteristic for configuration A-2 …............................. 59

Figure 5-15: PV array I-V characteristic for configuration A-3 ................................ 59

Figure 5-16: MPPT converter test 10 with $65.6 \mathrm{~V}$ MAX $\mathrm{PV}$ array voltage ......................... 60

Figure 5-17: Results of MPPT converter test 4 with 131.2 $\mathrm{V}_{\mathrm{MAX}} \mathrm{PV}$ array voltage ........ 61

Figure 5-18: Results of MPPT converter test 6 with $262.4 \mathrm{~V}_{\text {MAX }} \mathrm{PV}$ array voltage ........ 61

Figure 5-19: Test 12, both PV arrays at $65.6 \mathrm{~V}_{\mathrm{MAX}}$, MPPT powering E-120 ................. 62

Figure 5-20: Test 13, both PV arrays at $65.6 \mathrm{~V}_{\mathrm{MAX}}$, MPPT powering E-130 .................. 63

Figure 5-21: Test 4, PV west at 65.6 $\mathrm{V}_{\text {MAX }}$ direct, PV east at 131.2 $\mathrm{V}_{\text {MAX }}$, MPPT powering E-120.

Figure 5-22: Test 15, PV west at 65.6 $\mathrm{V}_{\mathrm{MAX}}$ direct, PV east at 262.4 $\mathrm{V}_{\mathrm{MAX}}$, MPPT

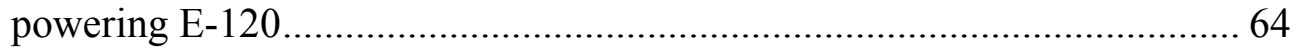

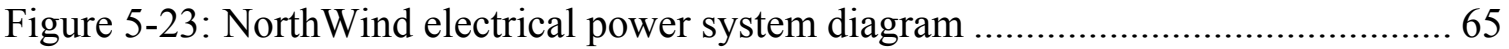

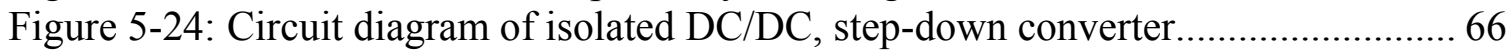

Figure 6-1: Additional 10-cell PEM stack cells to be installed in series with existing 20cell stack inside E-120 electrolyzer 69

Figure 6-2: Impacts of adding 10 additional electrolyzer cells to the 20 -cell stack ....... 70 


\section{Introduction}

\subsection{Project Overview}

Xcel Energy and the U.S. Department of Energy's (DOE) National Renewable Energy Laboratory (NREL) have collaborated to design, install, and operate the Wind2H2 project. As the largest provider of wind generated electricity in the United States ${ }^{3}$, Xcel Energy is working proactively with NREL to establish and understand state-of-the-art renewable electrolysis equipment and the operation of a renewable hydrogen production facility. Hosted at NREL's National Wind Technology Center (NWTC), the Wind2H2 system was approved for initial operation as a demonstration project in March 2007 and is successfully producing hydrogen directly from renewable energy (RE) sources. This unique research-oriented project uses solar and wind energy to produce and store hydrogen. The stored hydrogen can be used both as a transportation fuel and as an energy storage medium, effectively allowing RE to be stored and converted back to electricity at a later time.

The Wind2H2 project is helping researchers understand the hurdles and potential areas for improvement in emerging renewable electrolysis technologies. By allowing engineers to operate and configure an integrated electrolysis facility, this project has enabled the investigation and analysis of hydrogen production, compression, storage, and electricity generation that will provide valuable data as renewable electrolysis systems move towards commercialization. The Wind2 $\mathrm{H} 2$ project allows operation of the electrolyzer system in a variety of configurations, including grid connected operation, direct connection of a photovoltaic (PV) array to the electrolyzer stack, and coupling of a wind turbine to the electrolyzer stack. The wide array of system configurations enables engineers to evaluate system performance and investigate means to better integrate a renewable electrolysis system and optimize energy use. Information from the Wind2H2 project is expected to be used to improve future system performance and lower the cost of hydrogen from renewable energy.

Figure 1-1 shows the major components, power electronics (PE), electrical flow (red), and hydrogen flow (blue) of the Wind2 $\mathrm{H} 2$ project. The following components and configurations are specifically covered in this report:

- Alkaline electrolyzer (E-110) baseline performance characteristics

- PEM electrolyzer (E-120 and E-130) baseline performance characteristics

- E-120 and E-130 operation directly connected to PV source

- E-120 and E-130 operation powered by PV source via maximum power point tracking DC-to-DC (DC/DC) PE

- E-120 and E-130 operation powered by 10 kilowatt $(\mathrm{kW})$ wind turbine via maximum power point tracking (MPPT) AC-to-DC (AC/DC) PE.

\footnotetext{
${ }^{3}$ American Wind Energy Association, (2008). “AWEA 2008 Annual Rankings Report.” Accessed April, 2008. http://www.awea.org/publications/reports/rankings.pdf.
} 


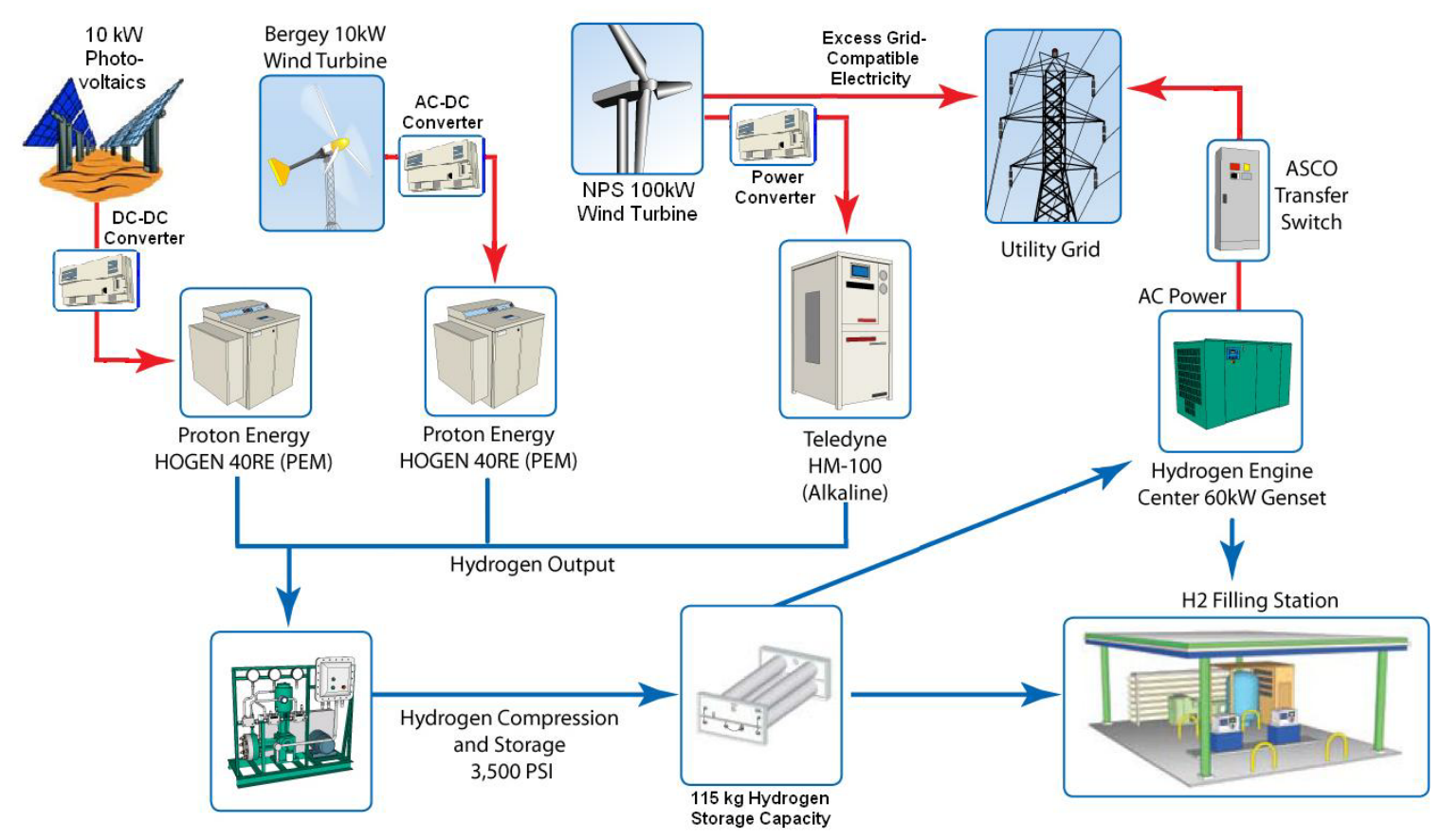

Figure 1-1: Overall Wind2H2 system diagram

A number of Wind2H2 investigations of system components and configurations are either planned or underway. These activities will be covered in an upcoming Wind2H2 report:

- Hydrogen compressor (C-200) performance

- Hydrogen generator (G-400) performance

- E-120 and E-130 operation with $10 \mathrm{~kW}$ wind turbine using upgraded AC/DC converter

- Next phase of PV-powered electrolysis testing with optimally sized polymer electrolyte membrane (PEM) stack

- Equipment maintenance and error logs

- Progress update and plan for connection of $100 \mathrm{~kW}$ wind turbine to $30 \mathrm{~kW}$ alkaline electrolyzer stack

- Update on the construction of the hydrogen filling station

- Update on the installation of additional hydrogen storage capacity

\subsection{Project Objectives}

The Wind2H2 project provides a unique opportunity to demonstrate and optimize integrated RE systems for producing, compressing, and storing hydrogen for end-use as a transportation fuel or conversion back to grid-compatible electricity. A cost goal of \$2 - 
$\$ 3$ per kilogram ( $\mathrm{kg}$ ) (delivered) of hydrogen as a transportation fuel has been set forth by $\mathrm{DOE}^{4}$. At the same time, to enable greater penetration of renewable energy sources, DOE has a target of reducing the cost of central production of hydrogen from wind-based electrolysis to $\$ 3.10 / \mathrm{kg}$ by 2012 , with a further target of $\$ 2 / \mathrm{kg}$ by 2017 . This research aims to bring renewable electrolysis technology closer to that goal. This demonstration project aims to investigate ways to improve the system efficiency and to reduce the capital costs of producing, delivering, and using hydrogen from renewable resources.

The Wind2 2 2 project is focused on the investigation; characterization; and PE design, build, and testing to integrate wind and PV energy sources with electrolytic hydrogen production. The research is evaluating commercially available electrolysis systems that are closely coupled with wind turbines and PV panels. This project provides a unique opportunity where the wind turbine and PV array are co-located with the electrolysis system enabling more direct connection between the RE source and the electrolyzer stack to improve system capital cost and efficiency. There are several key focus areas of this research:

- Direct-coupling RE sources with new optimized PE packages tied directly to the electrolyzer stack

- Analysis of the effects of variable power on electrolytic hydrogen production

- Cost and efficiency analysis of RE to electrolyzer systems

- Recommendations for RE source and electrolyzer stack/system sizing

- Control strategies and improved design to better accommodate RE sources.

By accomplishing these tasks, the Wind2H2 project seeks to fulfill a number of objectives. First and foremost, the Wind2H2 project is being used to demonstrate operation of a renewable electrolysis system, allowing researchers to evaluate actual system performance and costs and to identify areas for cost and efficiency improvements. Additionally, the project provides operational experience with a renewable electrolysis hydrogen production facility, enabling project engineers to investigate operational challenges and to explore system-level integration issues and opportunities for performance and cost improvements resulting from system-level optimization. The project also seeks to investigate how to maximize the use of renewable energy resources in renewable hydrogen production systems by optimizing energy transfer from PV arrays and wind turbines to electrolyzer units. Finally, the project is designed to explore operational challenges and opportunities related to energy storage systems and their potential for addressing electric system integration issues inherent with high penetrations of variable renewable energy resources.

A number of specific tasks for this project have been defined to support the above program objectives. These areas of research and analysis are designed to provide meaningful data and analysis that will both define the current opportunities in renewable

\footnotetext{
${ }^{4}$ See Section 5.2 for the full description and assumptions of this analysis.
} 
hydrogen production and establish recommendations for the future industrial development of these technologies. These tasks include:

- Explore system-level integration issues related to multiple electrolyzers that produce hydrogen gas at different pressures

- Evaluate the ability to integrate energy from variable speed wind turbines and PV arrays directly to the hydrogen producing stacks of commercially available electrolyzers

- Determine the system impacts and ability of each electrolyzer technology to accommodate the varying energy input from wind turbines and photovoltaics

- Evaluate appropriate safety and control systems for the safe operation of RE sources for hydrogen production

- Explore operational challenges and opportunities related to energy storage systems and their potential for addressing electric system integration issues inherent with variable energy resources

- Demonstrate operation of a wind-to-hydrogen system to enable evaluation of actual system costs and identify areas for cost and efficiency improvements

- Gain operational experience of a hydrogen production facility, including the compression of product gas and the use of a hydrogen internal combustion engine to generate electricity during peak demand hours

- Design, build, and integrate dedicated wind- and PV-to-electrolyzer stack PE to more closely couple the RE resources and electrolyzer stacks.

\subsection{Hydrogen Production and Renewable Electrolysis}

Because of the effects of carbon emissions on global climate change, a carbonconstrained world is coming, and alternative energy sources will be required to supplement the carbon-intensive sources that currently power homes, businesses, and motor vehicles. Natural gas is available, but the supply is limited, and its costs are expected to rise because of increased demand. Coal will continue to supply power for much of our electricity demand, but technologies to enable large-scale carbon capture and sequestration are in their infancy. Advanced nuclear energy plants can be used to produce greenhouse gas-free electricity, but issues surrounding waste disposal, risk, and escalating capital costs remain.

One promising solution to this problem is the direct use of renewably generated hydrogen in fuel cells or in internal combustion engines for transportation and electricity generation. Hydrogen, the lightest element, is not a primary energy source like oil or coal but instead is an energy carrier like electricity. Hydrogen can be manufactured or extracted from hydrogen-rich materials such as coal, natural gas, biomass, or water. Currently, the primary means of manufacturing hydrogen is to strip it from natural gas (which is mostly methane, $\mathrm{CH}_{4}$ ) via steam methane reforming. 
Today's commercial electrolyzer systems are designed for operation from grid supplied $\mathrm{AC}$ electricity with little regard for system efficiency. Integrating power electronics, between the RE source and stack, provides opportunity to improve efficiency and to reduce capital cost of the system. Capital cost is significant, and its reduction can aid in the economic feasibility of both central and distributed hydrogen production. Greater understanding of the system performance under variable input power will help to guide the design of optimized renewably coupled systems. Renewable hydrogen can offer benefits both in enabling higher penetration of RE sources as well as in emerging hydrogen markets to assure that the emerging hydrogen economy accomplishes the required environmental benefits as well.

Increased focus on adding RE sources to the energy system has recently been punctuated by the release of a report from DOE on how the United States can achieve 20\% wind power by 2030 (refer to www.20percentwind.org). This coincides with continuing scrutiny of how to integrate hydrogen into the mix as both a transportation fuel and a grid support for variable RE sources. The Wind2 $\mathrm{H} 2$ system is a renewably powered project that is enabling the investigation and analysis of hydrogen production, compression, storage, and electricity generation providing valuable data as the case for electrolysis is made.

In large-scale centralized production of hydrogen, there may be advantages to directly coupling RE sources with the electrolyzer stacks and thereby eliminating some of the conversion and transmission losses inherent in using the grid as an intermediary. The benefit comes from two particular facts: 1) the electrolyzer stack can function effectively from variable sources, and 2) the stack, which accounts for the most of the electricity load, operates on direct current (DC).

Variable speed wind turbines operate more efficiently than constant speed turbines by maintaining a more optimal tip speed ratio over a wider range of wind speeds. The variable speed rotor typically drives a multi-poled generator directly producing varying magnitude/frequency alternating current (AC) that must be rectified to DC before being inverted to constant frequency $\mathrm{AC}$ to export to the grid. Conversion steps can be consolidated in these configurations by bypassing the grid and powering the electrolysis stack directly. PV arrays generate DC power, so significant conversion losses may be avoided by direct-coupling with optimally sized components. Configuring and sizing the PV array to better match the electrolyzer stack operating point will reduce losses.

Producing hydrogen with domestic RE sources will reduce the impact of greenhouse gasses emitted into the atmosphere, lessen our dependence on foreign oil for transportation, and improve national security. Wind energy is currently the lowest cost $\mathrm{RE}$ source, and is the leading near term candidate for renewably generated hydrogen production. As wind energy penetration increases it could be beneficial to produce hydrogen during times of high wind and low electricity demand, and then generate electricity from stored hydrogen when demand is high. Energy storage systems have the potential address electric system integration issues inherent with variable wind and PV energy resources, thereby enabling higher amounts of renewable sources on the electric system. 


\subsection{NREL and Xcel Energy Partnership}

NREL and Xcel Energy signed a cooperative agreement for an innovative, wind-tohydrogen research, development, and demonstration project. Researchers were tasked with analyzing and comparing hydrogen production from wind, PV, and power from the electric grid. The partnership between NREL and Xcel Energy supports the goals of DOE's Hydrogen, Fuel Cells \& Infrastructure Technologies Program. NREL is DOE's primary national laboratory for renewable energy and energy efficiency research and development.

Xcel Energy is a major U.S. electricity and natural gas company with operations in 10 western and midwestern states. Xcel Energy leads the nation in providing wind energy to its customers - more than any other utility in the United States, according to the American Wind Energy Association. At the end of 2007, Xcel had roughly 2,800 megawatts (MW) of wind capacity installed on their system, and their long range plans call for them to have 6,000 MW of wind on their entire system by 2020. Xcel Energy has a strong commitment to protecting the environment and a long history of bold environmental initiatives to help reduce the impact of electricity production. This Wind2H2 project is another example of Xcel Energy's dedication to environmental stewardship.

This partnership combines NREL's expertise in renewable energy and hydrogen production with Xcel Energy's expertise in energy transmission, distribution, and use. Xcel Energy invested roughly $\$ 1$ million in the project. NREL and DOE invested approximately $\$ 1$ million to upgrade NREL's infrastructure and are providing ongoing funding for researcher time to operate the facility and to conduct the data analysis. After the demonstration is completed, Xcel Energy plans to move the equipment elsewhere on its system.

This partnership provides a unique opportunity to analyze and compare hydrogen production from wind, PV, and the electricity from the grid. The research-based demonstration project uses hydrogen as both an energy storage medium and a transportation fuel and is helping stakeholders and researchers to understand both the hurdles and potentials for improvement in an emerging technology. This project will explore new synergies for hydrogen as an energy storage medium and as a transportation fuel. Most important, the project aims to overcome the variable aspect of RE sources by enabling energy storage for later use when demand for electricity is high or as a fuel for the transportation sector.

\subsection{Project Status and Plan}

Commissioning of the Wind2H2 demonstration project occurred in March 2007. System shakedown, safety system improvements, instrumentation, hazardous classification, and PE development and installation occurred throughout 2007. In March 2008, the system cleared NREL's final safety review to enable daily operations with various RE configurations. Since then, new instrumentation and data archiving have been added to nearly every major device to monitor performance. In addition, software improvements to the system programmable logic controller (PLC) have enhanced the monitoring and control of the equipment. 
Figure 1-2 outlines the four major areas of work that comprise the Wind2H2 project: 10 $\mathrm{kW}$ wind-powered electrolysis, PV-powered electrolysis, $100 \mathrm{~kW}$ wind-powered electrolysis, and hydrogen filling station. In addition to these four areas, modeling and cost analysis work will continue in parallel. This report includes technical performance and analysis for the PV-and wind-powered electrolysis efforts.

Phase 1 of the $10 \mathrm{~kW}$ wind-powered electrolysis consists of the initial design, development, and testing of the $\mathrm{AC} / \mathrm{DC}$ converter. The testing and analysis results from this work are presented in Section 4 of this report. Phase 2 of this effort focuses on upgrades to the software and hardware prior to the next round of hardware testing and analysis. Phase 1 of the PV-powered electrolysis effort consisted of design, build, and testing of the PE, system, and data analysis. The results from this effort are presented in Section 5.4 of this report. Phase 2 plans to add an addition half-stack to one of the PEM electrolyzers (E-120) to bring the operating voltage of the stack closer to the maximum power point (MPP) of the PV array.

The $100 \mathrm{~kW}$ wind-powered electrolysis effort is investigating the best option for closecoupling the turbine and the electrolyzer stack. In the meantime, Phase 1 will vary the electrolyzer stack current in real-time using a power signal from the wind turbine. Once the best option for integrating the turbine and electrolyzer stack is established, Phase 2 will include design and development of the required PE converter and subsequent system testing and analysis.

A hydrogen filling station is being installed at the Wind2 $\mathrm{H} 2$ project. Construction began in October 2008 with a 3500 psi fill pressure milestone completed in December 2008; 5000 psi fill pressure is expected to be completed in March 2009.

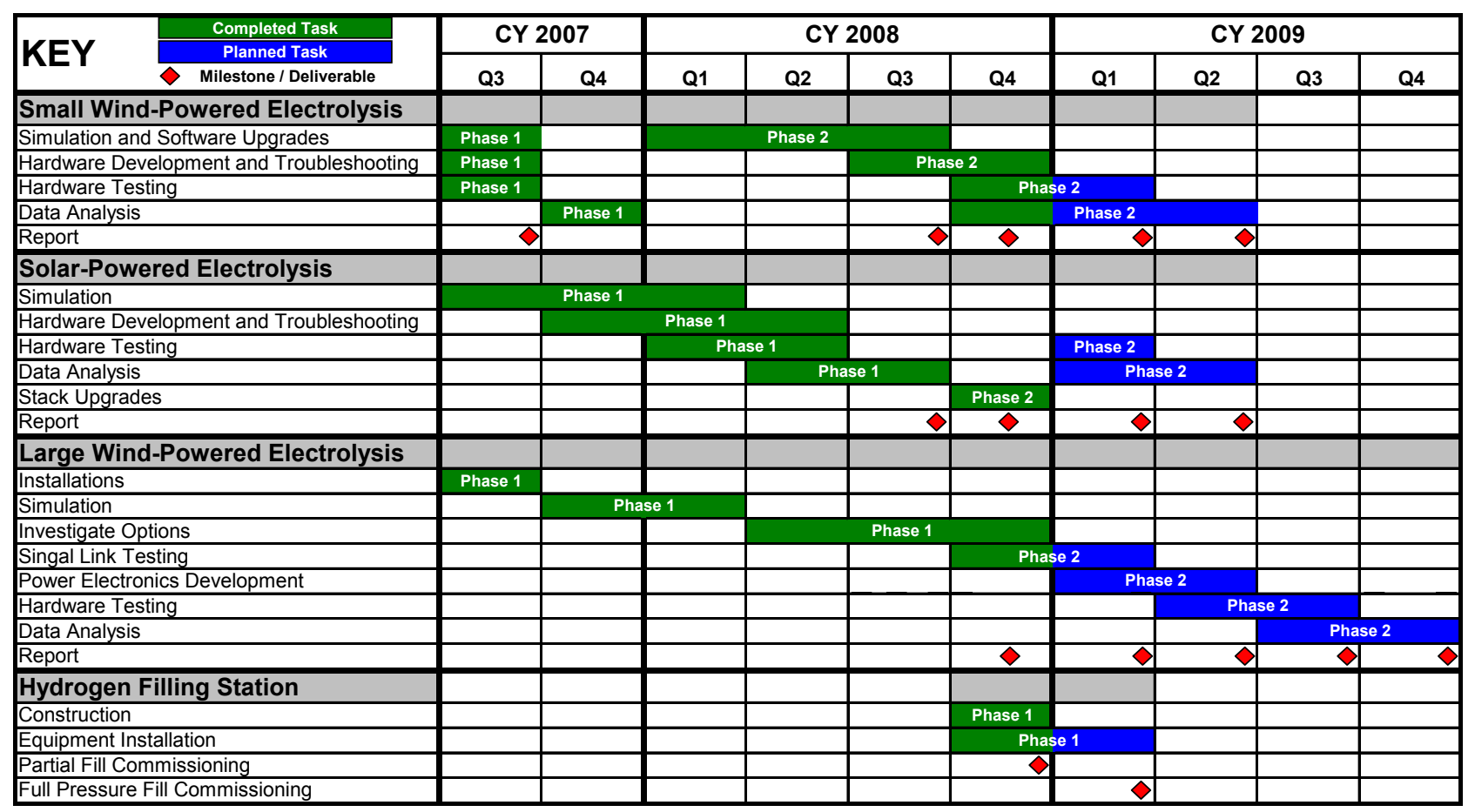

Figure 1-2: Wind2H2 project timeline 


\section{System Overview}

The Wind2H2 system integrates many systems to safely produce, compress, store, and utilize the product hydrogen gas. The heart of the system consists of three commercially available, hydrogen producing electrolyzers. Two of the electrolyzer systems are rated at $7 \mathrm{~kW}$, are of the PEM technology and are manufactured by Proton Energy Systems. The third electrolyzer system is rated at $40 \mathrm{~kW}$, is of the alkaline technology, and is manufactured by Teledyne Energy Systems. A two-stage diaphragm compressor, from Pressure Products Industries, fills the hydrogen storage tanks to a maximum of 3500 pounds per square inch gauge (psig). The stored hydrogen fuels an internal combustion engine generator set (genset), manufactured by the Hydrogen Engine Center, which provides up to $50 \mathrm{~kW}$ of AC power back to the grid. Further, a hydrogen vehicle filling station utilizing the hydrogen produced from wind and solar energy is installed on-site. As of December 2008, the vehicle fueling station was capable of filling to $3500 \mathrm{psi}$ and is planned to be upgraded to full pressure fills of $5000 \mathrm{psi}$ in March 2009.

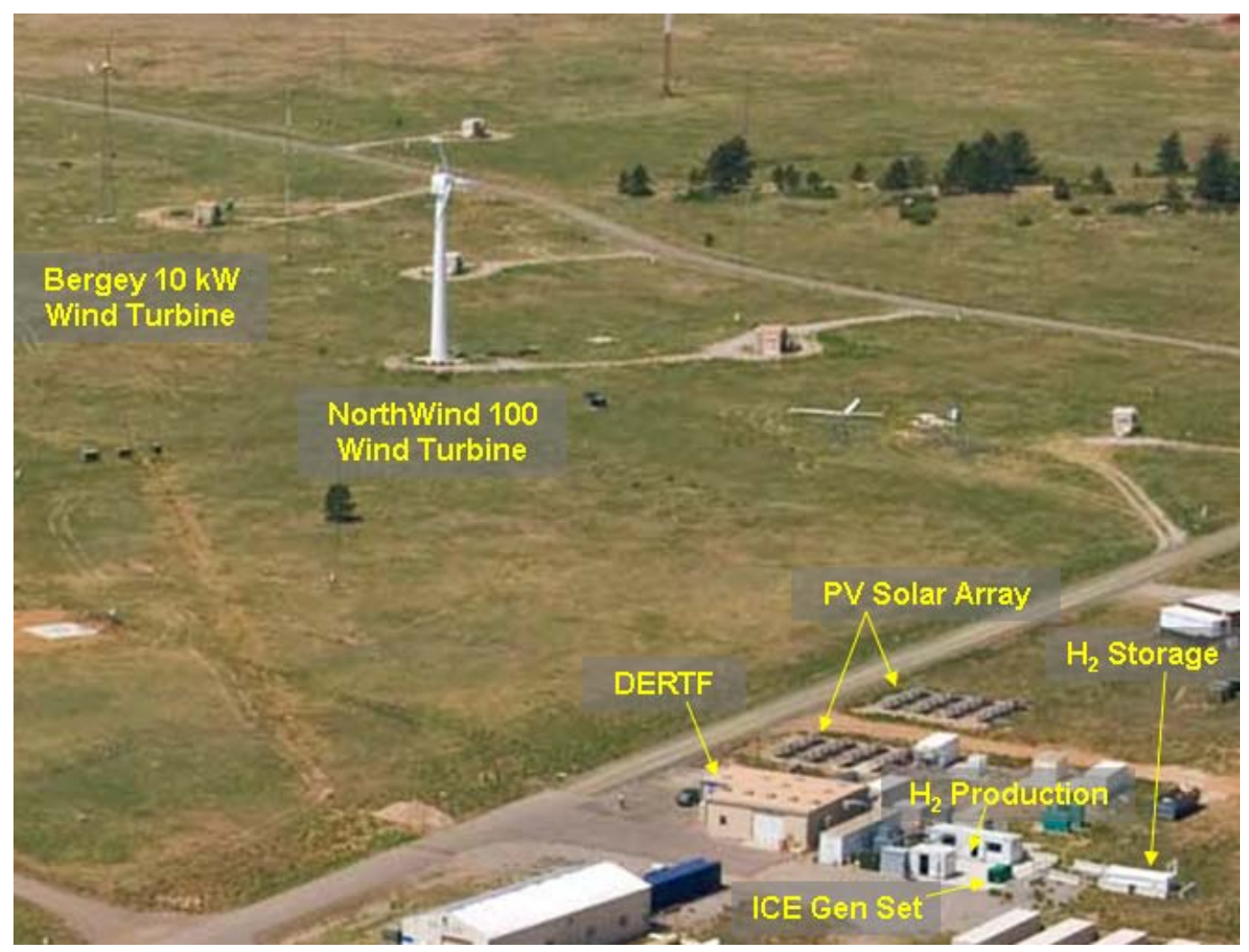

Figure 2-1: Aerial photograph of Wind2H2 site and equipment

Figure 2-1 shows an overhead view of the entire Wind2H2 site. Several RE system configurations are possible enabling some of the "greenest" hydrogen production in the world. Figure 2-2 shows the "baseline" grid connected configuration used for individual electrolyzer efficiency and performance testing. Figure 2-3 shows one of the various 10 $\mathrm{kW}$ PV-powered electrolysis configurations from which the first rounds of test results are 
presented in this report. The $10 \mathrm{~kW}$ wind turbine-to-electrolysis configuration (Figure 24) shows the wind turbine interfaced to one of the $6 \mathrm{~kW}$ PEM electrolyzer stacks. (The PEM electrolyzer systems were measured at $7 \mathrm{~kW}$, with their stacks consuming $\sim 6 \mathrm{~kW}$.) The $100 \mathrm{~kW}$ wind turbine-to-electrolysis system shown in Figure 2-5 utilizes the $60 \mathrm{~Hz}$, $480 \mathrm{~V}_{\mathrm{AC}}$ output of the wind turbine power system and a power signal to vary the alkaline electrolyzer stack current in real-time. Figure 2-6 represents a close-coupling of the 100 $\mathrm{kW}$ wind turbine to the electrolyzer stack.

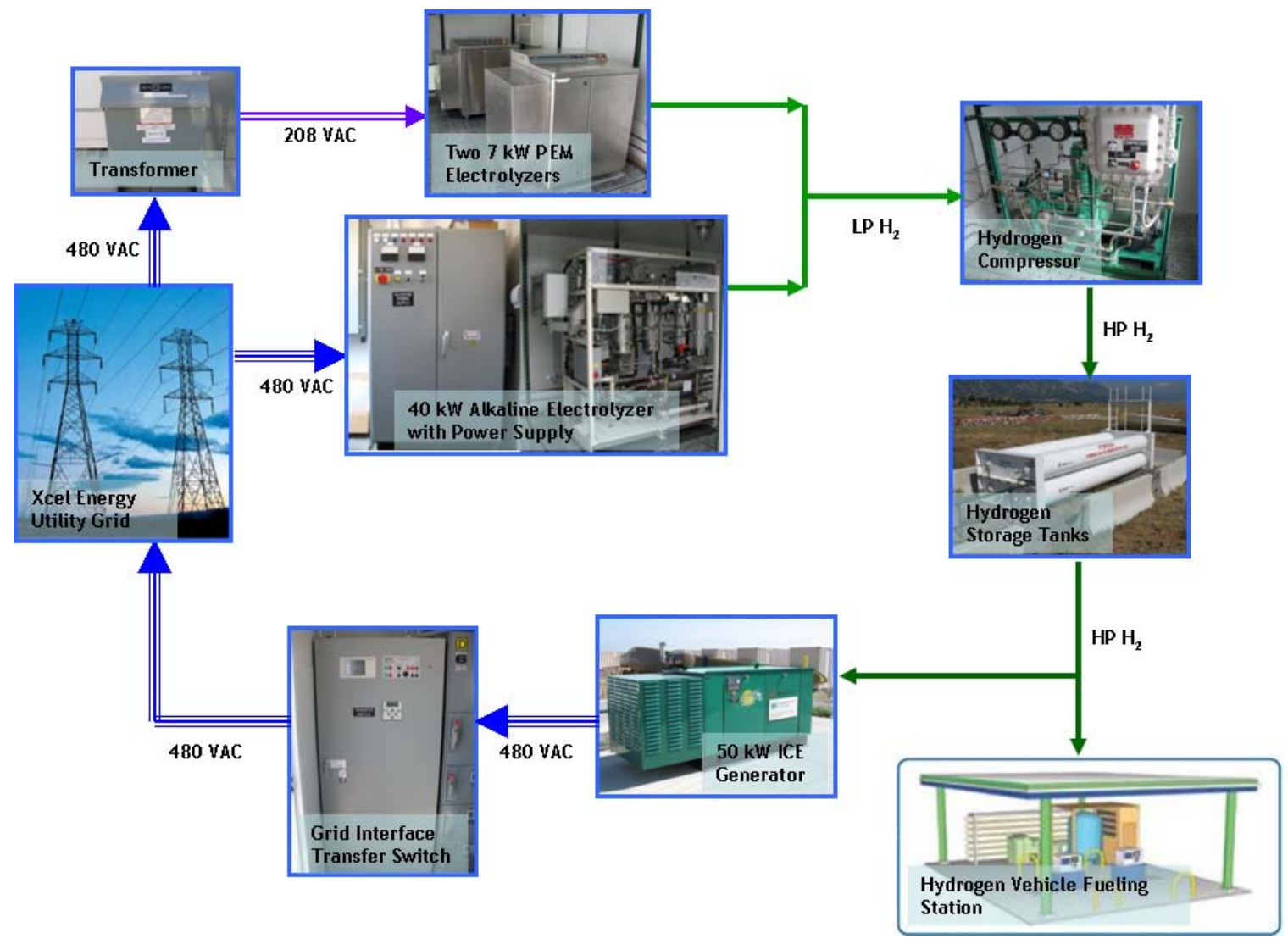

Figure 2-2: Baseline grid connected (AC) system configuration 


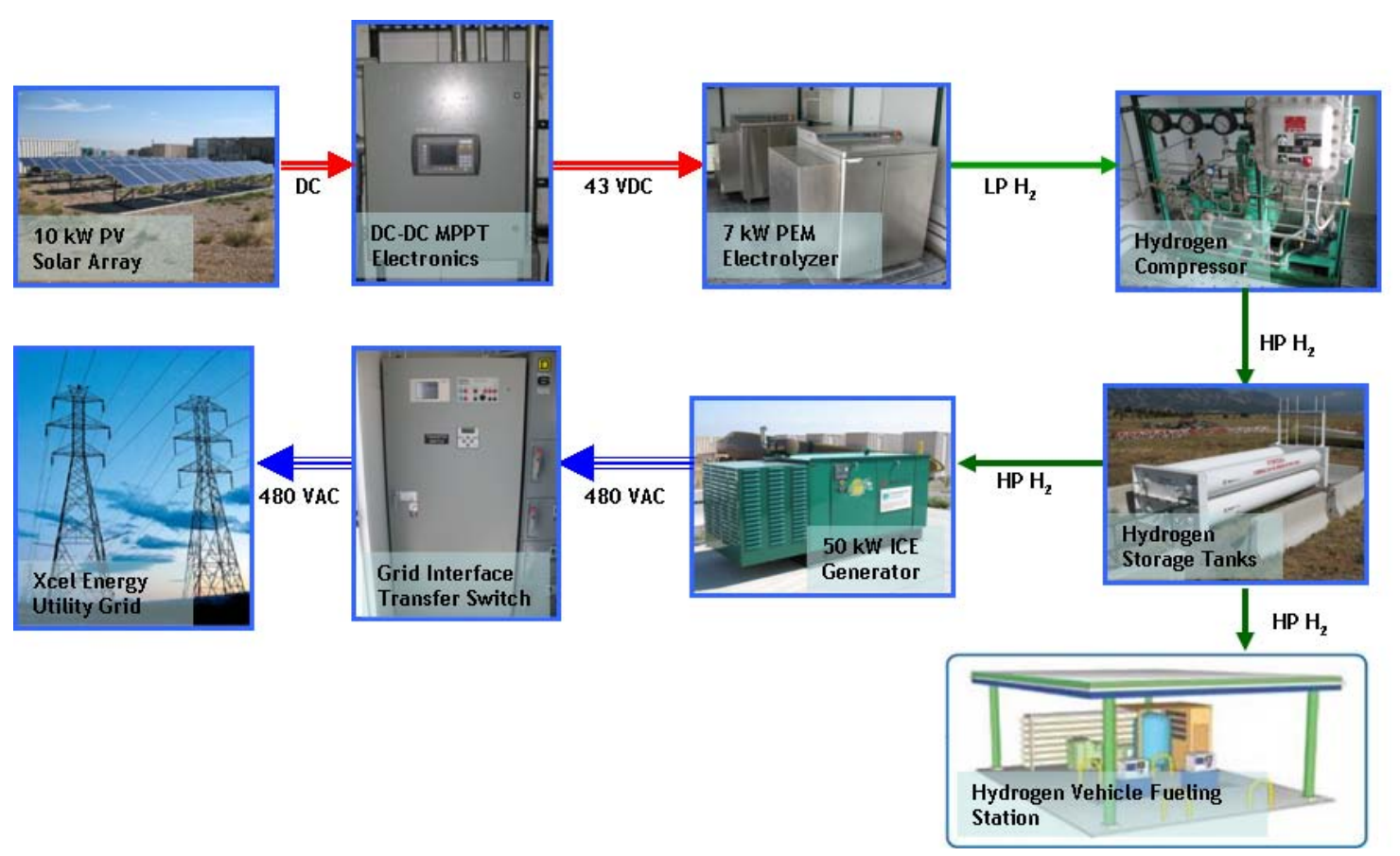

Figure 2-3: PV-powered electrolysis system configuration with DC/DC power converter to PEM electrolyzer stack

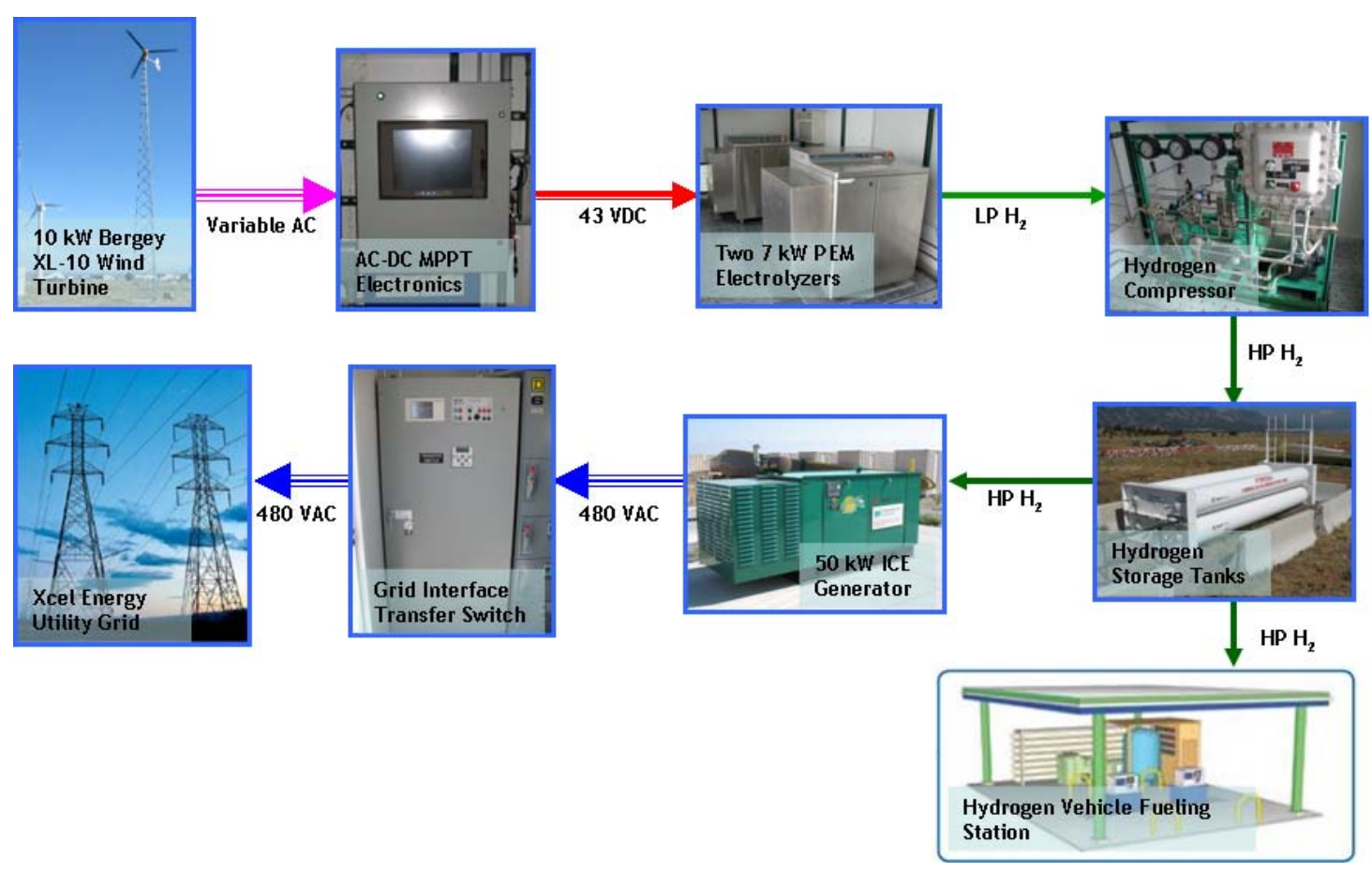

Figure 2-4: $10 \mathrm{~kW}$ wind powered electrolysis system configuration with AC/DC power converter to PEM electrolyzer stack 


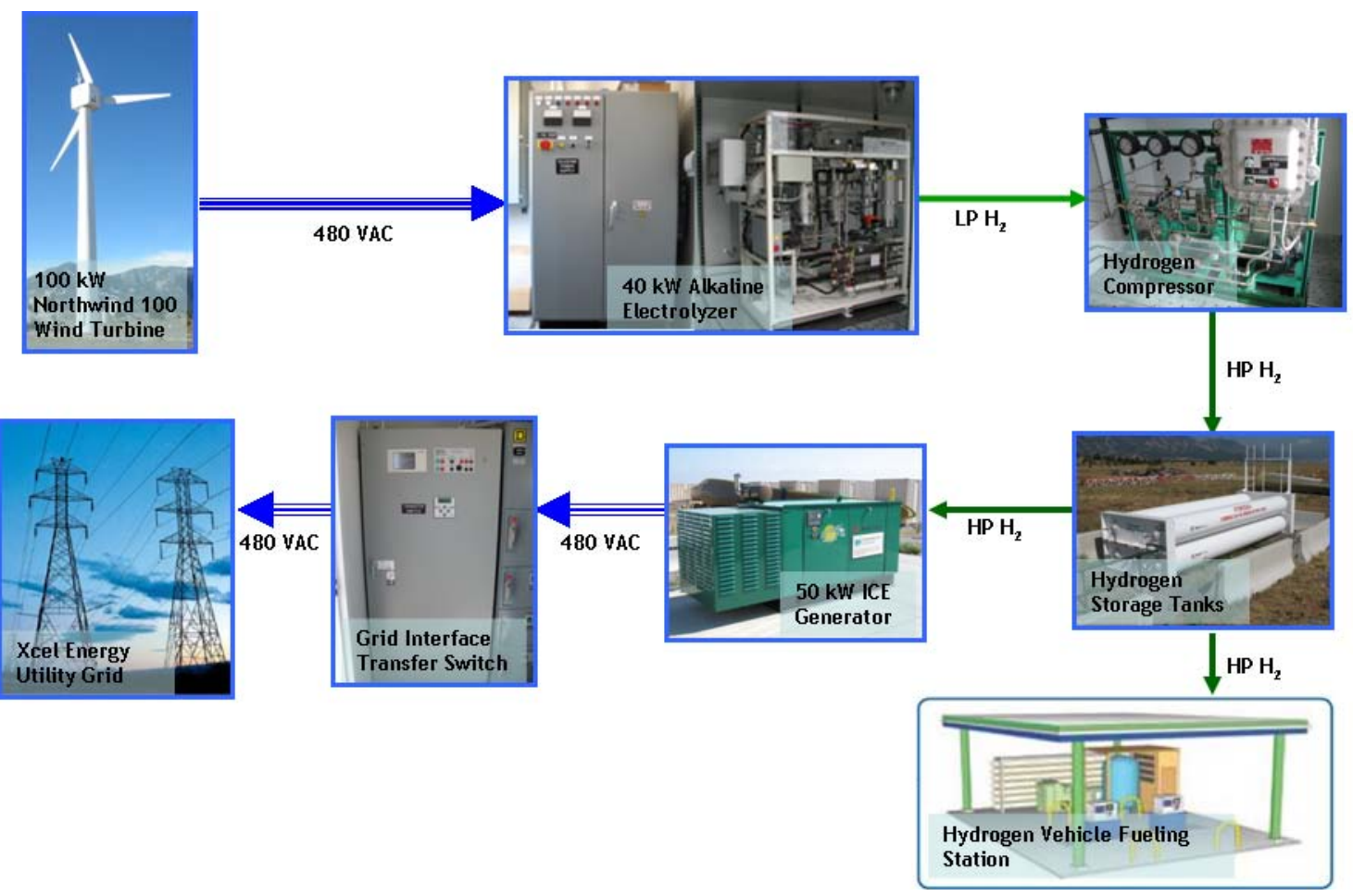

Figure 2-5: $100 \mathrm{~kW}$ wind powered electrolysis system configuration using real-time power signal to vary stack current

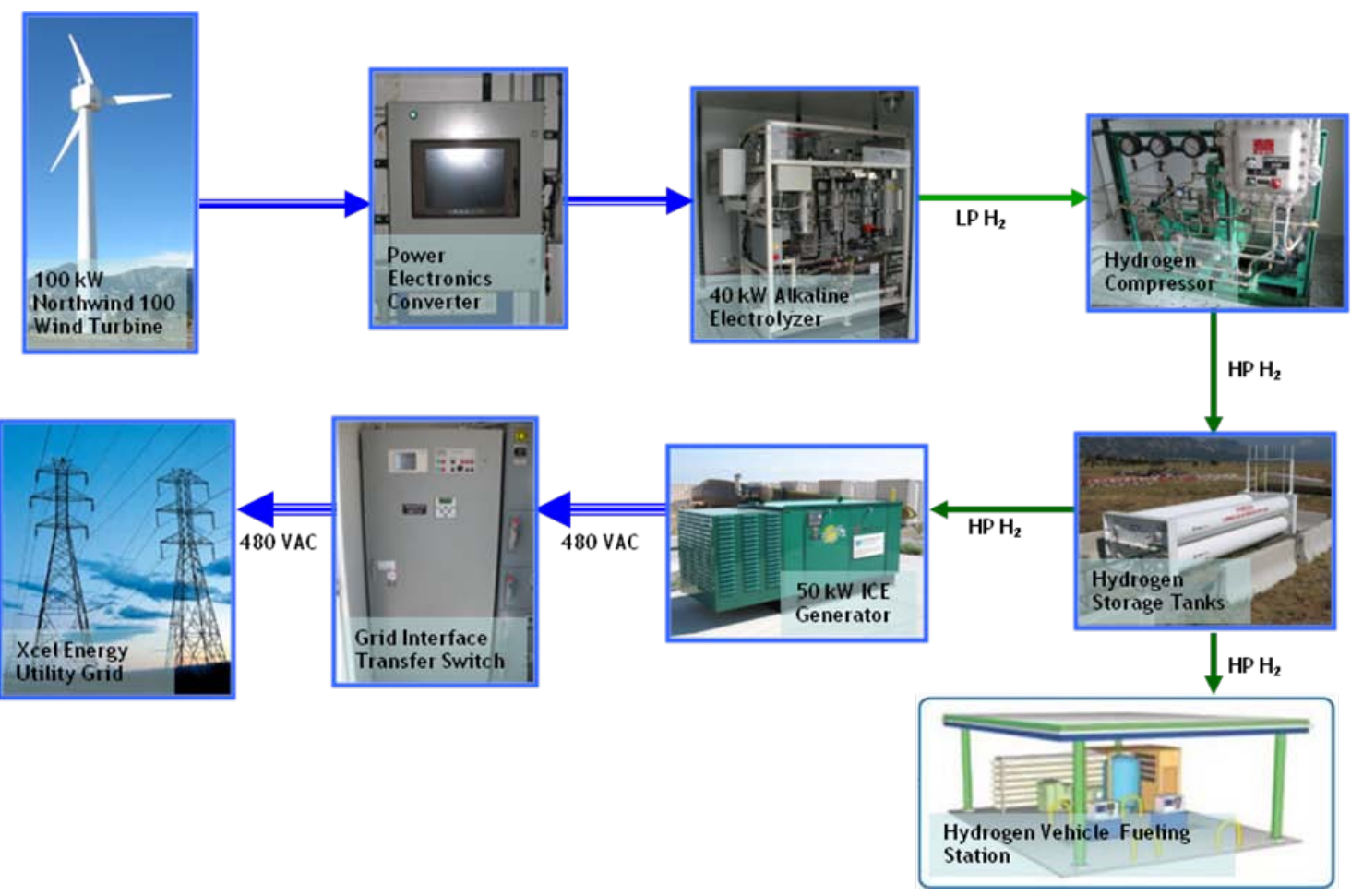

Figure 2-6: $100 \mathrm{~kW}$ wind powered electrolysis system with PE interface to stack 
The electrolyzers, compressor, and ancillary components are designed to run using gridsupplied electricity. However, both PEM electrolyzer stack connections have been modified to allow wiring directly to the DC buss network in the Distributed Energy Resources Test Facility (DERTF), bypassing the manufacturer-supplied grid interfacing $\mathrm{AC} / \mathrm{DC}$ power supply. In this way, the electrolyzer stacks can be connected to various renewable energy sources including a PV solar array directly, AC/DC, and DC/DC converters.

Various data-collection and monitoring sensors are integrated into the system components. Data are collected and archived by the main PLC and stored on the system computer. The PLC runs the control program that also has the ability to control system operation, monitor safety devices, perform emergency shutdown, and modify operating conditions.

The balance of the plant includes a glycol cooling loop that utilizes a fluid pump, heat exchanger, and cooling fan. Nitrogen gas is required by the alkaline electrolyzer for startup- and shutdown-purging cycles. A deliberate and robust safety system monitors hydrogen content inside the production and compression building while ultraviolet/infrared (UV/IR) cameras monitor for hydrogen-flare conditions. In addition, the building is continuously purged by a ventilation fan that is monitored by a differential pressure switch. Table 2-1 provides a summary of the major equipment in the Wind2H2 system.

Table 2-1: Ratings for the main Wind2H2 equipment

\begin{tabular}{|c|c|c|c|c|c|c|c|}
\hline Make & Model & Type & $\begin{array}{c}\text { AC } \\
\text { Voltage } \\
(\mathrm{V}) \\
\end{array}$ & $\begin{array}{c}\text { AC } \\
\text { Current } \\
\text { (A) }\end{array}$ & $\begin{array}{c}\text { Power } \\
(\mathbf{k W})\end{array}$ & $\begin{array}{l}\text { Pressure } \\
\text { (psig) }\end{array}$ & $\begin{array}{c}\text { Hydrogen } \\
\text { Flow } \\
\left(\mathrm{Nm}^{3} / \mathrm{h}\right) \\
\end{array}$ \\
\hline $\begin{array}{c}\text { Teledyne } \\
\text { Technologies }\end{array}$ & HMXT-100 & Electrolyzer & $480,3 \varphi$ & $58^{*}$ & $40^{*}$ & 147 & 5.6 \\
\hline $\begin{array}{l}\text { Proton } \\
\text { Energy } \\
\text { Systems }\end{array}$ & $\begin{array}{c}\text { HOGEN S40 } \\
\text { RE }\end{array}$ & Electrolyzer & $208,1 \varphi$ & $35^{*}$ & $7 *$ & 200 & 1.05 \\
\hline $\begin{array}{l}\text { Pressure } \\
\text { Products }\end{array}$ & $2 \mathrm{~L}-072 \mathrm{H} 044 \mathrm{H}$ & Compressor & $480,3 \varphi$ & $2.1^{*}$ & $2.2^{*}$ & 3500 & 6.8 \\
\hline $\begin{array}{l}\text { Hydrogen } \\
\text { Engine } \\
\text { Center }\end{array}$ & HEC649I-RLB & Generator & $480,3 \varphi$ & $60 *$ & $50 *$ & 100 & $50 * *$ \\
\hline Leeson & $\begin{array}{c}\text { C184T17FC31 } \\
\mathrm{C} \\
\end{array}$ & Fan Motor & $208,3 \varphi$ & 19.6 & 7.1 & - & - \\
\hline Baldor & NP1257L & Pump Motor & $120,1 \varphi$ & 7.4 & 0.8 & - & - \\
\hline Reliance & $\mathrm{H} 656 \mathrm{C}$ & Fan Motor & $120,1 \varphi$ & 9.4 & 1.1 & - & - \\
\hline
\end{tabular}




\subsection{Hydrogen System}

\subsubsection{PEM Electrolyzers (E-120 and E-130)}

PEM electrolysis is also referred to as solid polymer electrolyte, or polymer electrolyte membrane (also PEM), and represents a system that incorporates a solid protonconducting membrane that is not electrically conductive. The membrane serves a dual purpose: as the gas-separation device and as the ion (proton, $\mathrm{H}^{+}$) conductor. High-purity, de-ionized (DI) water is required in PEM-based electrolysis, requiring a minimum of 1 mega ohm-centimeter $(\mathrm{M} \Omega-\mathrm{cm})$ resistive water that helps extend stack life.

In a PEM electrolyzer, the electrolyte is contained in a thin, solid ion-conducting membrane rather than an aqueous solution as in an alkaline electrolyzer. This allows the $\mathrm{H}^{+}$ion (proton) or hydrated water molecule $\left(\mathrm{H}_{3} \mathrm{O}^{+}\right)$to migrate across the membrane from the anode side of the membrane to the cathode side. It also acts as the gas separator between the hydrogen (cathode) and oxygen (anode). The most commonly used membrane material is Nafion from DuPont. Commercially available PEM electrolyzers utilize a bipolar design and can operate at a high differential pressure (200-2000 psi typically) across the reinforced membrane.

De-ionized water is typically introduced at the anode of the cells and a potential is applied across the stack to dissociate the water. The protons migrate across the membrane and rejoin with electrons supplied by the power source at the cathode to form molecular hydrogen $\left(\mathrm{H}_{2}\right)$ gas. PEM electrolyzers are typically operated at current densities above 1,500 milliamps per centimeter squared $\left(\mathrm{mA} \mathrm{cm}^{-2}\right)$ - two to seven times higher than their alkaline counterparts. Stack efficiency decreases as current density increases but is traded to increase hydrogen production to offset the higher capital costs of PEM systems.

With respect to photovoltaics as an energy resource in the Wind2H2 project, the three modes of operation available for the PEM electrolyzers are: grid only, PV only and PV and grid. In PV and grid mode, the grid will supplement current to the stack when the PV array is supplying less than the rated stack current (135 A). The electrolyzer system requires a total of about $7 \mathrm{~kW}$ when operated in grid only mode, which includes about $500 \mathrm{~W}$ for ancillary loads. The largest consumer of the ancillary power is a circulation fan $(\sim 250 \mathrm{~W})$ that continually forces fresh air through the generation cabinet. The system incorporates a combustible gas $(\mathrm{CG})$ detector that monitors the air flow from the generation cabinet and will shut the system down if twenty-five percent of the lower flammability limit (LFL) of hydrogen in the air is reached. 


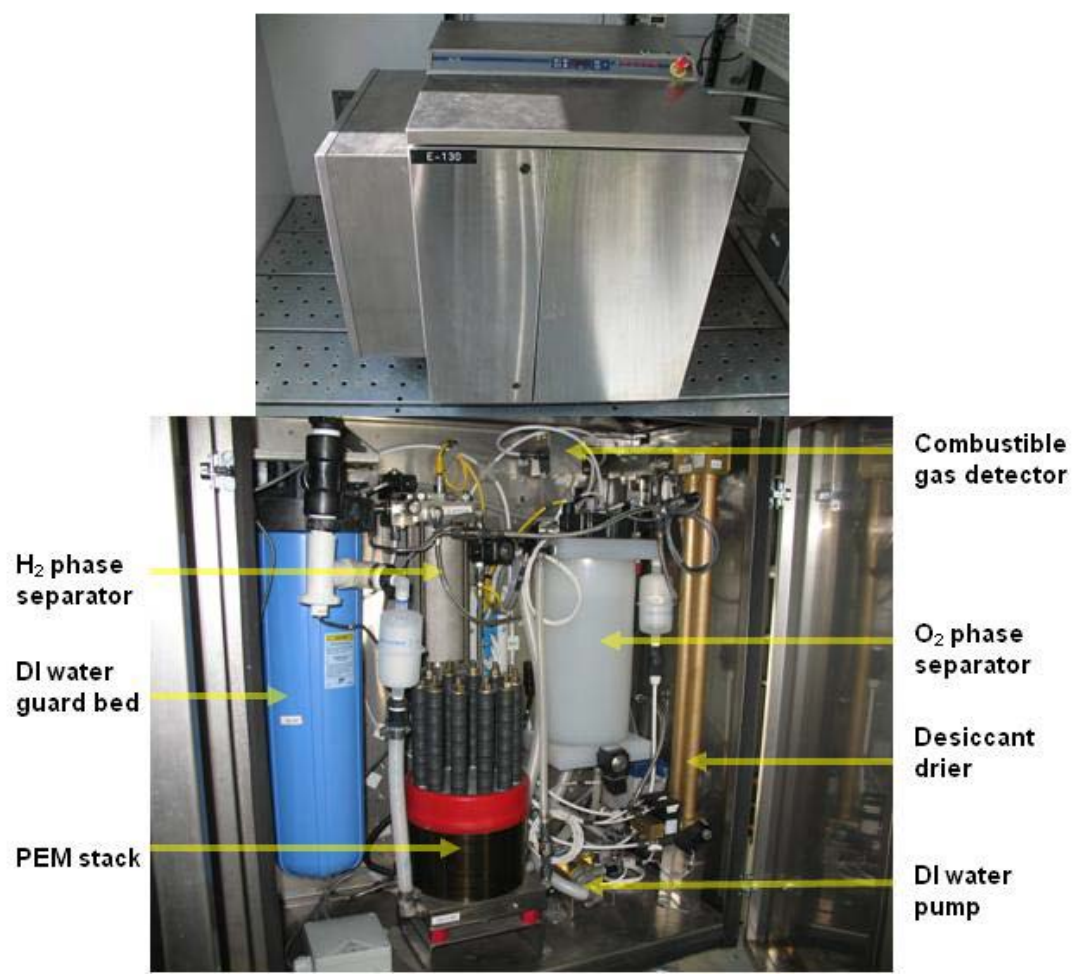

Figure 2-7: PEM electrolyzer enclosure and internal components

The Wind2H2 system includes two PEM electrolyzers that output $\sim 1.05$ normal cubic meters per hour $\left(\mathrm{Nm}^{3} / \mathrm{hr}\right)$ or 40 standard cubic feet per hour (SCFH) of hydrogen with a purity of $99.999 \%$. The electrolyzers require an AC grid connection (200-240 V, 1 phase) regardless of the mode in which they are operated. Figure 2-7 shows the enclosure and internal components of the PEM electrolyzer.

The modifications made to the PEM electrolyzers are:

- Current and voltage sensors that directly measure the stack (DC) and grid (AC) electrical parameters

- Digital and serial communication between the main PLC and electrolyzers, allowing on/off control and operational monitoring

- Wiring the stack directly to a DC buss source in the DERTF to allow interconnection with PV- and wind-sourced PE.

The HOGEN 40RE electrolyzer provides a simple user interface to select the electricity source (grid only, PV only, or PV and grid). In addition, maintenance and error notification are provided to the user via this display. The majority of the input power to the unit is used by the stack $\left(\sim 6 \mathrm{~kW}_{\mathrm{DC}}\right)$ to produce hydrogen. The additional AC electrical energy (about $500 \mathrm{~W}$ ) is used for ancillary loads such as DI water pump, ventilation fan, valves, safety systems, and control power. 


\subsubsection{Alkaline Electrolyzer (E-110)}

The alkaline electrolyzer is a well-established technology that employs an aqueous solution of water and 25-30 weight percent (wt. \%) potassium hydroxide (KOH). However, sodium hydroxide and sodium chloride have also been used in other alkaline systems. The liquid electrolyte enables the conduction of ions $\left(\mathrm{K}^{+}, \mathrm{OH}^{-}\right)$between the electrodes. The electrolyte is not consumed in the reaction but does need to be maintained and replaced periodically. Typically, commercial alkaline electrolyzers are run with current densities in the range of $200-600 \mathrm{~mA} \mathrm{~cm}^{-2}$ compared with $>1500 \mathrm{~mA} \mathrm{~cm}^{-2}$ in the PEM systems.

The HMXT-100 uses an aqueous solution of potassium hydroxide (25\% wt. KOH, equivalent specific gravity 1.236 at $20^{\circ} \mathrm{C}$ ) as the electrolyte to produce hydrogen and oxygen at a balanced pressure of 145 psig. The balance of plant includes: DI water pump, electrolyte pumps, hydrogen-gas drying, system-pressure monitoring and control, and a remote AC-rectifier power supply for grid operation. Figure 2-8 shows a labeled photo of the major systems of the HMTX-100 hydrogen generator from Teledyne Energy Systems. In addition to the generator in the production and compression building, there is a power supply/controller located in the nearby control room.

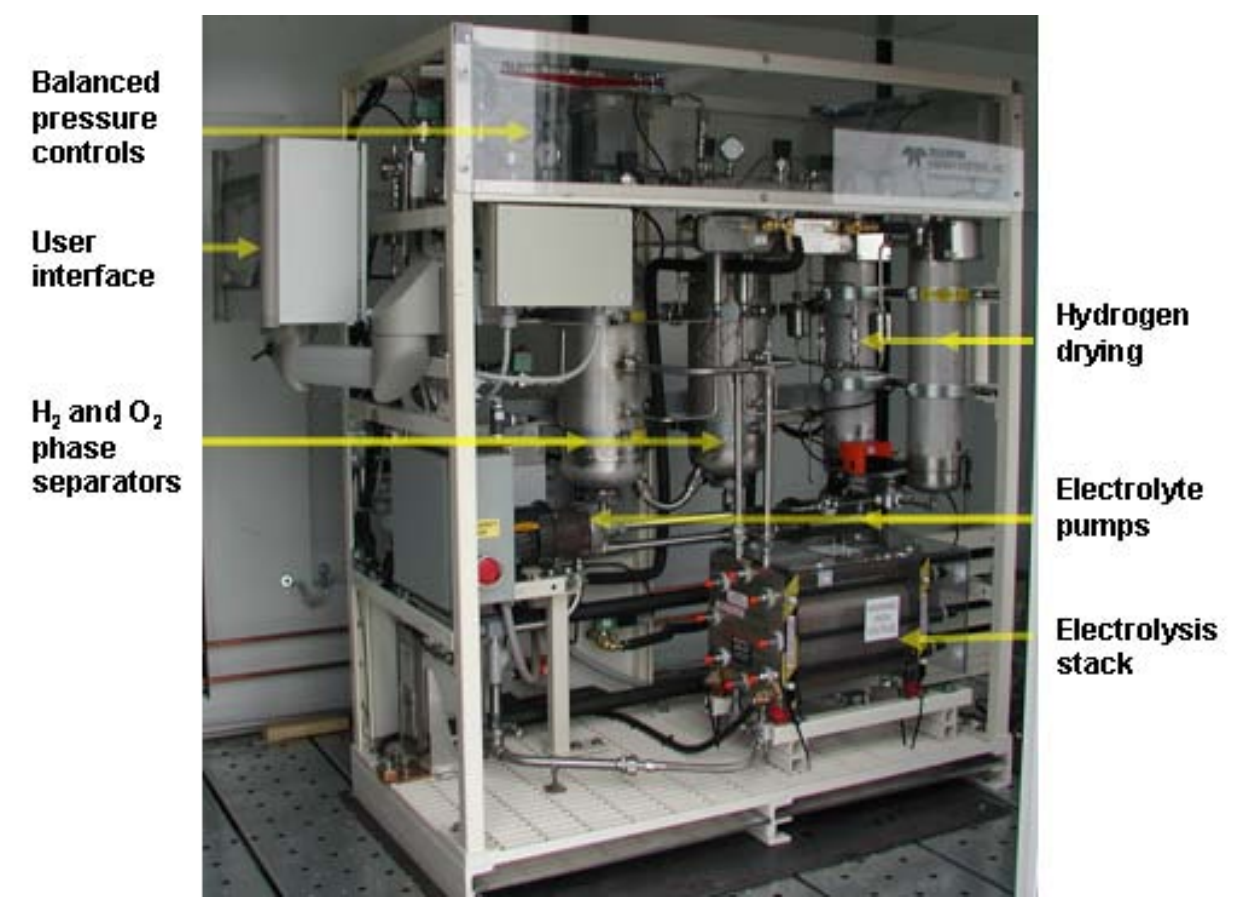

Figure 2-8: Alkaline hydrogen generator system components

The modifications made to the alkaline electrolyzer are:

- Current and voltage sensors that directly measure the stack DC electrical parameters-AC power and root-mean-squared (RMS) current input to the system

- Digital and serial communication interfaces from the generator to the control room PLC, allowing operational monitoring and emergency stop. 
The alkaline electrolyzer provides a graphical user interface to control and monitor the operation of the generator. Alarms and error messages are logged. Externally, a glycol/water loop provides cooling for the electrolyte and hydrogen-gas drying.

\subsubsection{Compressor (C-200)}

The compressor, from Pressure Products Industries, is presented between $30 \mathrm{psi}$ and 150 psi suction pressure from the electrolyzers and compresses the gas into the storage tanks up to $3500 \mathrm{psi}$ when they are full. It is a two-stage, triple diaphragm compressor rated for 3 horsepower, drawing up to $2.2 \mathrm{~kW}$ of power at $480 \mathrm{~V}_{\mathrm{AC}}$.

Figure 2-9 shows the compressor with major components labeled. The compressor can be stopped and started remotely from the control room software interface or manually from the control electronics interface at the device. AC current and active power are monitored and logged during testing.

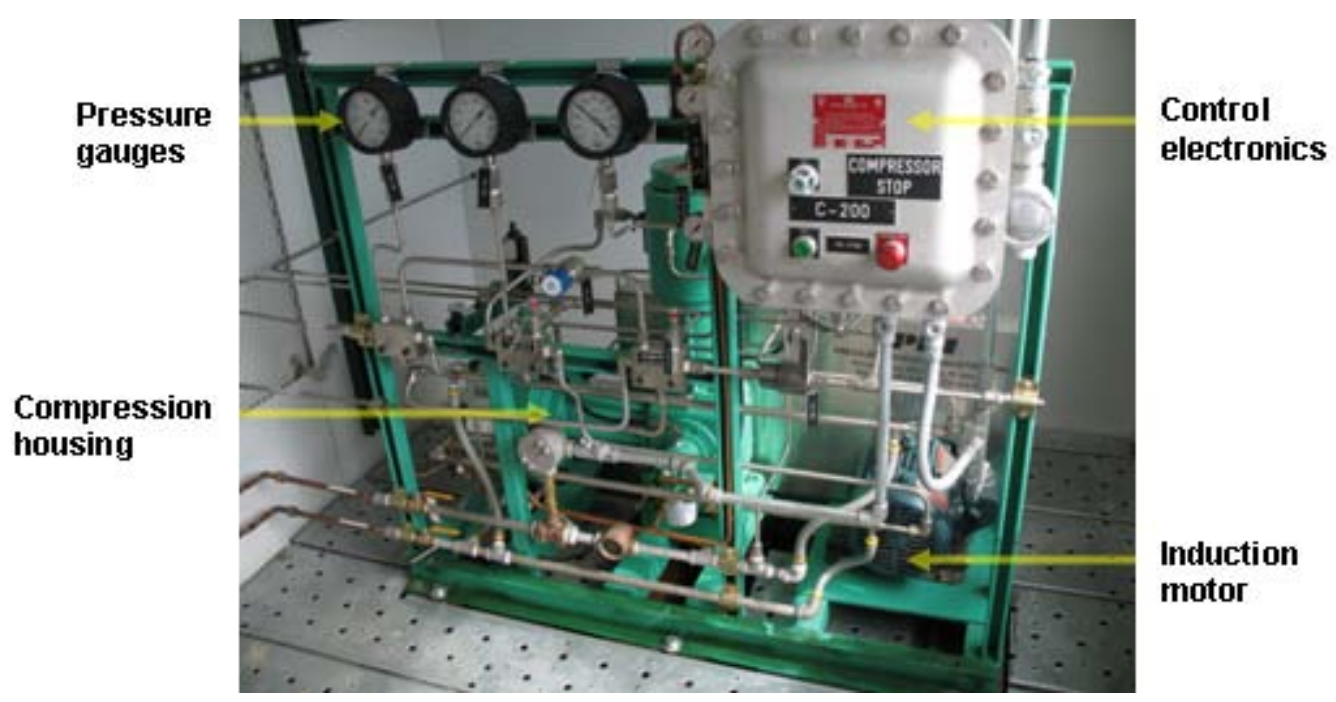

Figure 2-9: Hydrogen compressor

\subsubsection{Hydrogen Storage Tanks}

Five seamless, steel pressure vessels, manufactured by CP Industries, store the compressed hydrogen-gas product at pressures up to 3500 psi. Each vessel measures 20 feet in length with an outer diameter of 2 feet, providing a volume of $46.1 \mathrm{ft}^{3}\left(1.3 \mathrm{~m}^{3}\right)$. The total "liquid water volume" of storage is therefore $230.5 \mathrm{ft}^{3}\left(6.5 \mathrm{~m}^{3}\right)$. At rated conditions of $3500 \mathrm{psig}$ and $30^{\circ} \mathrm{C}$, each vessel can hold $23.1 \mathrm{~kg}$ of $\mathrm{H}_{2}$ gas for a total holding capacity of $115.5 \mathrm{~kg} \mathrm{H}_{2}$. A pneumatically driven isolation valve and dual handoperated needle valves provide safety isolation of the high-pressure gas from the rest of the system. Figure 2-10 shows the gas manifold and major components of the storage tank set. 


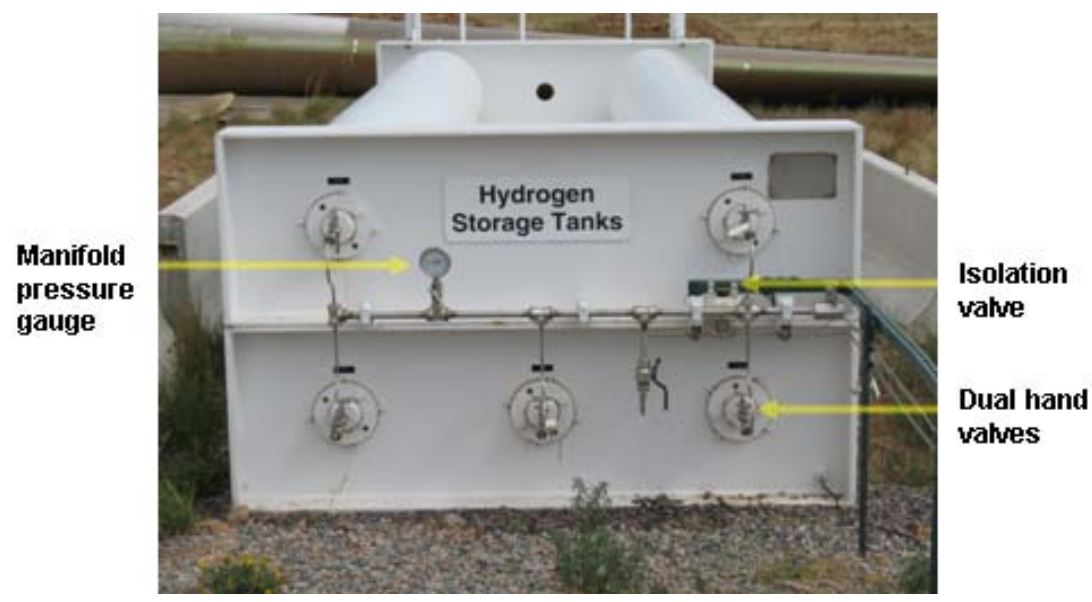

Figure 2-10: Hydrogen storage tanks

\subsubsection{Internal Combustion Generator (G-400)}

An internal combustion engine (ICE) uses hydrogen gas as fuel to generate electricity. The generator (Figure 2-11), manufactured by the Hydrogen Engine Center, is capable of exporting $50 \mathrm{~kW}$ of electricity to the grid. It can be automatically started and stopped by the system control program and is allowed to passively synchronize with the grid prior to the transfer switch closing to enable energy export.

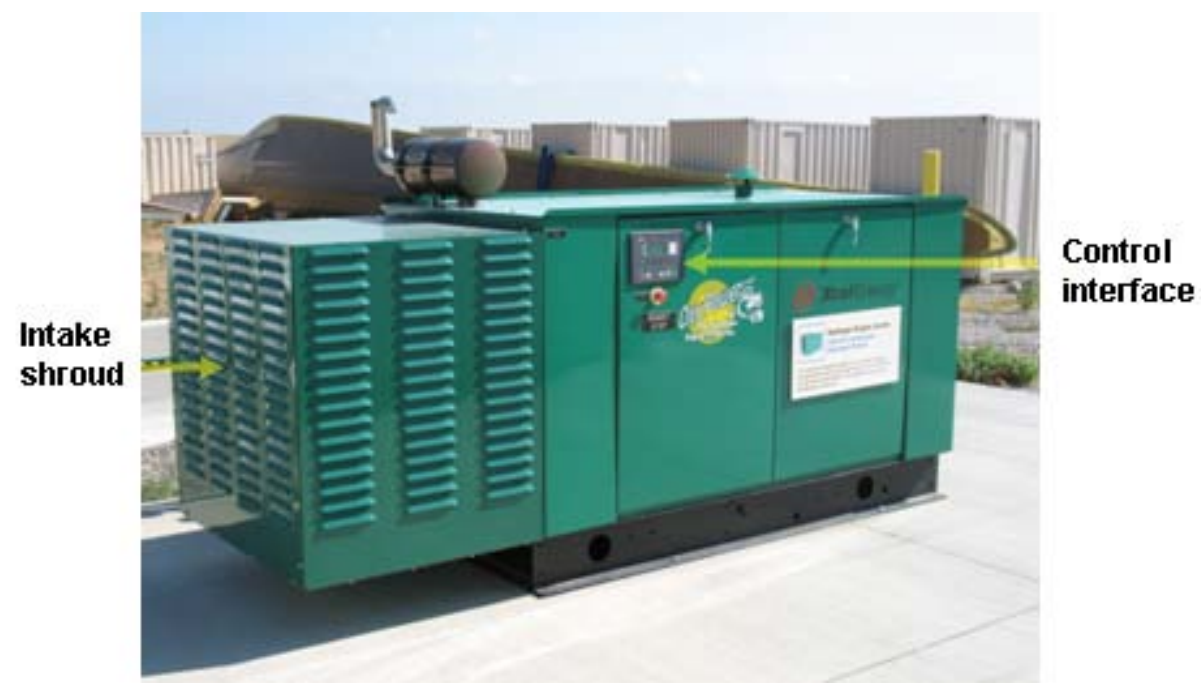

Figure 2-11: Hydrogen-fueled internal-combustion generator

In April 2008, the generator was retrofitted with a new air intake shroud to protect the unit from blowing snow and with a muffler to vent the exhaust upward.

\subsection{Safety Systems and Controls}

\subsubsection{Production and Compression Building}

The following safety features have been designed into the production and compression building and must be preserved to maintain safe operations: 
- Sealed conduit penetrations into devices and building to eliminate gas migration

- Intrinsically safe devices (non-sparking) including lighting, heaters, and air conditioner

- Ventilation fan, differential pressure verification and passive louvers

- Blast panels

- Pressure- and leak-tested hydrogen piping

- Component, connection, and joint minimization to reduce the likelihood of a hydrogen leak

- Pipe and vessel purging with nitrogen before and after opening fittings, components, or piping to avoid flammable combinations of hydrogen and air.

\subsubsection{Emergency Stops}

Three system-wide Emergency Stop (E-Stop) switches are located in the following places:

- Control building on PLC cabinet

- Left-hand side outside main doors of the production and compression building

- Inside production and compression building on left-hand side of PLC cabinet.

An additional E-Stop is integrated into the main control and monitoring user interface software. Though this is a software button, it has the same effect as pushing any of the physical E-Stop switches.

Activation of any of the system E-Stop switches will abruptly stop all hydrogen production, compression, or power export from the ICE generator. Activation of a system E-Stop will automatically close the pneumatically driven valve to isolate the highpressure hydrogen in the storage tanks. Note that the alkaline electrolyzer will stop hydrogen production immediately on an E-Stop or stop command, but always enters a nitrogen purge mode lasting 10 to 15 minutes.

\subsubsection{Hydrogen Detection}

Two combustible gas detectors monitor the production and compression building air make-up. The first alarm signal is factory set to $10 \%$ of the LFL, continually monitored by the PLC, and will stop all hydrogen production immediately if activated. A piezoelectric audio alarm will sound inside the production and compression building when the alarm level is reached, and the normally green light emitting diode on the detector will flash red. The second alarm trip-point is factory set at $25 \%$ of the LFL and will open a normally closed relay contact. The relay contact is not monitored by the PLC, and therefore, system shutdown relies on the 10\% LFL signal from one or both of the detectors. The LFL of hydrogen in air is $4 \%$ by volume or 40,000 parts per million by volume (ppmv) $(1 \%=10,000 \mathrm{ppmv})$. 


\subsubsection{Ventilation}

An exhaust fan installed in the production and compression building runs continuously during hydrogen production to avoid potential build-up of hydrogen gas. The exhaust fan is required to run during all hydrogen production activities. Electrolyzer and compressor operation is inhibited until the differential pressure switch across the exhaust fan indicates proper air flow. The pressure switch is monitored by the PLC and will initiate a shutdown of hydrogen production and compression upon loss of differential pressure across the fan.

\subsubsection{Fire Detection and Alarm}

The fire detection and alarm system consists of two weatherproof fire alarm pull-boxes and two photoelectric smoke detectors one each installed on both buildings. The production and compression building has UV/IR and heat-rate anticipation detectors installed. A system-wide status signal is returned to the Wind2H2 system PLC and performs a system shutdown in the event that these contacts open. The main fire alarm panel is located in the east bay of the DERTF and will notify the fire department if any of these alarms are triggered.

\subsubsection{Hydrogen Vent Flare Monitor}

Normal operation of the electrolyzers and compressor generates a small amount of waste hydrogen gas. All vent lines exit the production and compression building on the west side and extend roughly 5 feet above the roof line. A cross-like manifold caps the vent lines where a $100-\Omega$ platinum $(\mathrm{Pt})$ resistive temperature device (RTD) monitors for higher-than-normal temperatures associated with a hydrogen-flaring condition. Currently, the PLC is programmed to shut down the system if the RTD measures $66^{\circ} \mathrm{C}\left(150^{\circ} \mathrm{F}\right)$ for 15 consecutive minutes. However, it may be determined after more operational experience is gained and further research is conducted, that flaring the hydrogen vent may be the preferred state of operation. At that point, the controlled shutdown will be disabled, but an operator notification will remain on the main user interface in the control building. Hydrogen flaring is considered highly likely due to the low ignition energy of 17 microjoules $(\mu \mathrm{J})$ compared with gasoline that has an ignition energy of $240 \mu \mathrm{J}$.

\subsubsection{High Pressure Isolation}

Hydrogen is compressed and stored in five steel cylinders at pressures up to 3500 psig. The hydrogen storage isolation valve, located at the input manifold of the storage tanks, is pneumatically actuated by means of a solenoid valve to port compressed air to open the isolation valve. Removing the air enables the spring loaded valve to close. During hydrogen production and compression or hydrogen consumption in the ICE generator, the isolation valve is automatically opened. During all other dormant periods and during any alarm, the valve is automatically closed.

\subsection{Renewable Energy Sources}

\subsubsection{Photovoltaic Solar Array}

A $10 \mathrm{~kW}$ rated PV solar array is used to power the electrolyzer stacks to produce hydrogen. The array is made up of a total of ninety-six $110 \mathrm{~W}$ panels and is divided into two $5 \mathrm{~kW}$ sections that can be connected or used separately. The operator can choose to connect any number of panels together to configure this power source up to $10 \mathrm{~kW}$. In 
addition, the panels may be connected in different series and parallel combinations to achieve different DC voltage output levels. This versatile RE source is used to directly power the electrolyzer stack, bypassing the electrolyzer AC grid connection. Figure 2-12 shows the 48 panels making up the $5 \mathrm{~kW}$ east PV array located at NREL's DERTF.

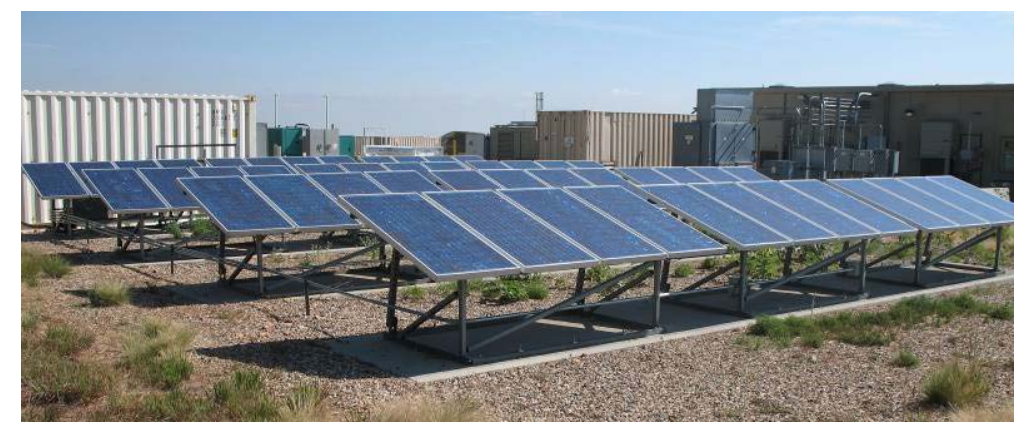

Figure 2-12: 5 kW east PV array at NREL's DERTF

Each panel of the array is rated for $110 \mathrm{~W}$ and is capable of operating at $\mathrm{V}_{\mathrm{MAX}}=16.4 \mathrm{~V}$, $\mathrm{I}_{\mathrm{MAX}}=6.68 \mathrm{~A}$ (open circuit voltage $\left(\mathrm{V}_{\mathrm{OC}}\right)=20.6 \mathrm{~V}$, short circuit current $\left(\mathrm{I}_{\mathrm{SC}}\right)=7.38 \mathrm{~A}$ ) under standard test conditions (STC). Standard test conditions consist of an irradiance of $1000 \mathrm{~W} / \mathrm{m}^{2}$, a standard reference AM1.5 spectrum, and a cell temperature of $25^{\circ} \mathrm{C}$.

Figure 2-13 shows typical current versus voltage (I-V) characteristic curves at various temperatures for a single panel in the array. However, the exact I-V curves shown in Figure 2-13 are for the $120 \mathrm{~W}$ model.

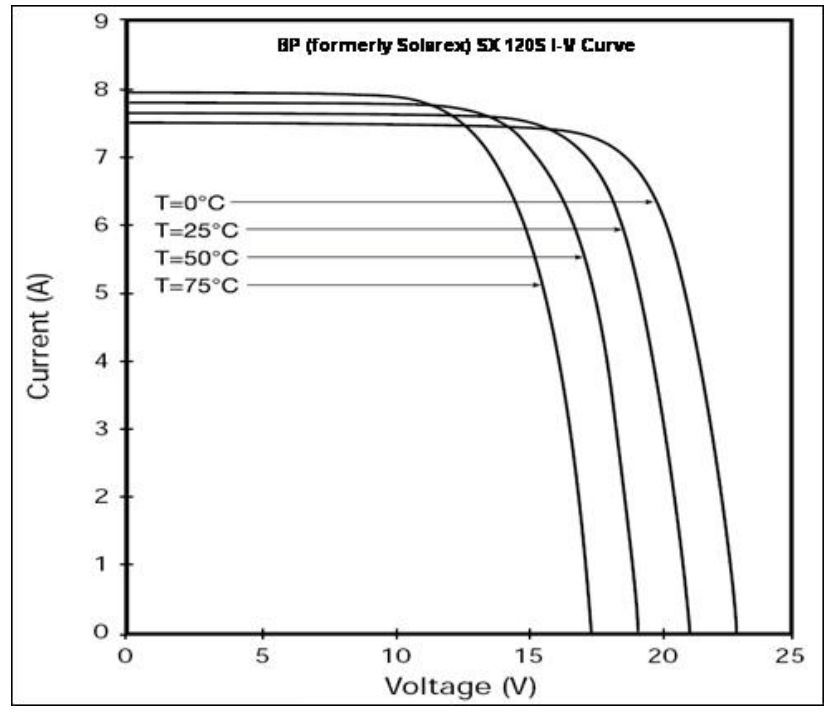

Figure 2-13: SX-120s solar panel I-V characteristic

Sets of four series-connected panels create sub-arrays capable of producing $\mathrm{V}_{\mathrm{MAX}}=65.6$ $\mathrm{V}\left(\mathrm{V}_{\mathrm{OC}}=82.4 \mathrm{~V}\right)$ with the same current ratings of a single panel. The entire east array 
consisting of 12 sets of 4 series-connected sub-arrays establishes a total array potential of $\mathrm{V}_{\mathrm{MAX}}=65.6 \mathrm{~V}, \mathrm{I}_{\mathrm{MAX}}=80.2 \mathrm{~A}\left(\mathrm{I}_{\mathrm{SC}}=88.6 \mathrm{~A}\right)$ resulting in $\mathrm{P}_{\mathrm{MAX}}=5258 \mathrm{~W}$ at $\mathrm{STC}$.

Due to the elevation of the test site (NREL's NWTC) of approximately $1855 \mathrm{~m}(6085 \mathrm{ft})$ and cloud reflection, the irradiance can approach $1300 \mathrm{~W} / \mathrm{m}^{2}$. In that case, if the PV array is tilted to the optimal angle for that day of the year at 12:00 p.m. the array could exceed its nameplate $\mathrm{I}_{\mathrm{MAX}}$ by nearly $30 \%$. $\mathrm{I}_{\mathrm{SC}}$ is directly proportional to the irradiance (meaning that, for example, if irradiance halves, so does $\mathrm{I}_{\mathrm{SC}}$ ).

\subsubsection{Bergey $10 \mathrm{~kW}$ Wind Turbine}

A $10 \mathrm{~kW}$ Bergey Excel-S/60 wind turbine (Figure 2-14) is connected to the Wind2H2 system through the DERTF's electrical switchgear. While this wind turbine is rated for $10 \mathrm{~kW}$, it typically produces only a maximum of 7 to $8 \mathrm{~kW}$ (Figure 2-16) in wind speeds from 15 to 20 meters per second $(\mathrm{m} / \mathrm{s})$. Thus, the turbine is a good match for powering one of the $6 \mathrm{~kW}$ PEM electrolyzer stacks. The turbine produces variable frequency and variable voltage AC power, depending on the rotor rotational velocity, which is proportional to wind speed. Figure 2-15 provides the overall system layout. The nominal rated voltage of the turbine is $240 \mathrm{~V}_{\mathrm{AC}}$ (under rated load) with a frequency range of 13 to $160 \mathrm{~Hz}$. Figure 2-16 is an NREL-generated plot of the Bergey turbine power curve.

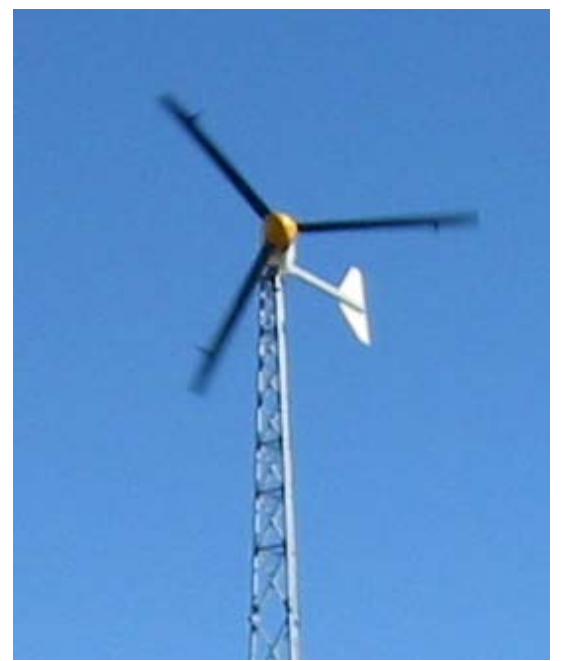

Figure 2-14: $10 \mathrm{~kW}$ Bergey Excel-S wind turbine at the NWTC 


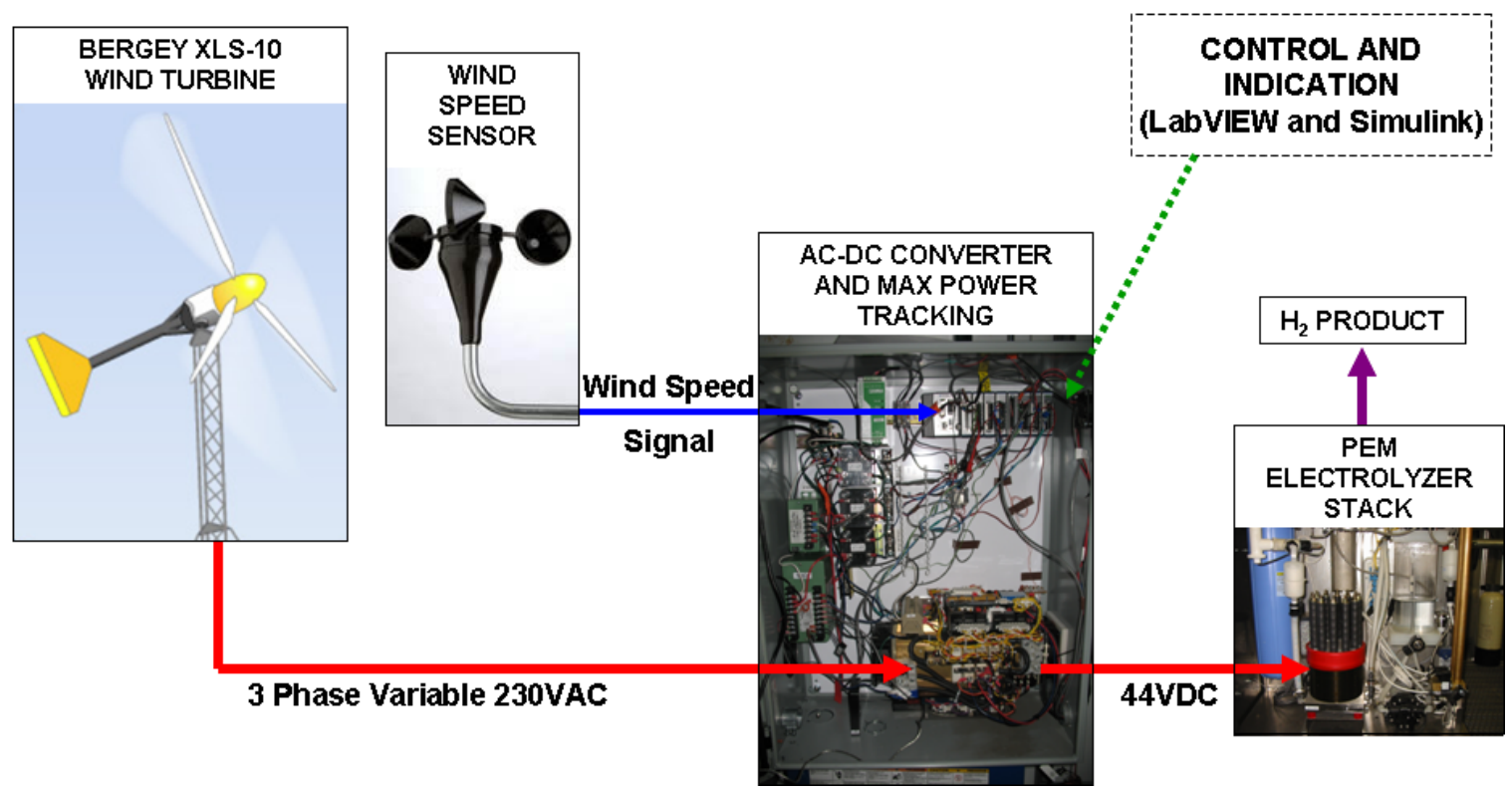

Figure 2-15: Enhanced wind-to-hydrogen system.

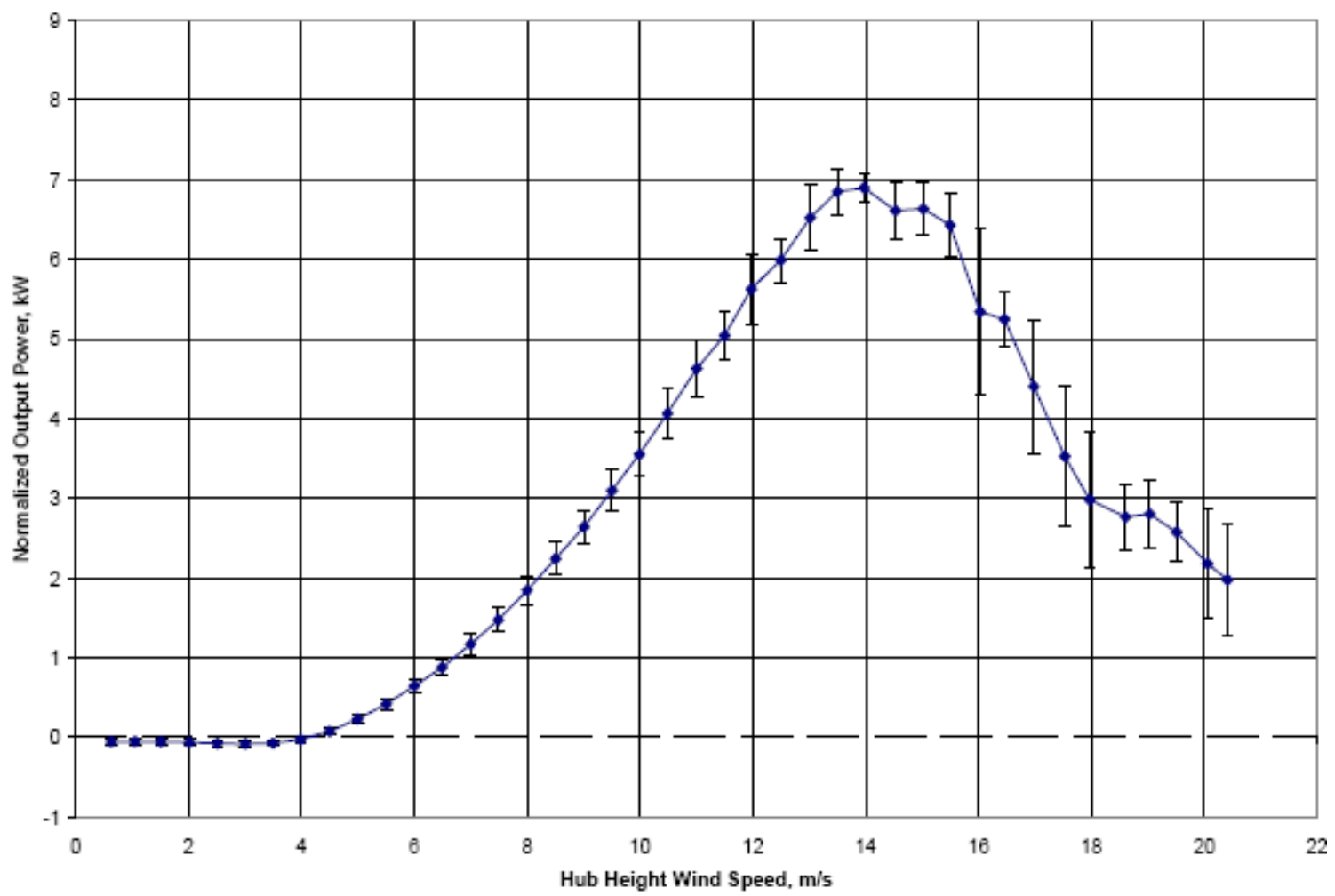

Figure 2-16: Bergey Excel-S experimental power data (average air density $\left.1.061 \mathrm{~kg} / \mathrm{m}^{3}\right)^{5}$

${ }^{5}$ van Dam, J.; Meadors, M. (2003). Wind Turbine Generator System Power Performance Test Report for the Bergey Excel-S/60 Wind Turbine with BW03 Airfoil Blades. NREL/EL-500-33450. Golden, CO:

National Wind Technology Center. 


\subsubsection{NorthWind 100 Wind Turbine}

Northern Power Systems NorthWind 100 (NW100) wind turbine is located on site 1.2 at the NWTC (Figure 2-17). The turbine is rated for $100 \mathrm{~kW}$ power output (Figure 2-18), contains a PE converter that exports electricity to the grid at $60 \mathrm{~Hz}, 3$ phase, and 480 $\mathrm{V}_{\mathrm{AC}}$. The NW100 wind turbine is a variable-speed, stall-regulated turbine with an active yaw system that points the turbine into the wind. The turbine employs a 28-pole wye (Y)connected synchronous generator with a salient pole wound rotor. The maximum generator output voltage is $575 \mathrm{~V}_{\mathrm{AC}}$ with variable frequency and voltage based on wind speed. The generator voltage is converted into a nominal $\pm 400 \mathrm{~V}_{\mathrm{DC}}$ link that also varies with wind speed. Three loads draw power from the DC link: the grid-tie inverter, the field exciter, and the dynamic brake. The inverter provides output AC, grid-compatible electricity from the DC link.

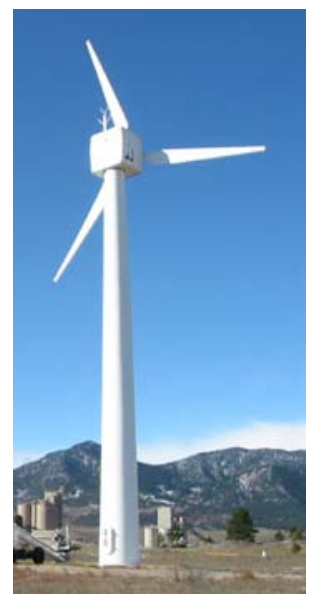

Figure 2-17: $100 \mathrm{~kW}$ NorthWind 100 turbine located at NREL's NWTC

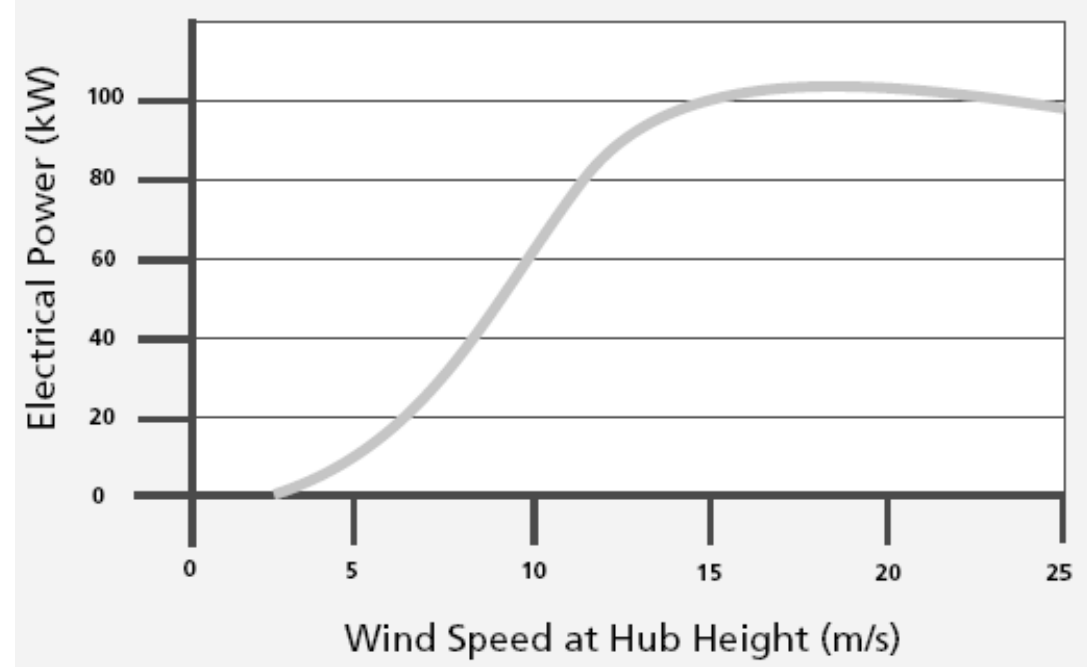

Figure 2-18: Manufacturer-provided power curve for NorthWind 100 turbine at standard (sea level) air density. 
At NREL, NW100 power system was modified to provide auxiliary DC power output to the DERTF for use in the Wind2H2 project. Northern Power Systems commissioned the relocated power converter/controller in the spring of 2007. The new controller is installed roughly 250 feet from the base of the tower inside the data shed. If determined feasible, the relocated controller will enable some energy from the generator or DC buss to be utilized for electrolysis at the Wind $2 \mathrm{H} 2$ project. In the near-term, a power signal from the wind turbine will proportionally drive the stack current of the $35 \mathrm{~kW}$ alkaline electrolyzer stack in real-time.

\subsection{Power Electronics}

\subsubsection{DC-to-DC Buck Converter with MPPT}

The Wind2H2 system uses a custom-built DC/DC MPPT power converter to step down different PV array voltages to that required by the $6 \mathrm{~kW}$ PEM electrolyzer stack. The power converter was designed to reduce cost, increase flexibility of energy input, and bring the system further toward commercial viability than previous designs utilizing expensive controllers and software. A low-cost PLC is interfaced with an off-the-shelf, insolated gate bipolar transistor (IGBT)-based PE module to monitor and control the system. A novel MPPT algorithm is programmed in the PLC, which allows the converter to draw power from the PV array at or near the MPP, thus maximizing utilization of the energy output of the PV array. Analog sensors monitor the voltage and current in and out of the power converter. These signals are exported from the local PLC controller via RS232 and transmitted to the main Wind2H2 system PLC via a Profibus communication link. Figure 2-20 shows the internal layout of the DC/DC power converter (bottom) and downstream capacitor and inductor filter elements (top).

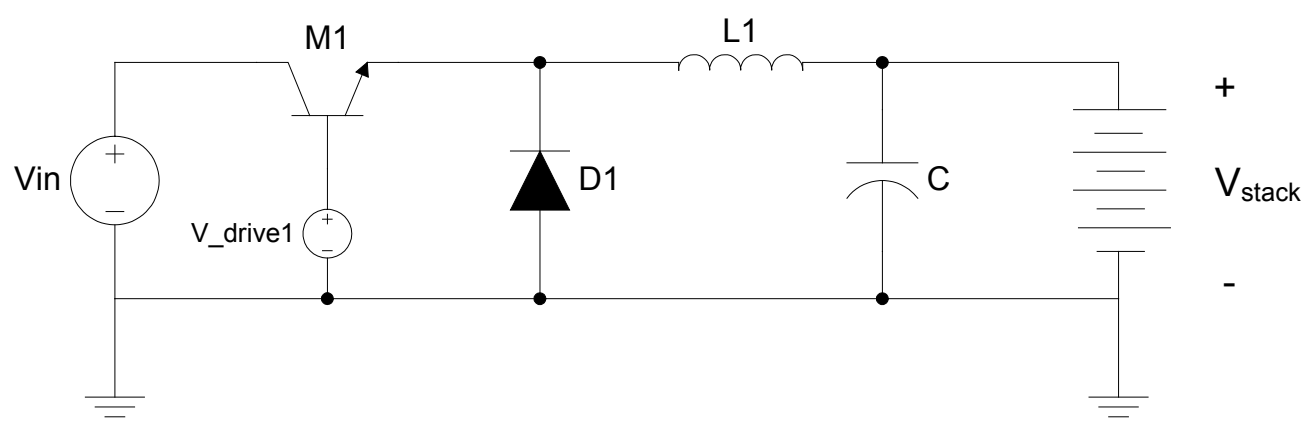

Figure 2-19: DC/DC step-down (buck) converter circuit 


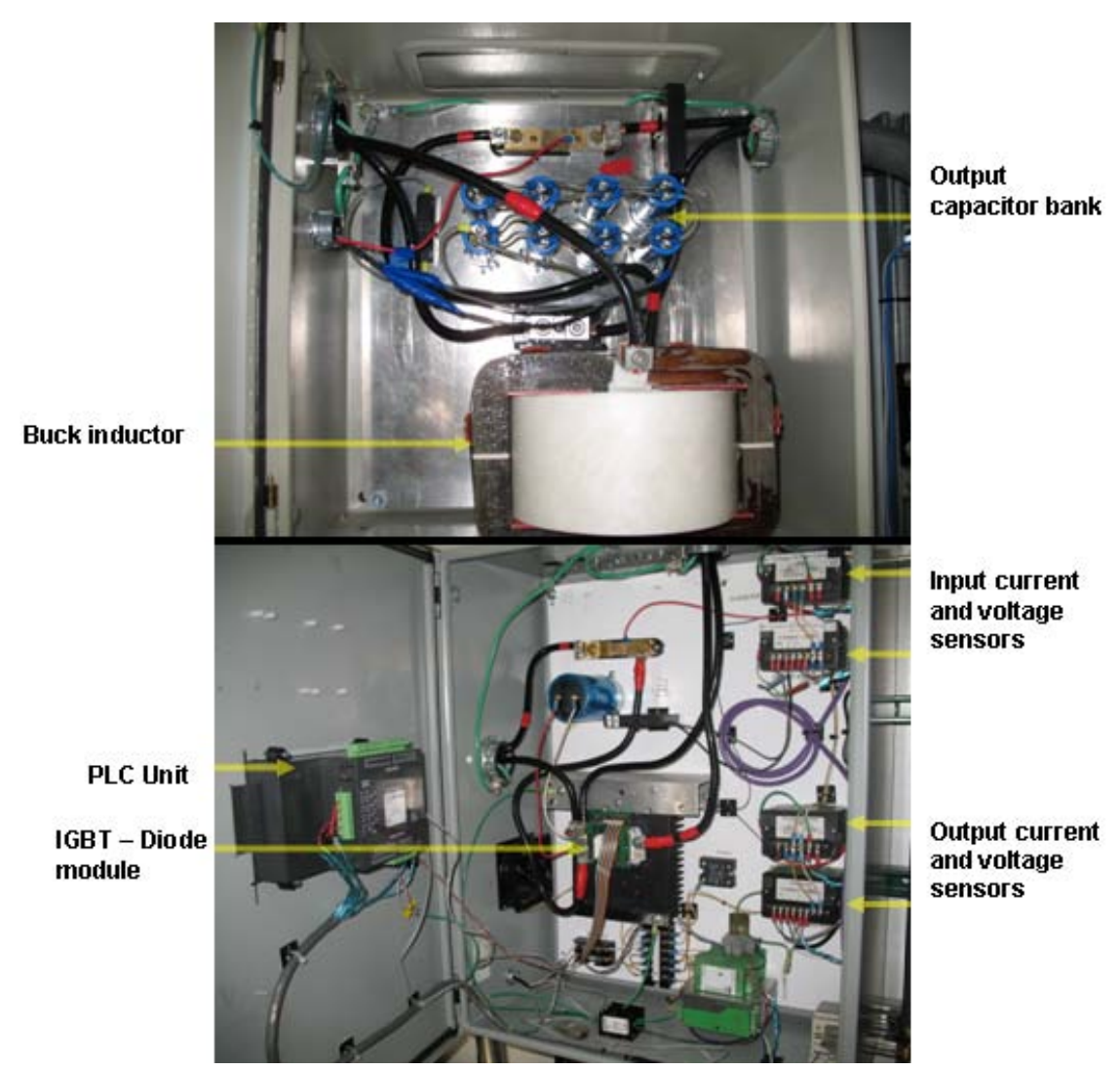

Figure 2-20: DC/DC step-down converter components (bottom) and filter elements (top)

The IGBT module includes two series connected IGBTs and anti-parallel diodes with a center tap, temperature sensor, and gate driver pins. In the buck (i.e., step-down) DC/DC converter circuit, only one IGBT and one of the anti-parallel diodes are used. The IGBT gate-driver circuit mounts directly on top of the IGBT module. This driver monitors the semiconductor temperature and collector-emitter voltages. In addition to the IGBT module, a high-frequency, 1 milliHenry $(\mathrm{mH})$ inductor is necessary to complete the buck converter circuit. The inductor transfers energy and smoothes the output from the chopped PV source to the electrolyzer stack. The duty cycle of the 5 kiloHertz $(\mathrm{kHz})$ switching frequency dictates the output voltage level. Finally, a capacitor bank is included at the output of the converter to smooth the voltage ripple. Figure 2-19 provides the circuit diagram of this step-down converter.

\subsubsection{AC/DC Turbine MPPT Converter}

An AC/DC PE converter is used to power the PEM electrolyzer stack from the $\sim 10 \mathrm{~kW}$ wind turbine. This converter conditions variable frequency and voltage $\mathrm{AC}$ power into varying DC output between 30 and $43 \mathrm{~V}$ required by the PEM stack. Currently, the converter is undergoing its third generation of improvement and refinement. The first two generations of the converter proved the concept of using a controlled rectifier to convert the power and implemented a control scheme to track the MPP of the turbine in variable wind conditions. The third generation, which will begin testing in early 2009 , includes a more accurate wind speed measurement located near the turbine hub, improved input power metering, and refined control algorithm. 
The third-generation converter incorporates an accurate wind speed measurement taken from an anemometer near the turbine hub to improve the performance of the MPPT algorithm. The controlled rectifier in the converter, while always maintaining the required DC power output to the electrolyzer stack, adjusts the impedance seen by the turbine such that the tip speed ratio of the turbine blades is optimized. In addition, a new device to measure the turbine power output will improve the accuracy of the control algorithm. The AC/DC converter is based on the controlled rectifier circuit shown in Figure 2-21. A firing angle, calculated by the control algorithm, directly controls the voltage output of the circuit. The L-C filter (Figure 2-22) on the output of the converter smoothes the output current and voltage to the electrolyzer stack.

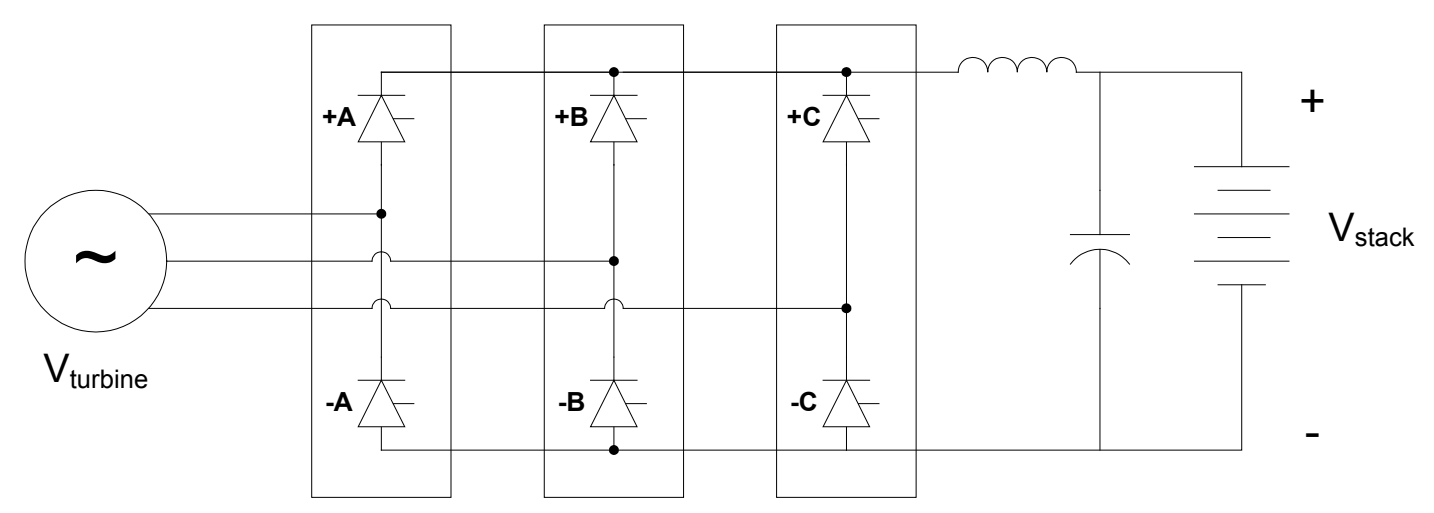

Figure 2-21: AC-to-DC controlled rectifier circuit 


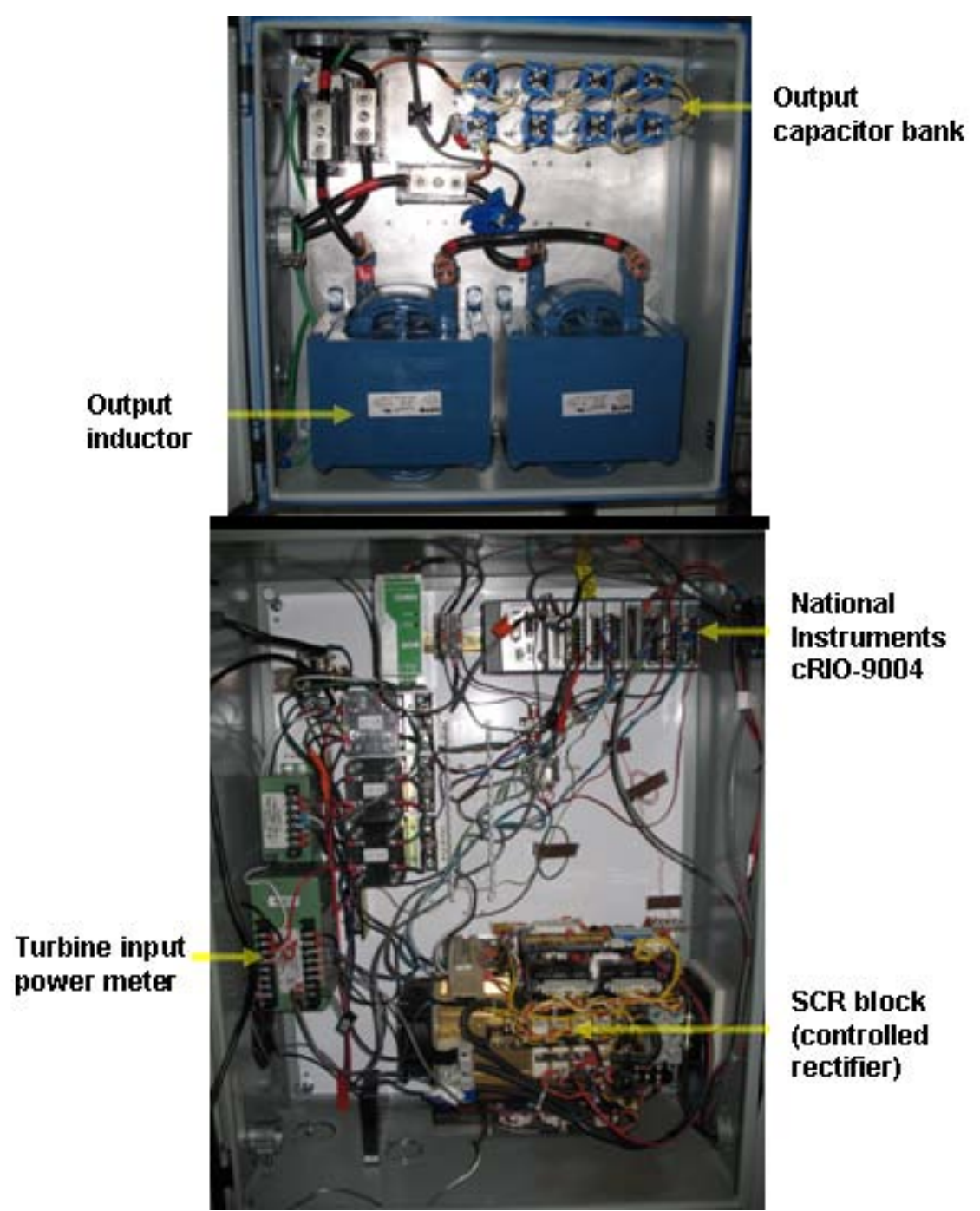

Figure 2-22: AC/DC converter internal components (bottom) and filter elements (top)

Prototype control hardware from National Instruments is used to quickly read and condition signal inputs and control outputs on a re-writable, field programmable gate

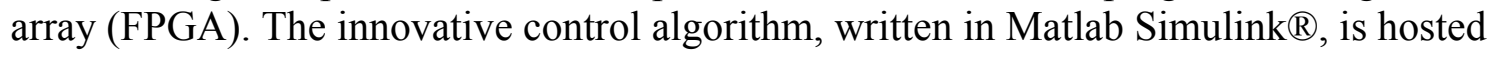
on a real-time computer connected to the FPGA. This converter system is expected to automatically track the maximum power operating point of the turbine-electrolyzer system using real-time monitoring of wind speed, accurate power measurements, and a novel control algorithm. With improved wind-speed measurement and power readings, the third generation converter will function as a wind turbine, MPPT converter supplying a $6 \mathrm{~kW}$ PEM electrolyzer stack even in highly variable wind conditions.

\subsection{Data Acquisition and Monitoring}

A graphical user interface (GUI) allows the operator to monitor, control, and configure the Wind2H2 system. A screen shot of the system overview page of this GUI is shown in Figure 2-23. Each equipment picture on the GUI can be opened to review the detailed input/output sensors embedded into the equipment. 


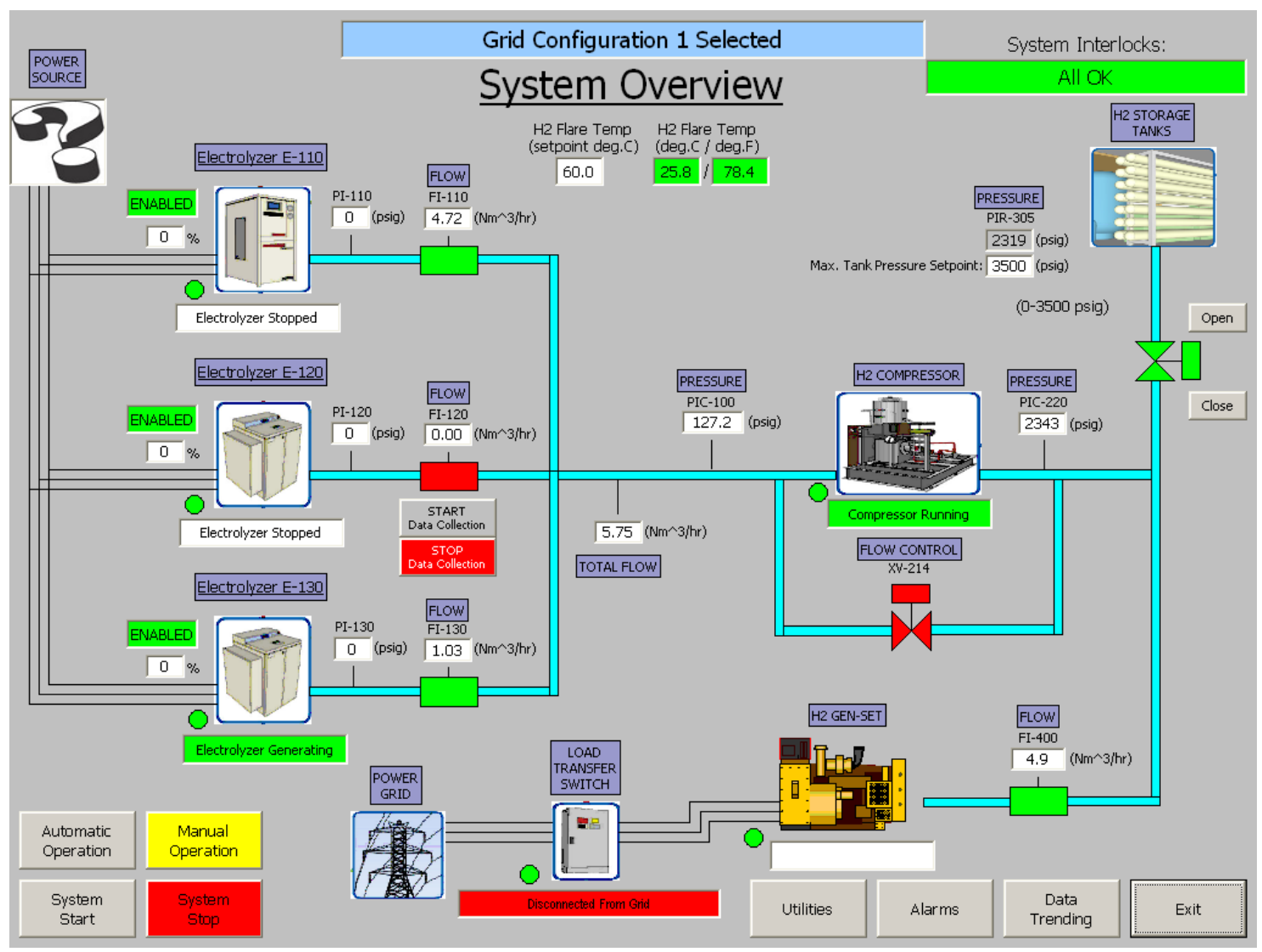

Figure 2-23: GUI system monitoring and controls interface

\section{System Installation and Operation}

\subsection{Introduction}

The Wind2 22 project is designed to demonstrate a renewable energy-based hydrogen production system and to gain operational experience with such a system. As a first-ofits-kind activity, the Wind2 2 project was designed by a diverse group of engineers from NREL and Xcel Energy. In addition, outside consultants from the University of Minnesota, University of North Dakota, and Fort Collins Utility reviewed aspects of the system design. The design team worked with Xcel Energy gas engineers to apply relevant natural gas codes and standards to the hydrogen-based system. The development of the Wind2H2 system allows researchers to evaluate system performance and cost, characterize electrolyzer performance under variable RE power, and identify opportunities for cost and performance improvements. (Reporting of the testing and evaluation of the Wind2H2 renewable electrolysis systems can be found in Sections 4 and 5.) The Wind $2 \mathrm{H} 2$ system also provides valuable operational experience that can be used to highlight operational challenges, explore system integration issues, and develop a set of lessons learned that will aid in the development of future RE-based electrolysis systems.

Since commissioning, the Wind2H2 system has undergone shakedown testing, performance improvements, and troubleshooting. The alkaline electrolyzer has logged 
approximately 300 hours, and the PEM electrolyzers have logged approximately 400 hours. The internal-combustion generator has not run as frequently as the rest of the system, logging about 100 hours. The full system has been approved for attended operation and is pending final approval for unattended operation. This section describes installation activities and operational experience with the system. Lessons learned from this experience are also presented.

\subsection{System Installation and Configuration}

Commissioning of the Wind2H2 demonstration project occurred in March of 2007. System shakedown, safety system improvements, instrumentation, hazardous classification, and PE development and installation occurred throughout the remainder of 2007. In March 2008, the system cleared NREL's final safety review to enable daily operations with various RE configurations.

Since then, new instrumentation and data archiving to monitor operational performance have been added to nearly every major device. In addition, software improvements to the system PLC have enhanced the monitoring and control of the equipment. The system PLC provides the necessary flexibility to integrate many devices that communicate with a variety of protocols.

Ultimately, NREL expects to be able to monitor and control the Wind2H2 system remotely. As a step towards this goal, engineers have been working to configure the system for unattended operation. System controls and safety systems continue to be verified as part of the periodic maintenance plan. Unattended operation would also require reliable communication between the PLC and each device. Today, researchers are able to control and monitor the system from the DERTF using a desktop mirror of the Wind $2 \mathrm{H} 2$ system control computer. Such remote operation from the adjacent laboratory is a critical step towards unattended operation.

The Wind2H2 system includes the operation of both PEM and alkaline electrolyzers at different hydrogen output pressures. This configuration presented a challenge during the design phase of the project that was previously untested by any other system known to the team. The three electrolyzers are piped in to a common line to feed the downstream compressor. The PEM electrolyzers have a maximum output pressure at 200 psi and the alkaline electrolyzer at 150 psi. During the project design, linear control valves were specified and, ultimately installed at the output of each electrolyzer to allow control of the hydrogen product flow. The purpose of these valves was to keep the hydrogen product pressure from reaching 150 psi, thereby putting the alkaline electrolyzer into an idle or standby mode. Complicating things was the realization that the installed control valves were not designed to operate in a Class I, Division 2 hazardous location. Fortunately, system shakedown revealed the compressor suction pressure only approaches $150 \mathrm{psi}$ as the storage tanks reach maximum pressure of $3500 \mathrm{psi}$. In other words, the compressor was found to be capable of accepting the flow from all three electrolyzers at full power while keeping the suction pressure below 150 psi. Consequently, due to the hazardous classification of the production building the control valves were removed from the system. 
As of this writing, full communication between each of the electrolyzers is still being pursued. Issues surrounding this delay involve both electrolyzer systems being designed by the manufacturers for local control via an operator touch-screen. Each system, PEM and alkaline, require different communications protocol and specific PLC programming to accomplish fully unattended control.

On the other hand, digital (on/off) communication between the PLC and compressor was straightforward during system installation. However, long hours were spent rewiring and configuring the compressor control circuit to extract operational status for display on the system monitor in the control building. In addition, extra work was required to wire the compressor in to the emergency stop interlock logic. Similarly, the hydrogen-fueled ICEgenerator requires digital signals to start, stop and to enter energy export mode. In this case, serial (RS485, MODBUS) communication between the PLC and the soft-load transfer switch (SLTS) was required. The SLTS receives commands from the main PLC and initiates start, stop, and energy export via digital signals with the hydrogen generator.

Now, as the 350 bar (5000 psi) hydrogen filling station is being designed, communications with the dispenser controller requires yet another communication method. A serial communication link must be established to collected vital fill parameters and data. In addition, there will be digital communication to transfer hydrogen alarm levels, emergency stops and a hydrogen flow pulse stream (1000 pulses $/ \mathrm{kg}$ ) which will be monitored to assure that the maximum fill-rate for a vehicle is not exceeded.

The DC/DC power converter that was designed, built, and tested at NREL requires communication between the power converters local PLC controller and the main Wind2H2 system PLC. This interface involves a serial signal from the local power converter PLC to a serial-to-Profibus converter. A 'purple hose' Profibus cable was then installed between the power converter located inside the DERTF and Wind2H2 control room to transfer the signals to the main Wind2H2 system PLC. At the main PLC, programming code was required to extract the signals and archive the data alongside the other data being collected.

\subsection{Safety, Hazardous Operations Review, and Readiness Verification}

The system was designed, built, and verified to meet the National Electric Code (NEC) Articles 500 and 501. These articles cover the requirements for electrical equipment in locations where flammable gases (Class I) are present, but are not intentionally released in to the room under normal operating conditions (Division 2). In addition, the following codes were referenced during the installation of system components:

- ANSI/ISA-12.12.01-2000, Nonincendive Electrical Equipment for Use in Class I and II, Division 2 and Class III, Division 1 and 2 Hazardous (Classified) Locations

- NFPA 497: Recommended Practice for the Classification of Flammable Liquids, Gases, or Vapors and of Hazardous (Classified) Locations for Electrical Installations in Chemical Process Areas 
- NFPA 55: Standard for the Storage, Use, and Handling of Compressed Gases and Cryogenic Fluids in Portable and Stationary Containers, Cylinders, and Tanks

- NFPA 70: National Electric Code

- American Society of Mechanical Engineers (ASME) Boiler and Pressure Vessel Code 2007

- B31.3 - 2002 - Process Piping

- CGA G-5.5 - Hydrogen Vent Systems

- AGA XF0277 - Classification of Gas Utility Areas for Electrical Installations

- API RP 500 (R2002) - Recommended Practice for Classification of Locations for Electrical Installations at Petroleum Facilities Classified as Class I, Division I and Division 2.

As part of the system installation, a number of safety features were incorporated, including emergency stops, hydrogen and fire detection, and alarm systems. A contract was established with Engineering Procurement \& Construction (EPC) for the design, installation, and testing of a fire detection and alarming system to be tied into the existing DERTF fire alarm panel. Two weatherproof fire alarm pull-boxes and two photoelectric smoke detectors were installed, one on each building. UV/IR detectors were installed on the south and north walls inside the production and compression building. Finally, a rateanticipation heat detector was also installed in the production and compression building. A system-wide fire alarm status signal is returned to the Wind2H2 system PLC and will perform a system shutdown in the event that these contacts open. The main fire alarm panel is located in the east bay of the DERTF and will notify the fire department in the case of any alarm.

Before systems operations commenced, a full hazardous operations analysis was conducted on the system to identify risk and consequences of a component failure. The NREL, EPC, and Xcel Energy team identified the various failure modes for every component within the system. To date, focus has been on single-level component failures and identifying engineering controls, safe practices, and administrative controls to reduce the overall risk rating to low for these potential failures.

A readiness verification $(\mathrm{RV})$ for the Wind2H2 installation was conducted on Monday, April 9, 2007. The RV was comprehensive in scope and rigorous, but limited to the hydrogen producing electrolyzers, compressor, storage, piping, component ratings, vent lines, building controls, and ancillary support devices. Excluded in the initial RV was the hydrogen-fueled ICE generator and the utility interconnection switch. Corrective actions were identified on a 21-page checklist as a result of this process. All findings were rectified prior to the system being approved for daily operations. 


\subsection{System Operational Experience}

Generally, the system has operated smoothly and has been available for various configuration testing. The Wind $2 \mathrm{H} 2$ system currently allows researchers to control and monitor the operation of the system from the DERTF laboratory using a desktop mirror of the Wind2H2 system computer. Energy from both the PV array and wind turbines is routed through the DERTF and NREL's PE before powering the stacks of the electrolyzers. To date, engineers have run the system for several hundred hours of attended operation.

Safety systems and emergency safety device functionality are routinely verified. To date, no problems have been encountered with the periodic testing of any safety systems. In addition, there have not been any unintentional or unsafe events to cause the system to automatically shut the system down.

To date, major downtime events have been rare. Downtime is logged by the operators and ranges from routine daily equipment faults to a major equipment failures. Significant downtime events are summarized below.

- The main power supply control board for the alkaline electrolyzer failed. Diagnosing the failure resulted in finding an absence of the voltage for the stack current control. Lead-time for this expensive replacement led to two weeks of downtime.

- PEM electrolyzer E-120 began discharging liquid water in the hydrogen product output. As of this writing, the problem has not been fully diagnosed, but symptoms indicate a problem with an aged desiccant drying system, possibly in need of maintenance.

- The internal combustion generator was not exporting the expected 50-60 kW of power. Correcting the generator's under-performance resulted in replacing a pressure-reducing valve that had an undersized flow coefficient $(\mathrm{Cv}=0.02)$ since the installation of the system.

- During initial leak monitoring, several hydrogen leaks were revealed as tank pressure exceeded $\sim 2000$ psi. Compression fittings, hand valves, and the tank isolation valve were all found to have significant leaks. The leaks were corrected by tightening fittings and re-packing valve assemblies. Periodic leak detection has not revealed significant hydrogen leaks since the adjustments were made. An ongoing log is being maintained to track any problematic fittings or devices.

- Typically at startup, the compressor experiences shutdown due to low oil pressure. In addition, air circulating in the glycol cooling system occasionally faults the equipment due to low flow.

\subsection{Operational Lessons Learned}

Designing and configuring the Wind $2 \mathrm{H} 2$ system with components and devices from a wide range of manufacturers presented significant challenges. Most notably, communication between the main Wind $2 \mathrm{H} 2$ system PLC and nearly every significant 
device (electrolyzers, compressor, soft-load transfer switch, power converter and dispenser) required significant time and communication programming.

The main Wind2H2 system PLC allows for expanding the number of modules to enable a wide variety of communication hardware. Many times additional software was required to allow the hardware to communicate with the specific manufacturer's communication protocol. Every manufacturer has a 'favorite' communications protocol and, once the interface is established, further time is spent extracting the required information from various registers. Since each manufacturer of the various equipment required in a renewable electrolysis production system uses different communications protocols, it is imperative that time be spent up front during system-level design and configuration to develop and test the necessary communication protocols to cover all system equipment.

As shown in Section 3.3, a large number of codes and standards may apply to renewable electrolysis hydrogen production facilities. As these systems are designed and constructed, it is important that project engineers are aware of these potentially relevant codes and standards. For the Wind $2 \mathrm{H} 2$ project, the design team produced a spreadsheet containing all of the codes listed Section 3.3 to track the sections that were relevant. Great care was taken to assure the production and compression building was designed and maintained as a Class I, Division 2 facility. However, one obvious barrier to this goal is that the PEM electrolyzers used in the Wind2H2 project are not designed for this hazardous classification. Confidence of the safety of the building rests with the PEM system approach to safety, namely; continuous ventilation and on-board combustible gas detection. The combustible gas detector requires calibration every 90 days and will shut the electrolyzer down if $25 \%$ of hydrogen's LFL is reached inside the cabinet. The alkaline electrolyzer requires a remote power supply with long control and DC power cables to achieve the classification rating. Furthermore, the team designed an extra monitoring and control systems to satisfy the higher-than-normal safety requirements of a government installation.

Daily operation of the Wind2H2 system has yielded a number of additional administrative procedures that were not initially anticipated. Periodic leak monitoring is performed due to the extreme weather and temperature swings experienced at the site and to assure that hydrogen leaks are corrected early. Equipment faults and unexpected shutdowns typically occur on a daily basis. The vast majority of these nuisance trips are simply recovered by clearing the error and restarting the equipment. Leak monitoring and equipment nuisance trips are logged manually to help determine statistical reliability metrics (e.g., mean-time between failure, mean-time between repair, mean-time to failure). These metrics are used to assess system or equipment reliability and maintainability, identify problems within the system, and enable comparisons with other similar equipment.

\section{Baseline Testing and Analysis}

\subsection{Introduction}

One of the overriding objectives of the Wind $2 \mathrm{H} 2$ project is to better integrate the various subsystems of the renewable electrolysis systems to optimize energy transfer and 
maximize renewable energy use while at the same time improving system performance and lowering overall system cost. In line with this objective, the Wind $2 \mathrm{H} 2$ project seeks to eliminate the redundancy of energy conversion devices, potentially both by directly coupling the RE source to the electrolyzer stack and also by reducing the amount of energy conversion stages between the RE source and the electrolyzer stack. To achieve this optimization, it is necessary to characterize the critical design parameters of the electrolyzer system, particularly the voltage and current characteristics of the electrolyzer stack. This section presents the results of this baseline system testing and electrolyzer characterization.

\subsection{PEM Electrolyzer Performance}

\subsubsection{E-130 Stack Polarization Curves}

The PEM electrolyzers were operated in grid only mode in order to acquire baseline system performance characteristics. Stack polarization curves were obtained by varying stack current from the onboard AC/DC power supply via the control signal from the main electrolyzer controller. A $0-5 \mathrm{Vdc}$ signal from the electrolyzer controller to the power supply results in a stack current ranging from 0-200 A. Operators installed a potentiometer to split the normally constant control signal to allow a full sweep of the stack current from its operating point of $135 \mathrm{~A}$ down to roughly $5 \mathrm{~A}$. Two sweeps were performed: one at startup $\left(35^{\circ} \mathrm{C}\right)$ and one during steady-state operation $\left(55^{\circ} \mathrm{C}\right)$. The dataacquisition system was modified to sample stack current and voltage once per second (1 sample per second, $1 \mathrm{~S} / \mathrm{s}$ ). This allowed a relatively quick sweep of the stack current to capture the required data while maintaining system temperature and (hydrogen and oxygen) pressures.

The polarization curves (Figure 4-1) reveal the impact of temperature on electrolyzer stack performance. As temperature increases, stack voltage decreases for a given current, resulting in lower stack power requirements as seen by the separation of the two curves. These stack polarization (V-I) curves dictate the operating point of the electrolyzer stack based on the temperature of the stack. De-ionized water temperature is used as a surrogate to stack temperature. The in/output DI water temperatures are averaged to determine the operating temperature of the stack. 


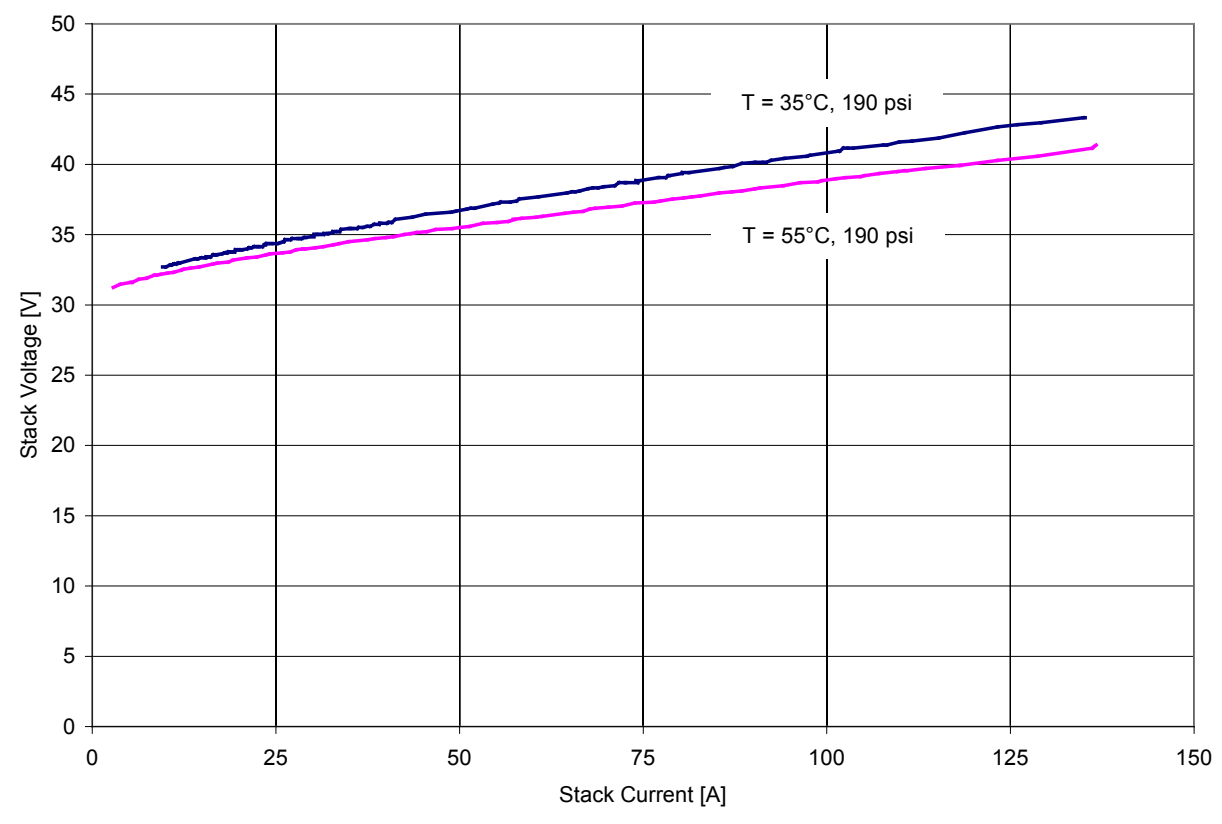

Figure 4-1: PEM E-130 stack polarization curves at $35^{\circ} \mathrm{C}$ and $55^{\circ} \mathrm{C}$

Depending on stack temperature and current, stack voltage varies from about $30 \mathrm{~V}$ to 43 $\mathrm{V}$. The stacks of E-120 and E-130 consist of 20 series-connected cells putting the voltage between 1.5 and $2.2 \mathrm{~V}$ per cell. The fairly linear response between $25 \mathrm{~A}$ and $135 \mathrm{~A}$ is a function of the ohmic losses (IR) associated with membrane resistance to the flow of protons. An energy penalty is also present in the stack voltage as electrochemical compression of the hydrogen gas at the cathode, and, to a lesser extent, oxygen at the anode results in an increase in stack voltage. Appendix B provides the details for calculating stack voltage efficiency under these conditions.

\subsubsection{E-130 Stack Voltage Efficiency}

During the current sweeps that produced the V-I characteristic curves of Figure 4-1, stack temperature and system pressure held nearly constant. In this case, the stack was operating at $55^{\circ} \mathrm{C}$, cathode pressure of $190 \mathrm{psi}$, and anode pressure of $30 \mathrm{psi}$, resulting in an ideal cell voltage of $1.52 \mathrm{~V}$. The measured operating voltage over the entire current sweep (Figure 4-1) is compared to this ideal voltage to produce the stack efficiency $\left(\eta_{\text {stack }}\right)$ curve of Figure 4-2.

$$
\eta_{\text {stack }}=\frac{V_{\text {ideal }}}{V_{\text {actual }}}
$$




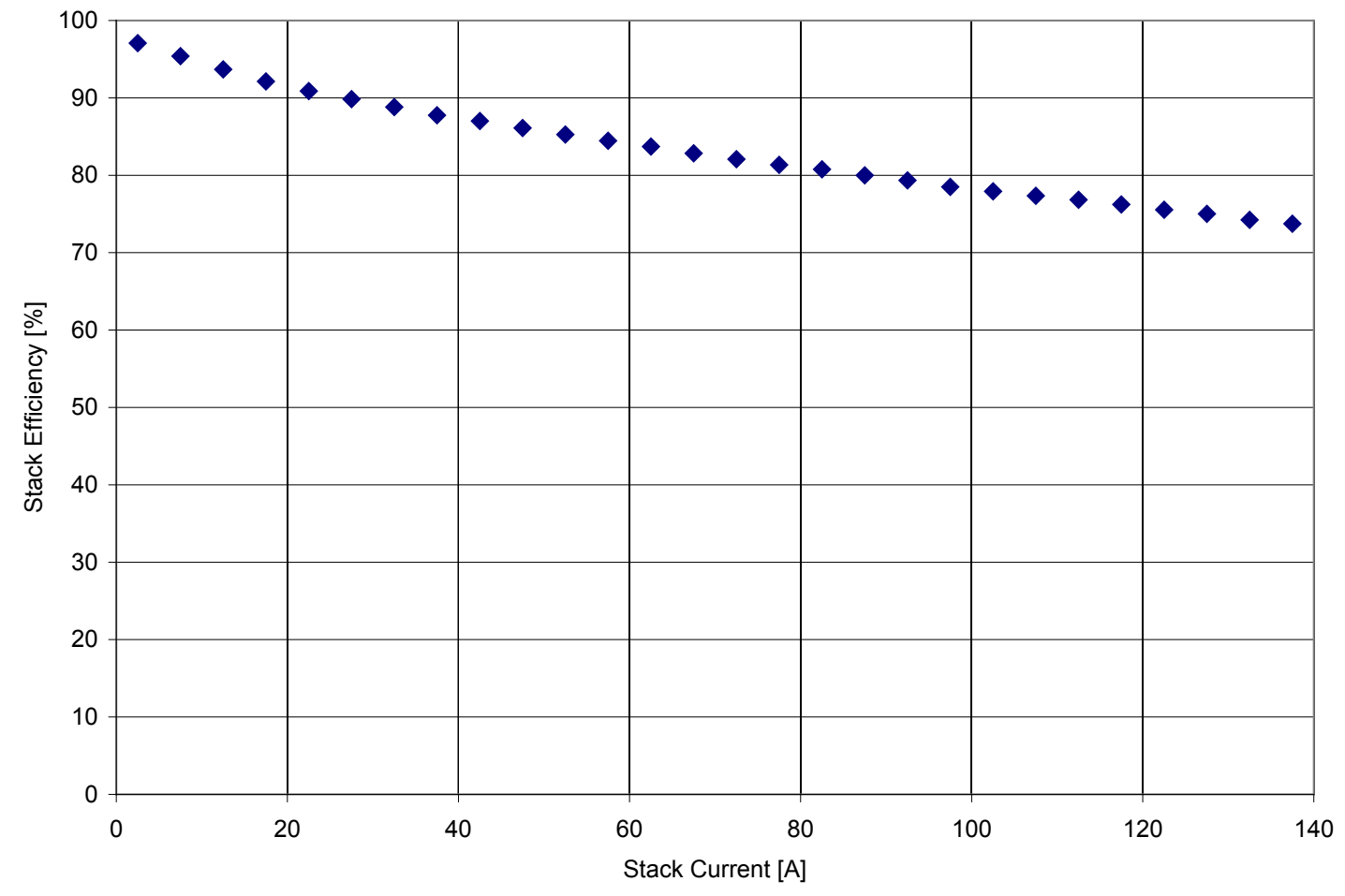

Figure 4-2: Stack-efficiency data at $55^{\circ} \mathrm{C}, 195$ psi cathode, and 30 psi anode for PEM electrolyzer E-130

\subsubsection{E-130 System Efficiency (HHV)}

The methodology used to calculate electrolyzer system efficiency is described in Appendix B. The system efficiency differs from the stack efficiency in that it is more than simply comparing the stack voltage over the range of currents with an ideal voltage. In the system efficiency case, the overall energy into the electrolyzer is taken with the energy content in the hydrogen output compared with the higher heating value (HHV) of hydrogen $(39.4 \mathrm{kWh} / \mathrm{kg})$.

The minimum amount of energy that must be consumed to split water into hydrogen and oxygen is known as the heat of formation (enthalpy) and corresponds to the HHV of hydrogen. The $\mathrm{HHV}$ is defined as the amount of energy released by the combustion of the fuel starting at $25^{\circ} \mathrm{C}$ and allowing the products to return to a temperature of $25^{\circ} \mathrm{C}$ after combustion. The HHV takes into account the latent heat of vaporization of water by measuring the heat released as the combustion products cool to $25^{\circ} \mathrm{C}$. The HHV represents the actual amount of energy required to electrolyze water.

While it has been customary to use the lower heating value (LHV) to measure the performance of electrolytic-hydrogen production, measurement of efficiency on an HHVbasis is more thermodynamically accurate. To enable a more broad interpretation of results, however, efficiency on both an HHV- and a LHV-basis are presented. It is important to recognize that for hydrogen, the difference between the LHV and the HHV is significant. The HHV of hydrogen $(142 \mathrm{MJ} / \mathrm{kg})$ is $18 \%$ greater than the LHV (120 
$\mathrm{MJ} / \mathrm{kg}$ ) because the LHV assumes that the latent and sensible heat of vaporization of the combustion products (i.e., water vapor) is not recovered between $150^{\circ} \mathrm{C}$ and $25^{\circ} \mathrm{C}$.

Table 4-1: Measured PEM electrolyzer system efficiency

\begin{tabular}{ccccc}
\hline $\begin{array}{c}\text { System } \\
\text { Power }\end{array}$ & $\begin{array}{c}\text { Stack } \\
\text { Current }\end{array}$ & $\begin{array}{c}\text { Measured } \\
\text { Hydrogen } \\
\text { FW }\end{array}$ & $\begin{array}{c}\text { System } \\
\text { Efficiency } \\
\text { Amps }\end{array}$ & $\begin{array}{c}\text { System } \\
\text { Efficiency } \\
\text { (HH }\end{array}$ \\
\hline 6.5 & 135 & 1.05 & 57.4 & 48.5 \\
(LHV) & $\%$ \\
5.7 & 123 & 0.92 & 56.8 & 48.0 \\
4.6 & 98 & 0.69 & 53.3 & 45.0 \\
3.9 & 83 & 0.46 & 41.7 & 35.2 \\
3.1 & 63 & 0.26 & 30.0 & 25.4 \\
2.1 & 38 & 0.10 & 16.9 & 14.3 \\
1.4 & 18 & 0.01 & 2.6 & 2.2 \\
\hline
\end{tabular}

Table 4-1 summarizes the data that are used to calculate the system efficiency. The stack current is included for reference. The system efficiency is maximum at the rated current of $135 \mathrm{~A}$ and reaches zero at about $15 \mathrm{~A}$. The hydrogen mass flow sensors are calibrated to "normal" conditions, which are $0^{\circ} \mathrm{C}, 1$ atmosphere (atm) pressure. The density of hydrogen at these conditions is $0.08988 \mathrm{~kg} / \mathrm{Nm}^{3}$ used in the system-efficiency calculation.

\subsection{Alkaline Electrolyzer Performance \\ 4.3.1 E-110 Stack Polarization Curves}

The alkaline electrolyzer was operated from grid power to acquire stack voltage and current data. The electrolyzer's AC/DC power supply has a local control mode where the stack current can be varied over the full range (0-220 A). These data were captured at two different operating temperatures. The temperature of the electrolyzer affects the polarization characteristic (Figure 4-3)

Depending on the temperature and current, stack voltage varies from about $50 \mathrm{~V}$ to 175 $\mathrm{V}$. The stack of E-110 consists of 75 series-connected cells, putting the cell voltage between 1.75 and $2.3 \mathrm{~V}$ when operated above $50 \mathrm{~A}$. The fairly linear response between $50 \mathrm{~A}$ and $220 \mathrm{~A}$ is a function of the ohmic losses (IR) associated with electrolyte resistance to the flow of ions. 


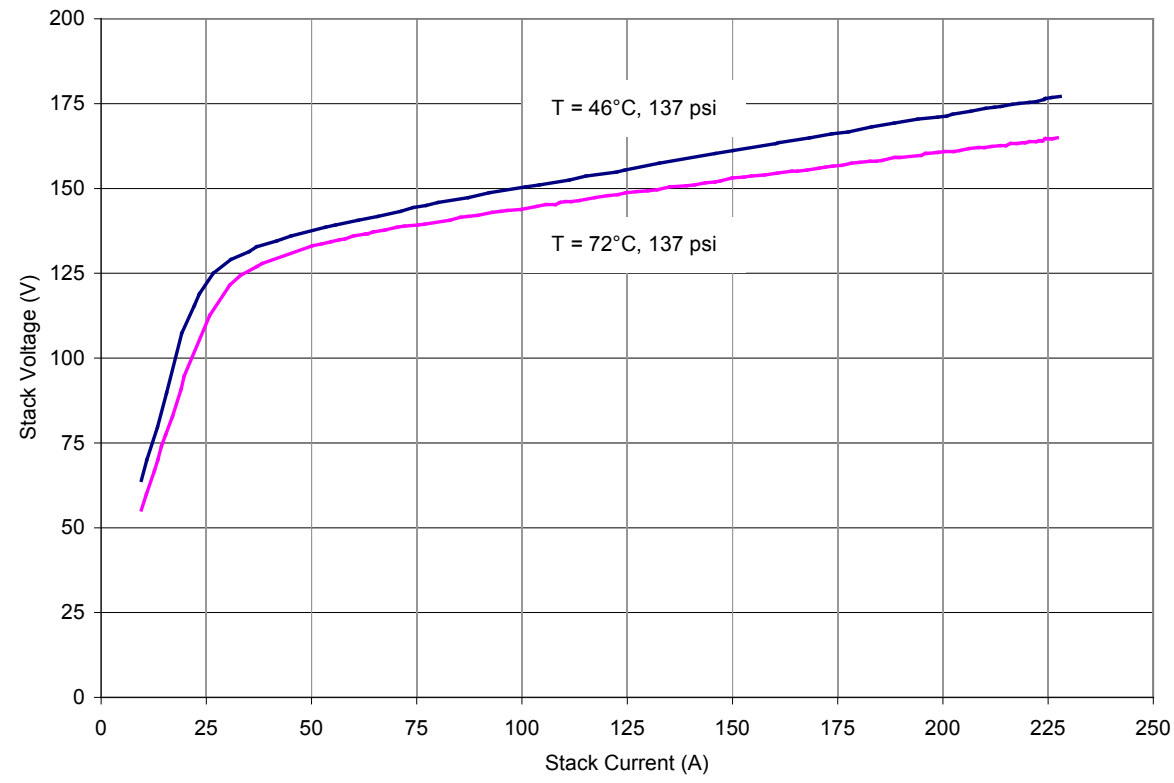

Figure 4-3: Alkaline E-110 stack polarization curves at $46^{\circ} \mathrm{C}$ and $72^{\circ} \mathrm{C}$

\subsubsection{E-110 Stack Voltage Efficiency}

During the current sweeps that produced the V-I characteristic curves of Figure 4-3, stack temperature and system pressure were held nearly constant. In this case, the stack was operating at $72^{\circ} \mathrm{C}$, cathode pressure of $137 \mathrm{psi}$, and anode pressure of $137 \mathrm{psi}$, resulting in an ideal cell voltage of $1.53 \mathrm{~V}$. The measured operating voltage over the entire current sweep (Figure 4-3) is compared to this ideal voltage to produce a stack efficiency $\left(\eta_{\text {stack }}\right)$ curve (Figure 4-4). Appendix B provides the details of the method for calculating the stack voltage efficiency under these temperature and pressure conditions.

$$
\eta_{\text {stack }}=\frac{V_{\text {ideal }}}{V_{\text {actual }}}
$$




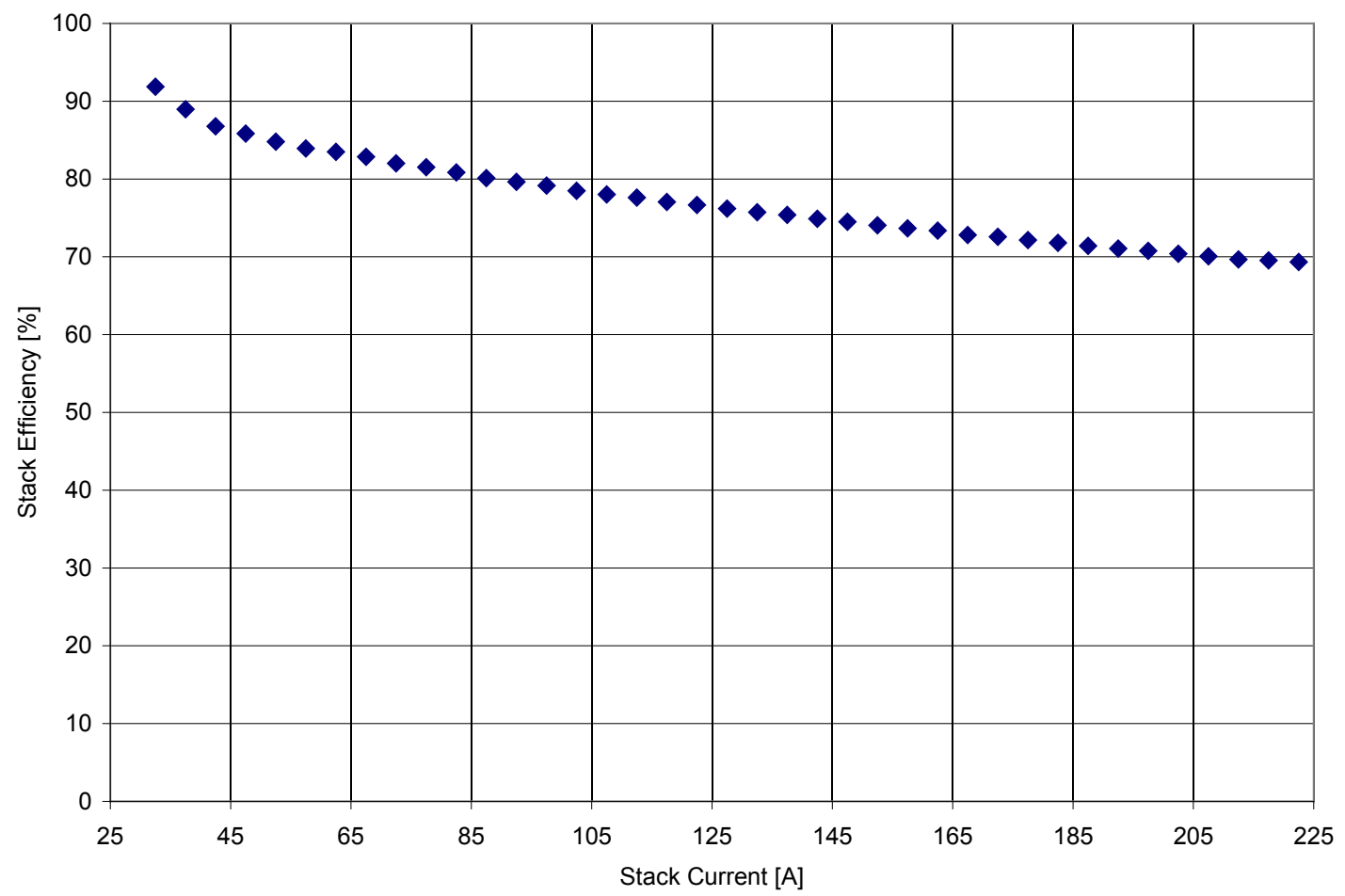

Figure 4-4: Stack efficiency data at $72^{\circ} \mathrm{C}$, cathode pressure of $137 \mathrm{psi}$, and anode pressure of 137 psi for alkaline electrolyzer E-110

\subsubsection{E-110 System Efficiency (HHV)}

Table 4.2 summarizes the data that are used to calculate the system efficiency. The stack current is included for reference. The system efficiency is based on the HHV of hydrogen $(39.4 \mathrm{kWh} / \mathrm{kg})$. The stack efficiency is maximum $41 \%$ at the rated current of $220 \mathrm{~A}$ and reaches zero just under a stack current of $40 \mathrm{~A}$.

Table 4-2: Measured alkaline electrolyzer system efficiency

\begin{tabular}{ccccc}
\hline $\begin{array}{c}\text { System } \\
\text { Power } \\
\text { kW }\end{array}$ & $\begin{array}{c}\text { Stack } \\
\text { Current } \\
\text { Amps }\end{array}$ & $\begin{array}{c}\text { Measured } \\
\text { Hydrogen } \\
\text { Flow } \\
\mathrm{Nm}^{3} / \mathrm{hr}\end{array}$ & $\begin{array}{c}\text { System } \\
\text { Efficiency } \\
\text { (HHV) }\end{array}$ & $\begin{array}{c}\text { System } \\
\text { Efficiency } \\
\text { (LHV) }\end{array}$ \\
\hline 40 & 220 & 4.7 & 41 & 35 \\
37 & 200 & 4.2 & 40 & 34 \\
33 & 175 & 3.7 & 39 & 33 \\
28 & 150 & 3.1 & 39 & 33 \\
22 & 125 & 2.5 & 40 & 34 \\
18 & 100 & 1.9 & 37 & 31 \\
14 & 75 & 1.2 & 31 & 26 \\
10 & 50 & 0.5 & 18 & 15 \\
8 & 41 & 0.2 & 7 & 6 \\
\hline
\end{tabular}


To verify the manufacturer's published flow rate of $5.6 \mathrm{Nm}^{3} / \mathrm{hr}$ at a stack current of 220 A, project engineers conducted tests using three different mass-flow sensors. During the testing, two of the mass flow sensors read $4.3 \mathrm{Nm}^{3} / \mathrm{hr}$, and the third reached $4.7 \mathrm{Nm}^{3} / \mathrm{hr}$ at rated stack current $(220 \mathrm{~A})$. Table 4-2 summarizes the system efficiency using the highest reading mass flow sensor. It is worth noting that if the rated flow was reached (5.6 $\mathrm{Nm}^{3} / \mathrm{hr}$ ) with a system power of $40 \mathrm{~kW}$, the system efficiency would reach $50 \%$. The mass-flow sensors are calibrated to "normal" conditions, which are $0^{\circ} \mathrm{C}, 1 \mathrm{~atm}$ pressure. The density of hydrogen at these conditions is $0.08988 \mathrm{~kg} / \mathrm{Nm}^{3}$ and used for the system efficiency calculation.

Figure 4-5 is a plot of experimental data showing the hydrogen flow output of the alkaline electrolyzer with various stack current. The flow fluctuations are due to a lack of averaging in the data-acquisition system. These experimental data are input to the efficiency calculation by averaging the hydrogen flow at each current level.

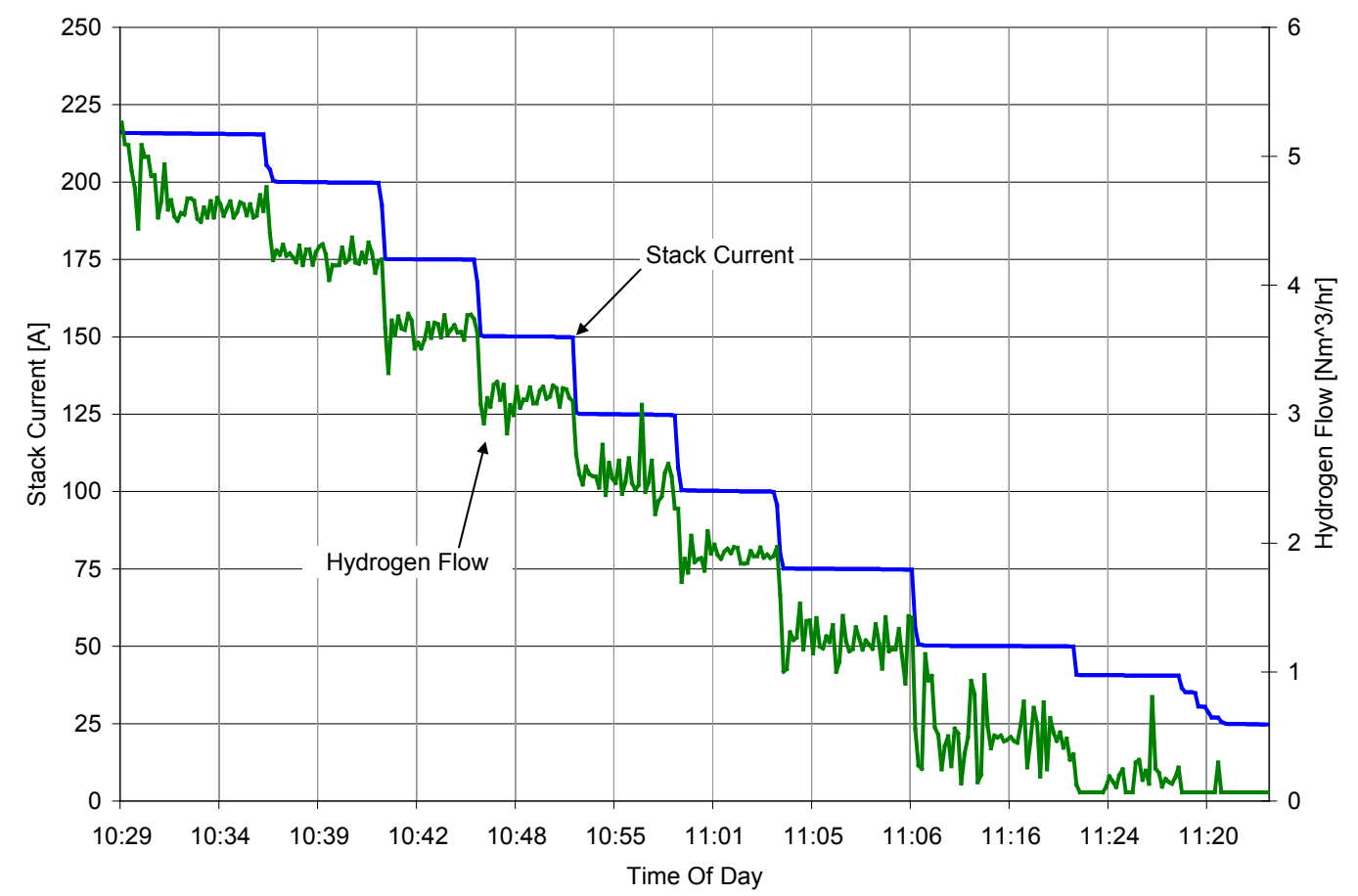

Figure 4-5: E-110 resulting hydrogen flow for different stack-current levels

\section{System Integration and Optimization}

\subsection{Introduction}

To enable greater penetration of renewable energy sources, hydrogen production from renewable electrolysis must be cost-competitive. Electrolyzer manufacturers are making ongoing efforts to reduce the capital cost of electrolyzer systems and to improve their performance. At the same time, the complete renewable electrolysis system, including the renewable power source, electrolyzer, and interfacing power electronics, must be integrated and improved to optimize energy transfer and maximize renewable energy use. 
The Wind2 $\mathrm{H} 2$ project presents an excellent research platform to investigate these integration and optimization opportunities. The Wind2 $\mathrm{H} 2$ system is being used to evaluate how to best match the output of renewable power systems to electrolyzer power requirements and how to improve the PE used to transfer power between the RE source and the electrolyzer. Based on their operational experience with the Wind2H2 system, project engineers have assessed the potential cost savings associated with such systemlevel optimization and begun to design and test simplified PE to maximize energy transfer from PV arrays and wind turbines to electrolyzer units. As discussed below, system-level improvements in PE alone might reduce the cost of hydrogen production via renewable electrolysis by $7 \%$.

\subsection{Economic Analysis of System Integration Opportunities}

While it is important to investigate how to best integrate a renewable electrolysis system and optimize performance at a systems level, researchers also need to explore the cost implications of these optimization efforts. An analysis was performed to better understand how a closer coupling of the wind turbine to the electrolyzer stack including the incorporation of more simplified PE would affect the cost of hydrogen from renewable electrolysis.

The variable-speed, $10 \mathrm{~kW}$ wind turbine employed by the Wind $2 \mathrm{H} 2$ project produces varying magnitude, varying frequency alternating current (known as wild AC) based on wind speed. As initially configured, the $10 \mathrm{~kW}$ wind turbine rectifies this wild AC-to-DC, and then uses an inverter to convert the DC to 3-phase $240 \mathrm{~V}$ nominal AC. This wild ACto-DC-to-AC conversion methodology is a typical configuration for wind turbine power electronics. In turn, the electrolyzer system incorporates power electronics to rectify the 3-phase AC-to-DC for use by the electrolyzer stack. A cost analysis of a large, windbased renewable electrolysis production facility using this typical PE system configuration was conducted using NREL's H2A Production Model, Version 2.1 (http://www.hydrogen.energy.gov/h2a production.html), which provides a levelized cost of hydrogen on a per kilogram basis based on a discounted cash flow, rate of return methodology. Following this baseline analysis, Wind2H2 engineers developed a conceptual design for a revised PE interface and developed cost estimates for this optimized system, which were used as inputs for a revised H2A Production analysis.

The H2A analysis of the baseline system was based on the Current (2005) Central Grid Electrolysis case study, version 2.1.1. ${ }^{6}$ In 2008, the H2A Production Model was revised significantly, and new standard hydrogen production case studies were developed. The $\mathrm{H} 2 \mathrm{~A}$ version 2 case study for central electrolysis production was based on gridelectricity, not wind electricity as had been analyzed in version 1 . To conduct the baseline wind electrolysis analysis, the version 2 central electrolysis case was modified using information on the wind turbine from the $\mathrm{H} 2 \mathrm{~A}$ version 1 wind electrolysis case, together with cost data from NREL's WindPACT Turbine Rotor Design Study. ${ }^{7,8}$ The hydrogen

\footnotetext{
${ }^{6}$ Ramsden, T. (2008). "Current (2005) Hydrogen Production from Central Grid Electrolysis", Version 2.1.1. H2A Production Case Study. http://www.hydrogen.energy.gov/h2a prod_studies.html.

${ }^{7}$ Ivy Levene. J. (2006). "Current (2005) Hydrogen Generation from Wind", Version 1.0.8. H2A Production Case Study.
} 
production facility modeled uses 1.5 MW wind turbines and 2.33 MW electrolyzer systems. Major cost components of these systems are shown in Table 5-1.

Table 5-1: Capital cost contributions for a wind-electrolysis facility

\begin{tabular}{crr}
\hline Capital Component (uninstalled) & Baseline System & Optimized System \\
\hline $\begin{array}{c}1.5 \text { MW Wind Turbine } \\
\text { Rotor }\end{array}$ & $\$ 248,000$ & $\$ 248,000$ \\
Drive Train & $\$ 1,280,000$ & $\$ 1,180,000$ \\
$\quad$ including power electronics & $\$ 100,000$ & $\$ 0$ \\
Control System & $\$ 10,000$ & $\$ 10,000$ \\
Tower & $\$ 184,000$ & $\$ 184,000$ \\
Balance of Station & $\$ 262,000$ & $\$ 262,000$ \\
including power electronics & $\$ 1,570,000$ & $\$ 1,350,000$ \\
2.33 MW Electrolyzer & $\$ 220,000$ & $\$ 0$ \\
New Power Electronics Interface & $\$ 0$ & $\$ 70,000$ \\
\hline Resulting Total Hydrogen Cost (\$/kg) & $\$ \mathbf{6 . 2 5}$ & $\$ \mathbf{5 . 8 3}$ \\
\hline
\end{tabular}

Wind $2 \mathrm{H} 2$ engineers then analyzed what components were included in the PE sections of the wind turbine and electrolyzer and how those components might be simplified if the wind turbine were more closely coupled to the electrolyzer stack. Since the electrolyzer stack requires DC power, the original PE package that converted wild AC-to-DC to 3phase $\mathrm{AC}$ and then back again to $\mathrm{DC}$ could be simplified to converting wild AC-to-DC, and then adding a DC/DC converter stage to provide the necessary DC voltage required by the electrolyzer stack.

To estimate the cost of hydrogen production from the modified system compared to the baseline system, both system performance and system cost must be considered. The modified design replaces the original DC to 3-phase AC and 3-phase AC-to-DC conversion steps with a single DC/DC conversion step. Based on a review of relevant literature, for the baseline design the DC to 3-phase conversion is assumed to be $95 \%$ efficient and, similarly, the rectification of 3-phase AC-to-DC is assumed to be $95 \%$ efficient as well. Therefore, the combined efficiency of these energy conversion steps in the baseline system is 90 percent. The modified PE design uses a single DC/DC converter that is similar to $\mathrm{DC} / \mathrm{DC}$ converters used in the Wind2 $\mathrm{H} 2$ project, which have a conversion efficiency of $90 \%$. Thus, the energy conversion efficiency is the same in both systems, so both systems will require the same amount of electricity to produce a kilogram of hydrogen. As such, a cost analysis comparing the baseline system to a system with improved PE will rest on differences in the capital costs of these two systems.

\footnotetext{
${ }^{8}$ Malcolm, D.J.; Hansen, A.C. (2006). WindPACT Turbine Rotor Design Study. NREL/SR-500-32495. Golden, CO: National Renewable Energy Laboratory.
} 
With this in mind, a cost analysis of the initial configuration and the optimized configuration was conducted. The original \$100,000 PE package was assessed to include $35 \%$ for the rectifier section and $65 \%$ for the inverter section. Thus, the rectifier section for a 1.5 MW wind turbine was estimated to cost $\$ 35,000$ and the inverter section $\$ 65,000$. The rectifier section would still be required in the optimized package to convert wild AC-to-DC. Based on available cost information for DC/DC converter technology, the new DC/DC section was assumed to cost $\$ 30 / \mathrm{kW}$. Thus, the DC/DC converter required for the $1.5 \mathrm{MW}$ wind turbine would cost $\$ 45,000$.

The total cost of the optimized power electronics section, incorporating both the rectifier section and DC/DC converter, would be $\$ 70,000$. This optimized power conversion system would replace the existing power electronics in the wind turbine and the electrolyzer. Based on the WindPACT turbine study, this change would remove $\$ 100,000$ in $\mathrm{PE}$ on the wind turbine side. In a separate cost analysis project conducted as part of the Wind $2 \mathrm{H} 2$ project, the PE section of an alkaline-based electrolyzer accounts for $14 \%$ of total system cost. ${ }^{9}$ For the electrolyzer system modeled, this would total $\$ 220,000$ for the PE section. These revised capital costs were entered into the H2A model to develop a new hydrogen production cost. As seen in Table 5-1, the resulting cost of hydrogen produced from wind-electrolysis is $\$ 5.83 / \mathrm{kg}$ compared to a baseline of $\$ 6.25 / \mathrm{kg}$, a $\$ 0.42 / \mathrm{kg}$ reduction in total cost. Thus, optimization of the power conversion system due to a closer coupling of the wind turbine to the electrolyzer stack can reduce the total cost of hydrogen by $7 \%$. This hydrogen cost savings results from reductions in capital cost alone. Project engineers expect that by better size matching of wind turbine and electrolyzer systems, the efficiency of the DC/DC conversion step of the modified system can be improved from $90 \%$ to $93 \%$ or more. Such performance improvements could further reduce the cost of hydrogen from a wind-electrolysis production system.

\subsection{Small Wind Powered Electrolysis Testing and Analysis 5.3.1 Objective}

Given the potential of power conversion optimization to reduce the cost of hydrogen production, Wind2H2 project engineers sought to develop power electronics and control algorithms to optimize and evaluate power transfer in the Wind2H2 system. Previous work included the development of a simulation program and initial hardware setup of a prototype system. ${ }^{10}$ During 2007, an integrated PE system was designed and tested with the Bergey $10 \mathrm{~kW}$ wind turbine and $6 \mathrm{~kW}$ PEM electrolyzer stack. This section provides an overview of the work that was completed and a summary of the tests that were conducted.

\footnotetext{
${ }^{9}$ Saur, G. (2008). Wind-To-Hydrogen Project: Electrolyzer Capital Cost Study. NREL/TP-550-44103. Golden, CO: National Renewable Energy Laboratory.

${ }^{10}$ Kramer, B. Integrated Power Electronics System to Produce Hydrogen Using Wind Energy. NREL Milestone Report AOP 3.6.4.
} 


\subsubsection{Approach}

In general, this section investigates opportunities to improve the energy capture from a permanent-magnet variable-speed wind turbine using hardware-in-the-loop. The variablespeed wind turbine produces wild AC based on wind speed, which is then converted to DC using a controlled rectifier circuit. This rectification is accomplished by controlling when solid state switches (thyristors) conduct current. By optimizing the control strategy of the thyristor switching circuit we maximize the energy capture from the wind turbine to the electrolyzer stack. Hardware-in-the-loop enables control algorithms to be simulated prior to being executed in the actual switching hardware.

\subsubsection{Simulation}

Modifications were made to a computer model that was designed to develop a control system to optimize the production of hydrogen from a PEM electrolyzer while providing control for the wind turbine. The simulation was used for live demonstrations of the proposed system and was used to further optimize the system by evaluating the hardware limitations such as the minimum allowable firing angle. The general block diagram is given in Figure 5-1.

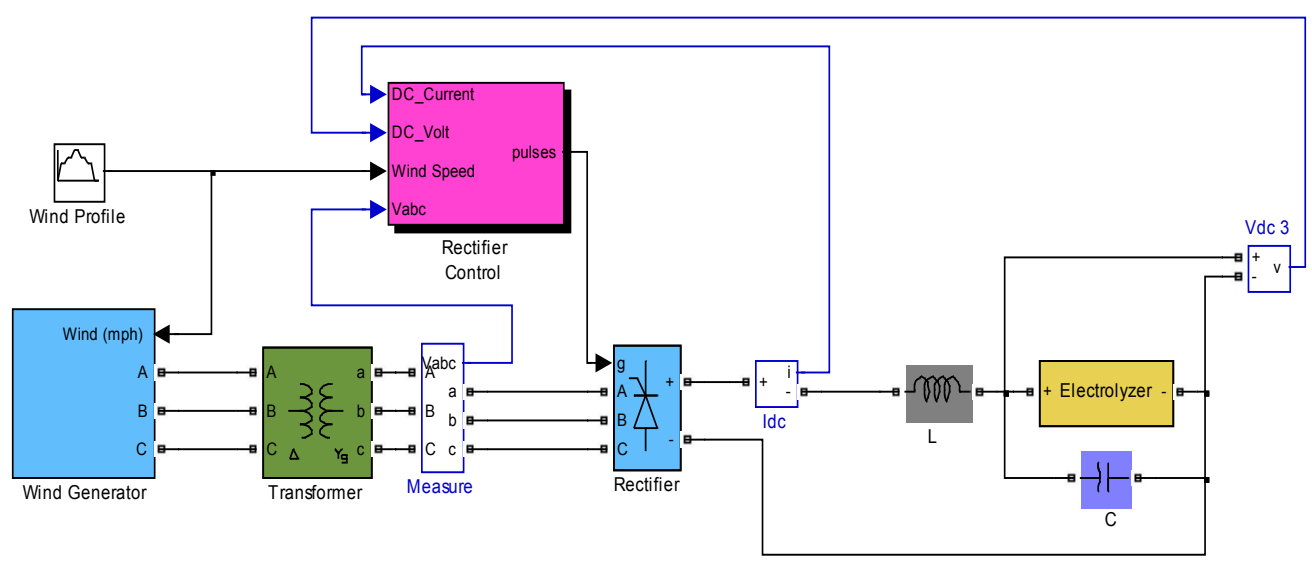

Figure 5-1: General model control block diagram

\subsubsection{Hardware}

The hardware prototype of the system was tested using a $0.3 \Omega$ resistor bank in place of the electrolyzer stack while the new electrolyzer test facility was being built. The control algorithm varies the firing angle based on the amount of power that is available from the wind turbine. According to the manufacturer, the lowest allowable setting for stable operation of the thyristor bridge is $10^{\circ}$. The power available to a load for a three-phase, full-wave bridge rectifier can be expressed as: ${ }^{11}$

$$
\mathrm{P}_{\mathrm{L}}=\frac{3 \mathrm{Em}^{2}}{4 \pi \mathrm{R}}(2 \pi+3 \sqrt{3} \cos (2 \alpha))
$$

\footnotetext{
${ }^{11}$ Shepherd, W.; Zhang, L. (2004) Power Converter Circuits. Portland: CRC Press.
} 
where:

$$
\begin{array}{ll}
\mathrm{P}_{\mathrm{L}} & =\text { Power at the Load (watts) } \\
\mathrm{Em} & =\text { Peak value of the phase voltage (Vac) } \\
\mathrm{R} & =\text { Load Resistance (ohms) } \\
\alpha & =\text { Firing angle (radians) }
\end{array}
$$

The percentage power loss between two different firing angles can be expressed as:

$$
\% \mathrm{P}_{\text {Loss }}=\frac{300 \sqrt{3}\left(\cos \left(2 \alpha_{2}\right)-\cos \left(2 \alpha_{1}\right)\right)}{2 \pi+3 \sqrt{3} \cos \left(2 \alpha_{1}\right)}
$$

If $\alpha_{1}=36^{\circ}$ and $\alpha_{2}=10^{\circ}$, it was estimated that the converter could produce approximately $29 \%$ more power with these new settings for a pure sinusoidal input from the source. As a result, adjustable potentiometers were added to the thyristor bridge controller board to control the span and zero for the firing angle and were adjusted to allow controllable alpha firing angles between $10^{\circ}$ and $118^{\circ}$.

Further development tests showed that the DC current shunt used to measure DC current caused the control to be oscillatory at low currents. The current shunt was replaced with a Hall-effect current sensor that had a higher sensor output, and the oscillatory control behavior was eliminated.

Potential transformers were added to the system to allow the phase-to-phase voltages to be measured. A current transformer was also added to the system to monitor the AC input current. The FPGA was reprogrammed to measure RMS phase-to-phase voltages and the AC phase current. Measurements were verified using a hand-held, digital volt meter. An $\mathrm{AC}$ power meter used to monitor the $\mathrm{AC}$ input power to the thyristor bridge was added and calibrated.

A software program was loaded onto a laptop computer to help facilitate the collection of data from the oscilloscope. The program stores the data in a format that can be easily read by Microsoft Excel.

\subsubsection{Control Strategy}

The control strategy developed in simulation was ported into the real-time environment. Voltage limit, current limit, and frequency limit control algorithms were added to protect the equipment. An upper input voltage limit shut-off was implemented to shut off the system should a high AC input voltage be sensed at the input of the PE. A closed-loop feedback voltage control was added to control the thyristor bridge at the voltage limit should the voltage-limit set point be reached. Development testing showed that the thyristor bridge hardware cannot operate below $10 \mathrm{~Hz}$. A hysteresis control was added to the control algorithm so the thyristor bridge shuts off below $10 \mathrm{~Hz}$ and restarts above 20 $\mathrm{Hz}$. 
The graphical user interface was modified to allow the control parameters to be tuned in real-time. With the wind simulator and fixed resistor load, tests were conducted to adjust the controller's tuning parameters to be responsive to both load and set-point changes, and the current, voltage, and frequency limit-control algorithms were tested.

Next, the wind simulator was disconnected from the converter and was replaced with the Bergey wind turbine, and the control system was further tuned together with a fixed resistor load. Conduit and wiring were installed from the DERTF DC buss to the new electrolyzer building and were terminated at the DC input of the PEM electrolyzer stack. The DC output of the PE converter was connected to the electrolyzer stack via DERTF busswork.

Currently, this system is undergoing upgrades aimed at enhancing the energy transfer from the turbine to the electrolyzer stack. One major upgrade is the installation of an anemometer at the same hub height as the turbine, about 50 meters away. Wind speed data are collected remotely and then sent to the AC/DC converter via the local data network. The AC/DC power converter reads the wind data and executes an MPPT algorithm that strives to keep the tip-speed ratio of the turbine at the optimal value for maximum energy extraction. Figure 5-2 illustrates the new anemometer data system.

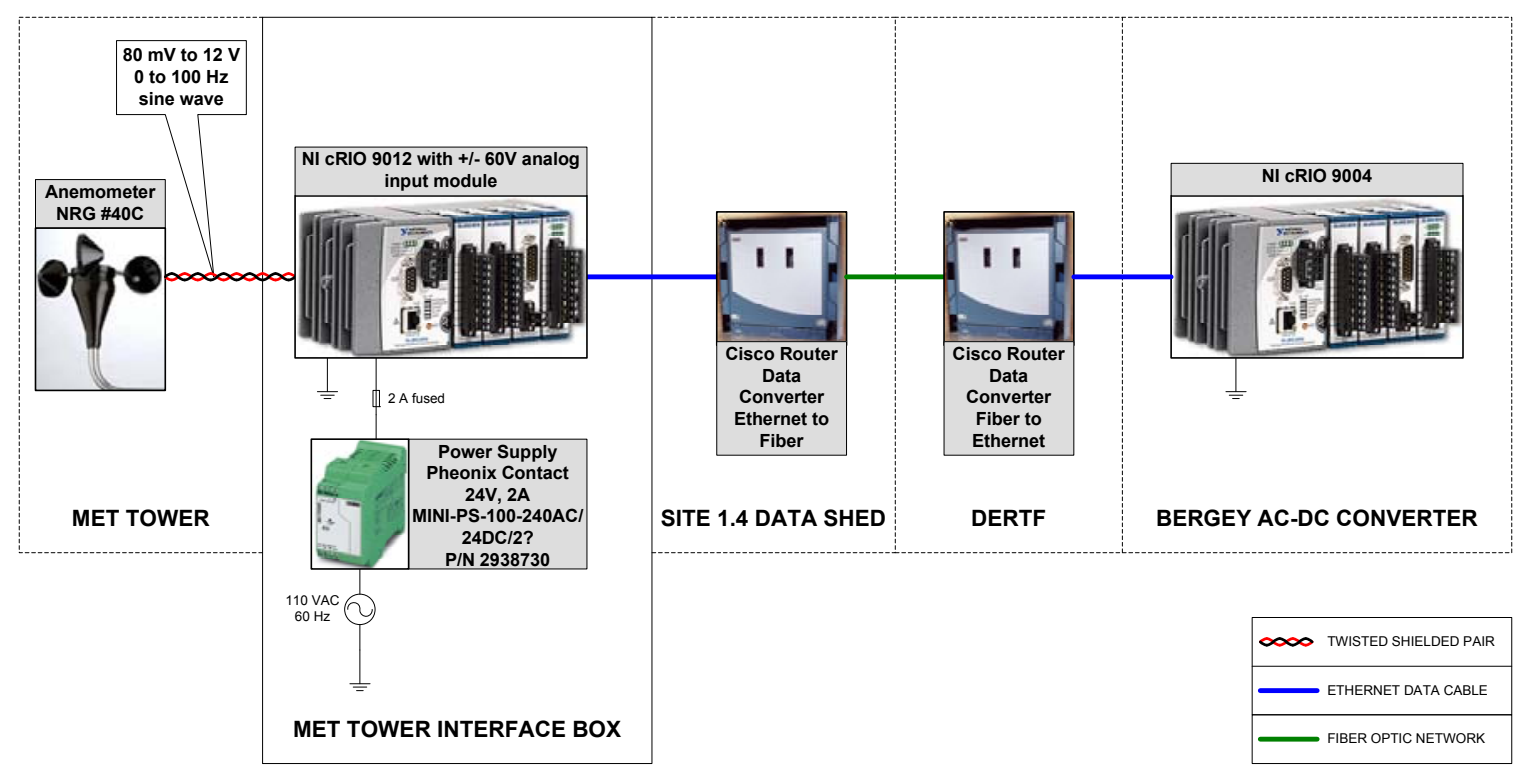

Figure 5-2: Anemometer wind-speed data-acquisition system for Bergey turbine

\subsubsection{Test Results}

The results of a 10-minute test were conducted on a windy day when the wind velocity varied from about 7 to 30 miles per hour (MPH). The wind speed as a function of time is given in Figure 5-3, and the resulting stack current and hydrogen produced is given in Figure 5-4. These results show the dynamic performance of the system during hydrogen production from wind power. 


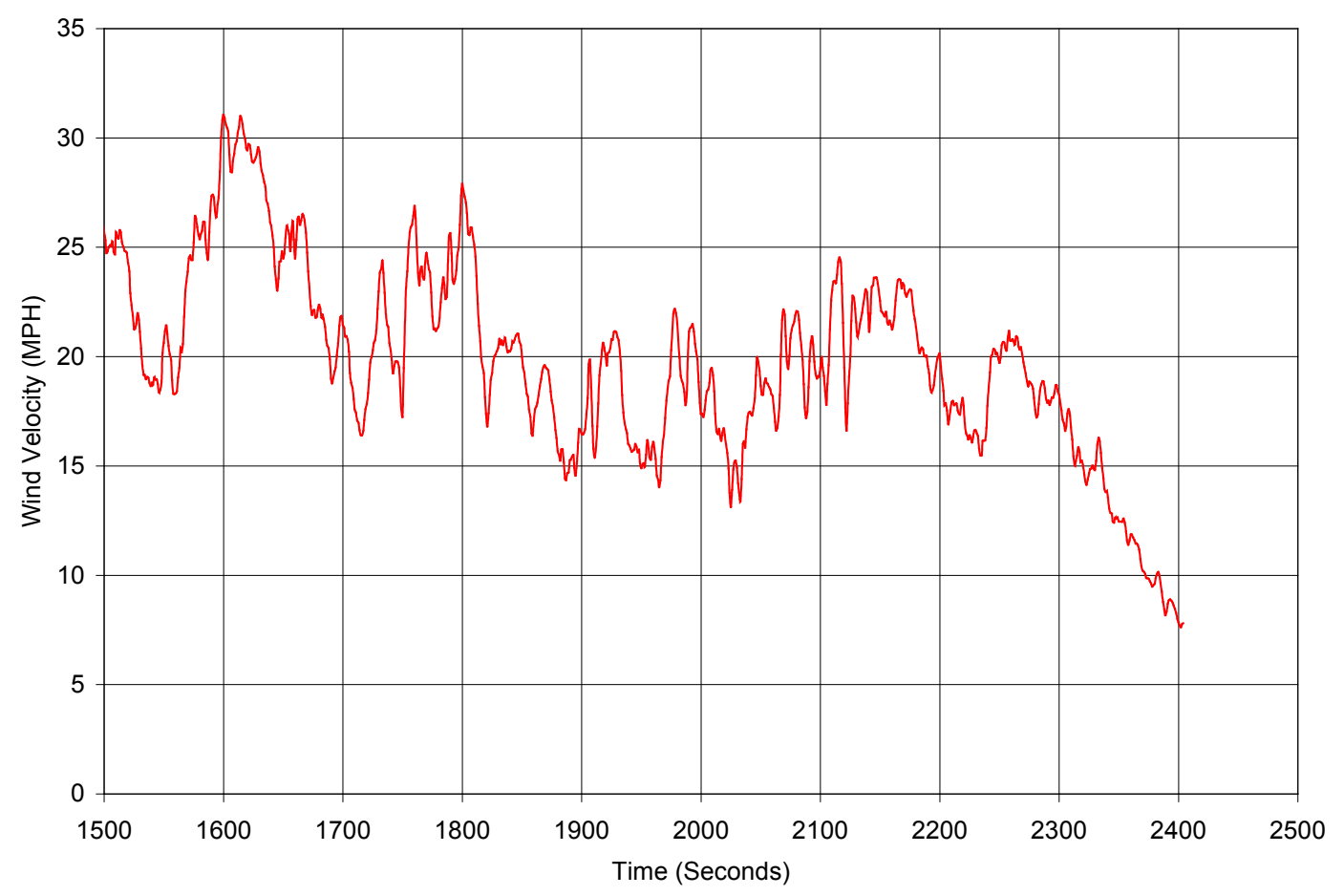

Figure 5-3: Wind velocity as a function of time

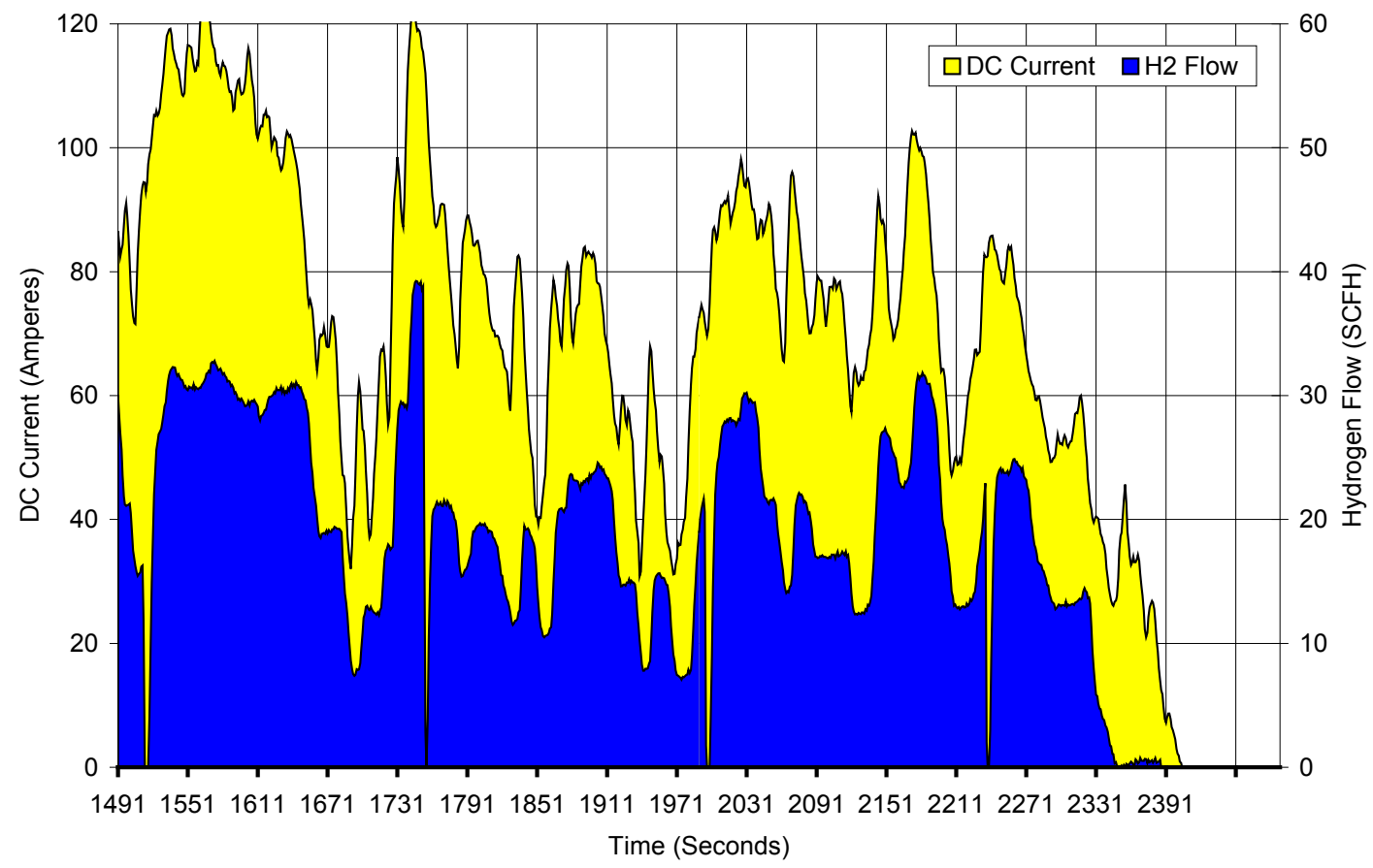

Figure 5-4: Hydrogen production and stack current as a function of time 
The stack resistance was calculated as a function of current using the real-time data from this test by dividing the measured stack voltage by the measured stack current. The results are given in Figure 5-5.

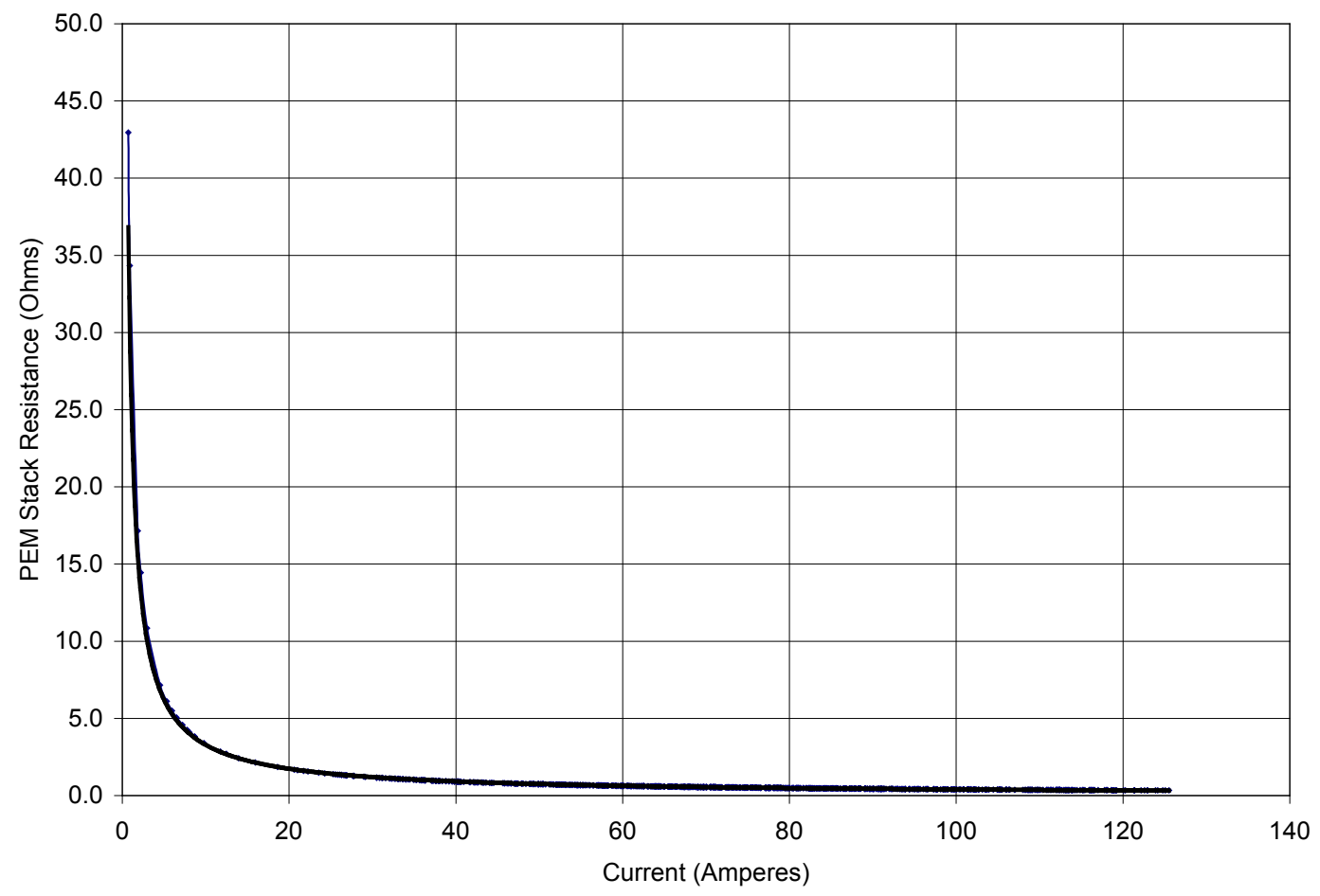

Figure 5-5: Stack resistance as function of current

Using a one second sample rate, the current and hydrogen flow rate data were collected for the wind profile shown in Figure 5-3. The resulting hydrogen flow rate as a function of current for this actual wind profile is shown in Figure 5-6. 


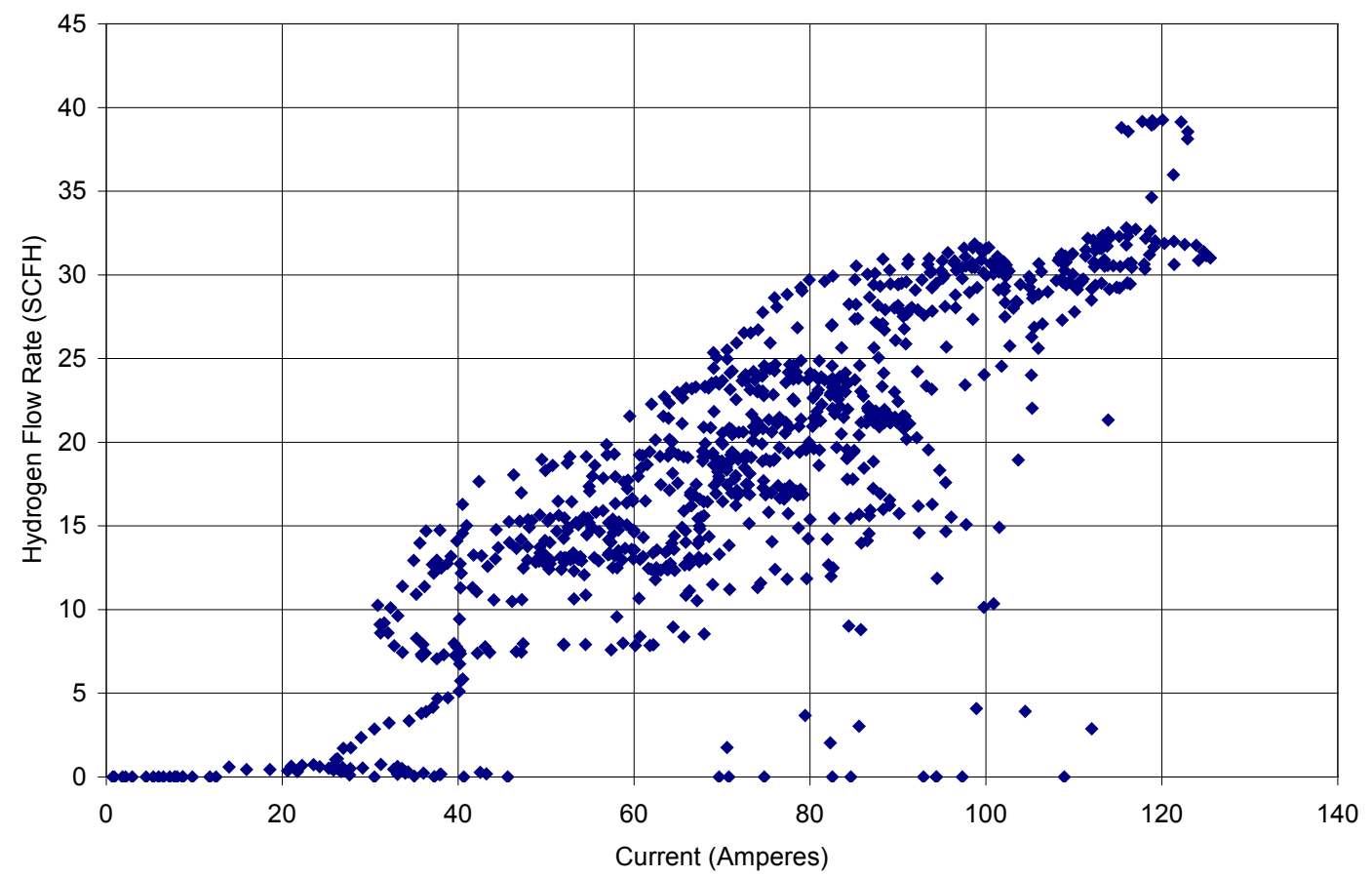

Figure 5-6: Hydrogen flow rate as a function of current for actual wind input

As the wind velocity increases, the wind turbine's AC frequency and AC voltage amplitude increase, and the amount of power available to produce hydrogen increases. From these test data, the power produced, hydrogen produced, and available wind-turbine power using the present hardware and software is shown as a function of wind speed in Figure 5-7. The objective is to use as much of the available wind power to produce hydrogen as possible. 


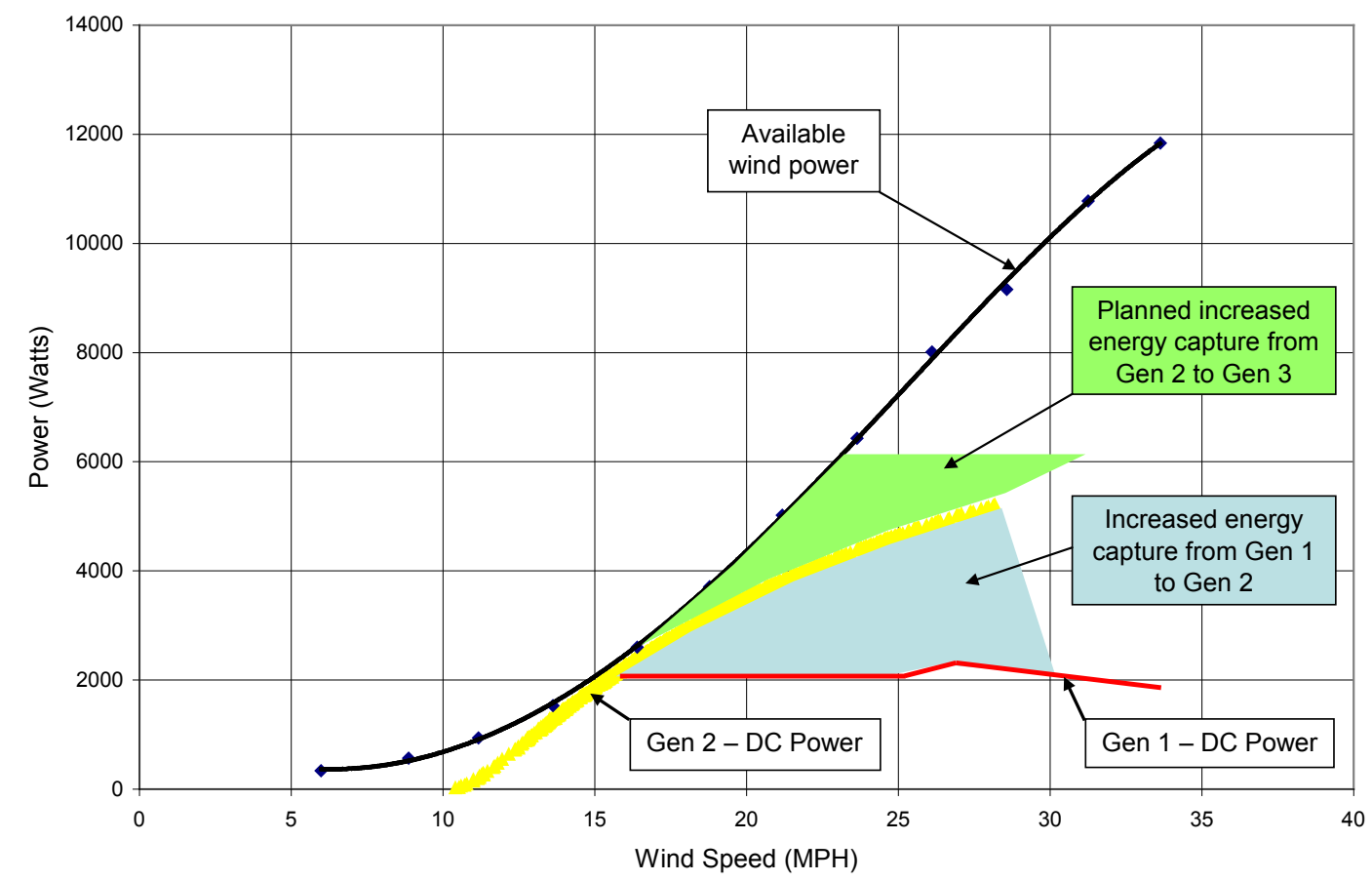

Figure 5-7: Realized and planned increase in energy capture from generation 1 through 3 AC-to-DC power converters

\subsection{Solar-Powered Electrolysis Testing and Analysis}

\subsubsection{Objective}

The main goal of this testing was to quantify the benefit of using the MPPT algorithm in the step-down DC/DC power converter compared with a direct connect PV-toelectrolyzer stack configuration. Relevant efficiencies, energy delivery to the electrolyzer stack, and system performance are presented.

\subsubsection{Overview and Results}

Several different system configurations using the PV array powering the PEM stack with and without the DC/DC PE were tested. Table 5-2 provides the various configurations used for testing toward the testing objectives.

The testing results allow a comparison of the amount of energy delivered to the electrolyzer stack with and without the MPPT PE. It is confirmed that, even though the power converter will have losses in the DC/DC conversion, the MPPT algorithm will maintain operation on the maximum power point of the PV array for more time to overcome the losses. This resulted in more energy delivered to the electrolyzer stack than the unoptimized direct PV to stack connection. 
Table 5-2: Test configuration matrix for solar PV electrolysis tests

\begin{tabular}{|c|c|c|c|c|c|c|c|}
\hline Test & Date & $\begin{array}{c}\text { Solar } \\
\text { Quality }\end{array}$ & Electrolyzer & $\begin{array}{c}\text { PV } \\
\text { Config. }\end{array}$ & $\begin{array}{l}\text { Array } \\
\left.\text { Tilt ( }{ }^{\circ}\right)\end{array}$ & $\begin{array}{c}\text { PV } \\
\text { Voltage } \\
\text { (V) }\end{array}$ & MPPT \\
\hline 1 & 2008-04-30 & $\underline{\mathrm{ok}}$ & E-120 & A-1 & 29.0 & 64.0 & No \\
\hline 2 & 2008-05-06 & poor & E-120 & A-1 & 29.0 & 64.0 & No \\
\hline 3 & $2008-05-12$ & $\underline{\mathrm{ok}}$ & E-120 & A-1 & 29.0 & 64.0 & No \\
\hline 4 & 2008-07-09 & good & E-120 & A-2 & 18.6 & 128.0 & Yes \\
\hline 5 & 2008-07-10 & good & E-120 & A-2 & 18.6 & 128.0 & Yes \\
\hline 6 & 2008-07-11 & great & E-120 & A-3 & 18.6 & 256.0 & Yes \\
\hline 7 & 2008-07-14 & poor & E-120 & A-4 & 18.6 & 64.0 & Yes \\
\hline 8 & $2008-07-15$ & poor & E-120 & A-4 & 18.6 & 64.0 & Yes \\
\hline 9 & $2008-07-16$ & $\underline{\mathrm{ok}}$ & E-120 & A-4 & 18.6 & 64.0 & Yes \\
\hline 10 & 2008-07-21 & $\underline{\mathrm{ok}}$ & E-120 & A-4 & 18.6 & 64.0 & Yes \\
\hline 11 & 2008-07-22 & $\underline{\mathrm{ok}}$ & E-120 & A-4 & 18.6 & 64.0 & Yes \\
\hline 12 & $2008-07-24$ & $\underline{\mathrm{ok}}$ & E-120, E-130 & B-1 & 18.6 & $\begin{array}{l}\text { 64.0 East } \\
\text { 64.0 West }\end{array}$ & $\begin{array}{l}\text { Yes } \\
\text { No }\end{array}$ \\
\hline 13 & $2008-07-25$ & $\underline{\mathrm{ok}}$ & E-120, E-130 & B-1 & 18.6 & $\begin{array}{l}\text { 64.0 East } \\
64.0 \text { West }\end{array}$ & $\begin{array}{l}\text { Yes } \\
\text { No }\end{array}$ \\
\hline 14 & $2008-07-28$ & $\underline{\mathrm{ok}}$ & E-120, E-130 & B-2 & 18.6 & $\begin{array}{l}\text { 64.0 East } \\
\text { 128.0 West }\end{array}$ & $\begin{array}{l}\text { Yes } \\
\text { No }\end{array}$ \\
\hline 15 & 2008-07-29 & poor & E-120, E-130 & B-3 & 18.6 & $\begin{array}{c}64.0 \text { East } \\
\text { 256.0 West }\end{array}$ & $\begin{array}{l}\text { Yes } \\
\text { No }\end{array}$ \\
\hline
\end{tabular}

There are several efficiencies that arise in analyzing this system. Incident sunlight is ultimately converted into hydrogen gas at a particular pressure, and this overall process has a particular efficiency. Solar PV panels, line losses, PE losses, ancillary power, electrolysis, and electrochemical compression all contribute to the losses and give the system its overall efficiency. This overall system (sunlight-to-hydrogen) efficiency is not analyzed in this section. The focus here is on the difference in energy captured between using PE to track the MPP of the PV array versus directly connecting the DC from the $\mathrm{PV}$ array to the electrolyzer stack. To this end, the energy delivered to the stack is calculated by integrating the stack power over the period (T) of operation:

$$
E_{\text {stack }}=\int^{T}\left(I_{\text {stack }} * V_{\text {stack }}\right)
$$


The percent difference in energy captured by the PE case compared with the direct connect case is calculated by dividing the difference in energy by the stack energy from the MPPT electronics case:

$$
\%_{\text {EnergyDifference }}=\frac{\left(E_{\text {Stack-MPPT }}-E_{\text {Stack-Direct }}\right)}{E_{\text {Stack-Direct }}}
$$

Energy delivered to the electrolyzer stack is calculated for the two test configurations. Table 5-3 provides the details of the various test configurations used for the comparison testing. Figure 5-8 and Figure 5-9 illustrate the overall system, noting that the energy for each situation is calculated by integrating the instantaneous power to the electrolyzer stack. In addition, the efficiency of the PE can be calculated by dividing converter output power by input power shown in Figure 5-9. Although the insertion of the PE converter introduces additional losses in the system, the results show that more energy is delivered to the stack because of the maximum power point tracking. The control algorithm enables the electronics to operate near the PV MPP for a longer time in varying solar irradiance. This results in extracting more energy from the PV source in the same sunlight as the direct connection scenario.

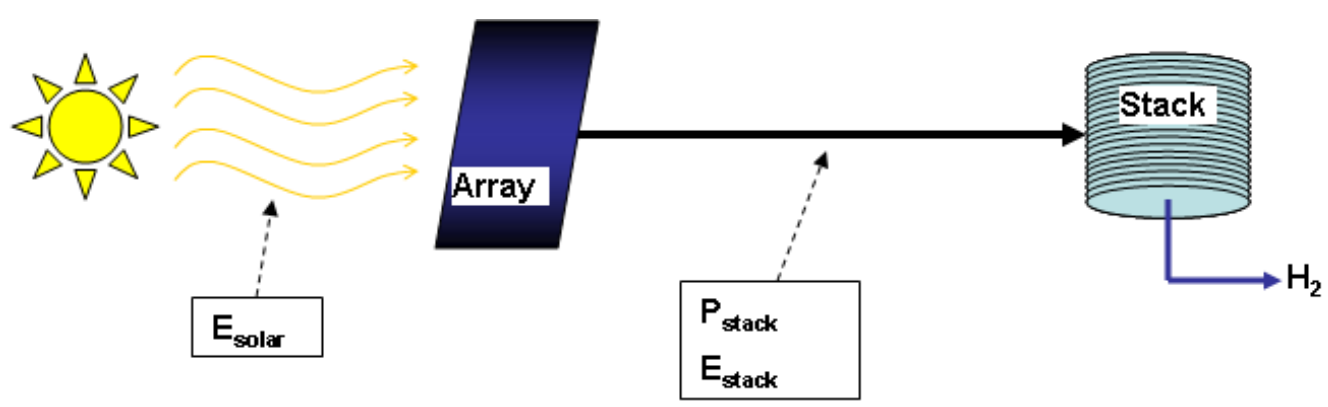

Figure 5-8: System efficiency illustration for direct connect configuration
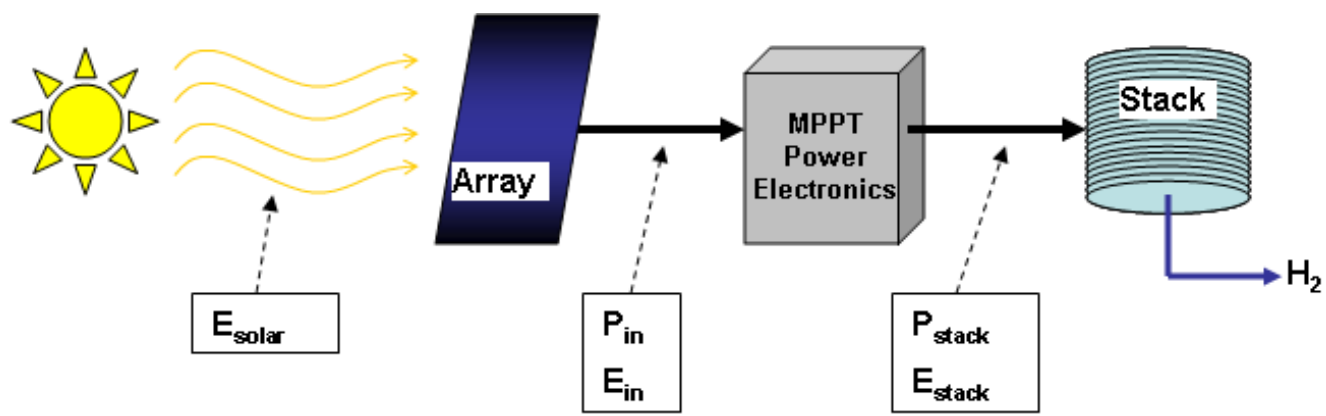

Figure 5-9: System-efficiency illustration for MPPT electronics configuration 
Table 5-3: Test results for direct connect versus MPPT PE testing.

\begin{tabular}{|c|c|c|c|c|c|c|c|}
\hline Test & Date & $\begin{array}{l}\text { Test } \\
\text { Type }\end{array}$ & $\begin{array}{l}\text { PV Array } \\
\text { MPP } \\
\text { Voltage } \\
\text { (V) }\end{array}$ & $\begin{array}{c}\text { PV Array } \\
\text { Max Power } \\
\text { (W) }\end{array}$ & $\begin{array}{l}\text { PE } \\
\text { Eff. } \\
(\%)\end{array}$ & $\begin{array}{c}\text { Stack } \\
\text { Energy } \\
(\mathrm{Wh})\end{array}$ & $\begin{array}{c}\text { Difference } \\
\text { in Stack } \\
\text { Energy } \\
(\%)\end{array}$ \\
\hline 1 & $2008-04-30$ & Direct & 65.6 & 7013 & - & 14413 & - \\
\hline 2 & 2008-05-06 & Direct & 65.6 & 7013 & - & 15382 & - \\
\hline 3 & $2008-05-12$ & Direct & 65.6 & 7013 & - & 25181 & - \\
\hline 4 & 2008-07-09 & MPPT & 131.2 & 7013 & $85.5 \%$ & 22958 & - \\
\hline 5 & 2008-07-10 & MPPT & 131.2 & 7013 & $86.4 \%$ & 28931 & - \\
\hline 6 & 2008-07-11 & MPРT & 262.4 & 7013 & $75.4 \%$ & 27240 & - \\
\hline 7 & $2008-07-14$ & MPPT & 64.0 & N/A & N/A & N/A & - \\
\hline 8 & $2008-07-15$ & MPPT & 65.6 & 7013 & $87.0 \%$ & 19752 & - \\
\hline 9 & $2008-07-16$ & MPPT & 65.6 & 7013 & $88.6 \%$ & 28248 & - \\
\hline 10 & $2008-07-21$ & MPPT & 65.6 & 7013 & $86.9 \%$ & 24165 & - \\
\hline 11 & $2008-07-22$ & MPPT & 65.6 & 7013 & $86.8 \%$ & 21236 & - \\
\hline 12 & $2008-07-24$ & Direct & 65.6 & 5258 & - & 9192 & \\
\hline 12 & 2008-07-24 & MPPT & 65.6 & 5258 & $87.7 \%$ & 10117 & $+10.1 \%$ \\
\hline 13 & $2008-07-25$ & Direct & 65.6 & 5258 & - & 14962 & \\
\hline 13 & $2008-07-25$ & MPPT & 65.6 & 5258 & $88.6 \%$ & 16788 & $+12.2 \%$ \\
\hline 14 & $2008-07-28$ & Direct & 65.6 & 5258 & - & 9792 & \\
\hline 14 & $2008-07-28$ & МРPT & 131.2 & 5258 & $81.5 \%$ & 11555 & $+18.0 \%$ \\
\hline 15 & 2008-07-29 & Direct & 65.6 & 5258 & - & 10987 & \\
\hline 15 & 2008-07-29 & MPРT & 262.4 & 5258 & $65.4 \%$ & 13231 & $+20.4 \%$ \\
\hline
\end{tabular}




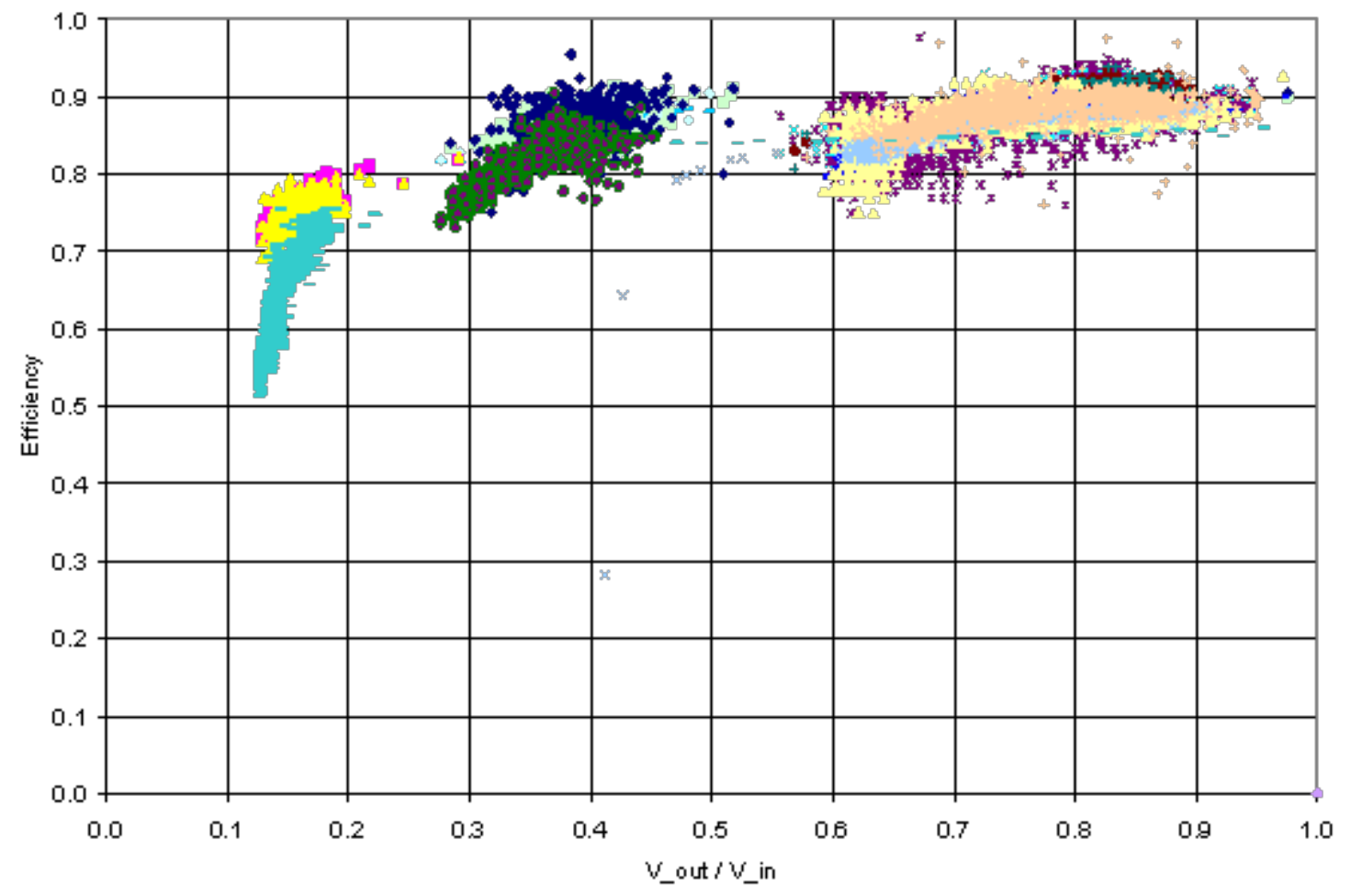

Figure 5-10: PE efficiency measurements and calculations for all tests

Figure 5-10 shows the efficiency of the PE for each test run with the solar PV array. Efficiency declines as the difference between input and output voltage increases. In other words, the efficiency improves as the voltage conversion ratio $\left(\mathrm{V}_{\mathrm{OUT}} / \mathrm{V}_{\mathrm{IN}}\right)$ approaches 1 .

The amount of energy delivered to the stack can be directly compared in tests $12,13,14$ and 15 because the tests were run on the same day for the same amount of time. The percent increase in energy delivered to the stack is calculated using the percentage difference calculation shown here:

$$
\%_{\text {difference }}=\frac{\left(\%_{\text {MPPT-delivered }}-\%_{\text {Direct-delivered }}\right)}{\%_{\text {Direct-delivered }}}
$$

For the remaining cases, the energy delivered to the stack must be normalized with the irradiance sensor to account for differing amounts of solar energy available for each test. This is accomplished by calculating the percentage of incident solar energy delivered to the stack for each test (shown in the rightmost column of Table 5-3).

It can be seen in Table 5-4 that the PE efficiency decreases as the PV array voltage increases. This is caused by the converter operating at a low duty cycle to step down the high voltage to the lower stack voltage. However, the greatest energy is delivered to the stack with high solar array voltage input. It is not clear from this set of testing why more energy is delivered in this case, but it is thought that the system is operating nearer to the 
MPP of the PV array for more of the day. This finding will be investigated and explained in future testing and reports. It is possible that there is an optimal voltage configuration of the PV array that allows the greatest energy delivery when using the MPPT power converter.

Table 5-4: Percentage energy capture increase for MPPT tests compared to direct tests

\begin{tabular}{cccccccc}
\hline Configuration & Direct- & Direct- & Direct- & Direct- & Direct- & Direct- & Direct- \\
& $\mathbf{1}$ & $\mathbf{2}$ & $\mathbf{3}$ & $\mathbf{1 2}$ & $\mathbf{1 3}$ & $\mathbf{1 4}$ & $\mathbf{1 5}$ \\
\hline MPPT-4 & $5.8 \%$ & $-6.2 \%$ & $11.0 \%$ & $15.0 \%$ & $10.1 \%$ & $9.3 \%$ & $13.5 \%$ \\
MPPT-5 & $4.2 \%$ & $-7.7 \%$ & $9.3 \%$ & $13.3 \%$ & $8.4 \%$ & $7.7 \%$ & $11.8 \%$ \\
MPPT-6 & $5.5 \%$ & $-6.5 \%$ & $10.7 \%$ & $14.7 \%$ & $9.8 \%$ & $9.1 \%$ & $13.2 \%$ \\
MPPT-8 & $5.8 \%$ & $-6.2 \%$ & $11.1 \%$ & $15.1 \%$ & $10.2 \%$ & $9.4 \%$ & $13.5 \%$ \\
MPPT-9 & $8.6 \%$ & $-3.7 \%$ & $14.0 \%$ & $18.1 \%$ & $13.1 \%$ & $12.3 \%$ & $16.5 \%$ \\
MPPT-10 & $6.0 \%$ & $-6.1 \%$ & $11.2 \%$ & $15.2 \%$ & $10.3 \%$ & $9.5 \%$ & $13.7 \%$ \\
MPPT-11 & $5.9 \%$ & $-6.1 \%$ & $11.2 \%$ & $15.2 \%$ & $10.3 \%$ & $9.5 \%$ & $13.6 \%$ \\
MPPT-12 & $1.2 \%$ & $-10.3 \%$ & $6.2 \%$ & $\mathbf{1 0 . 1 \%}$ & $5.4 \%$ & $4.6 \%$ & $8.6 \%$ \\
MPPT-13 & $7.8 \%$ & $-4.5 \%$ & $13.1 \%$ & $17.2 \%$ & $\mathbf{1 2 . 2 \%}$ & $11.4 \%$ & $15.6 \%$ \\
MPPT-14 & $14.2 \%$ & $1.2 \%$ & $19.8 \%$ & $24.1 \%$ & $18.9 \%$ & $\mathbf{1 8 . 0 \%}$ & $22.5 \%$ \\
MPPT-15 & $12.3 \%$ & $-0.5 \%$ & $17.8 \%$ & $22.1 \%$ & $16.9 \%$ & $16.0 \%$ & $\mathbf{2 0 . 4 \%}$ \\
\hline
\end{tabular}

The matrix of percentages comparing each direct connect test result to each of the MPPTconverter test results is given in Table 5.4. Direct connect test two (Direct-2) resulted in higher-than-expected energy delivery to the stack (higher than any of the other similar direct connection tests). This was an unexpected result and may be due to fast changes in the solar irradiance that were not reflected in the measurement of solar irradiance. The solar irradiance is sampled once every minute while electrical data is sampled every 10 seconds, which may lead to this unexpected finding.

\subsubsection{Full Array Power Direct Connect (Tests 1-3)}

The first configuration tested did not use the DC/DC power converter utilizing MPPT. The PV array output was wired directly to the $6 \mathrm{~kW}$ PEM electrolyzer stack inside electrolyzer E-120. The stack operates at roughly $43 \mathrm{~V}$ at full stack current whereas the $\mathrm{PV}$ array MPP voltage (at $1000 \mathrm{~W} / \mathrm{m}^{2}$ irradiance and $25^{\circ} \mathrm{C}$ ) is $65.6 \mathrm{~V}$. This means that the system will not operate at the MPP of the solar array but rather receive the full current the array can provide. 


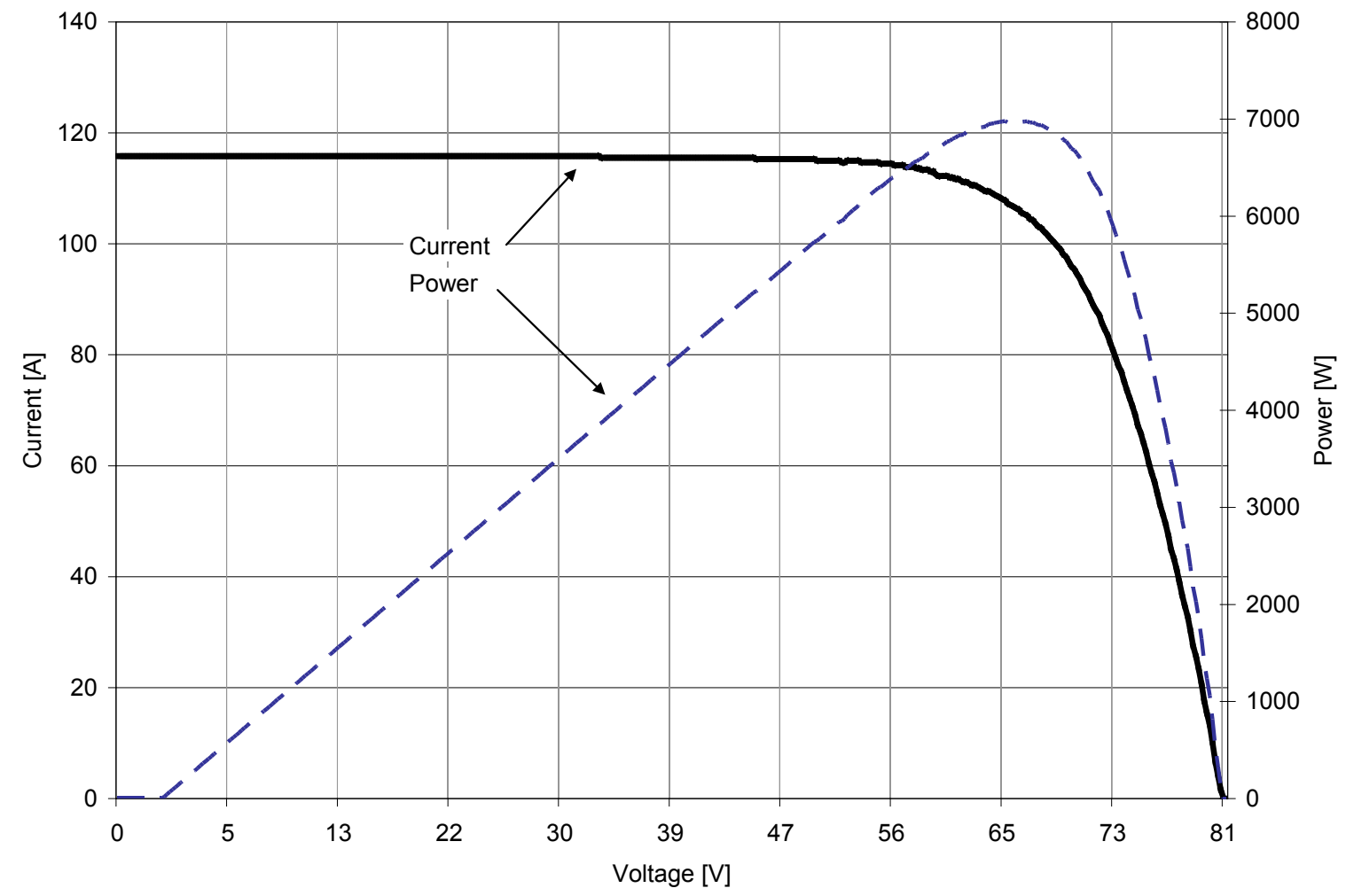

Figure 5-11: Solar array I-V and power characteristic for configuration A-1, 65.6 $V_{\text {MAX }}$

For the A-1 PV configuration (Table 5.2), the PV array is set up such that sets of four series-connected panels create sub-arrays capable of producing $\mathrm{V}_{\mathrm{MAX}}=65.6 \mathrm{~V}\left(\mathrm{~V}_{\mathrm{OC}}=\right.$ $82.4 \mathrm{~V}$ ) with the same current ratings of a single panel. The entire east array, consisting of 12 parallel sets of four series-connected sub-arrays plus four additional sub-arrays from the west array, establishes a total array potential of $\mathrm{V}_{\mathrm{MAX}}=65.6 \mathrm{~V}, \mathrm{I}_{\mathrm{MAX}}=106.9 \mathrm{~A}$ $\left(\mathrm{V}_{\mathrm{OC}}=81.6 \mathrm{~V}, \mathrm{I}_{\mathrm{SC}}=118.1 \mathrm{~A}\right)$, resulting in $\mathrm{P}_{\mathrm{MAX}}=7011 \mathrm{~W}$ at $\mathrm{STC}$.

Upon startup, the open circuit voltage of up to $81.6 \mathrm{~V}$ from the solar array is applied to the electrolyzer DC circuit breakers. Once the electrolyzer is ready to produce hydrogen, it closes the circuit breakers, thus connecting the PV array directly to the stack.

In the A-1 configuration (see Appendix A), the combined east and west PV array, operating at its maximum power point, is capable of supplying $7011 \mathrm{~W}$ under STC. During the May 12 test (refer to test 3 in Table 5.2), the stack maximum voltage reached about $42 \mathrm{~V}$ and $130 \mathrm{~A}$, resulting in about $5500 \mathrm{~W}$, well below the maximum power of which the array is capable (Figure 5-11). However, the maximum current achieved during the test of 130 A exceeded the PV nameplate $\mathrm{I}_{\mathrm{MAX}}$ by 23 A due to the increase in irradiance above the standard conditions at which the panels are rated (up to about 1200 $\mathrm{W} / \mathrm{m}^{2}$ ). The testing results below were taken from a test run on May 12, 2008, with the PV array angle set to about $29^{\circ}$, a near-optimal tilt angle based on time of the year for this latitude. 


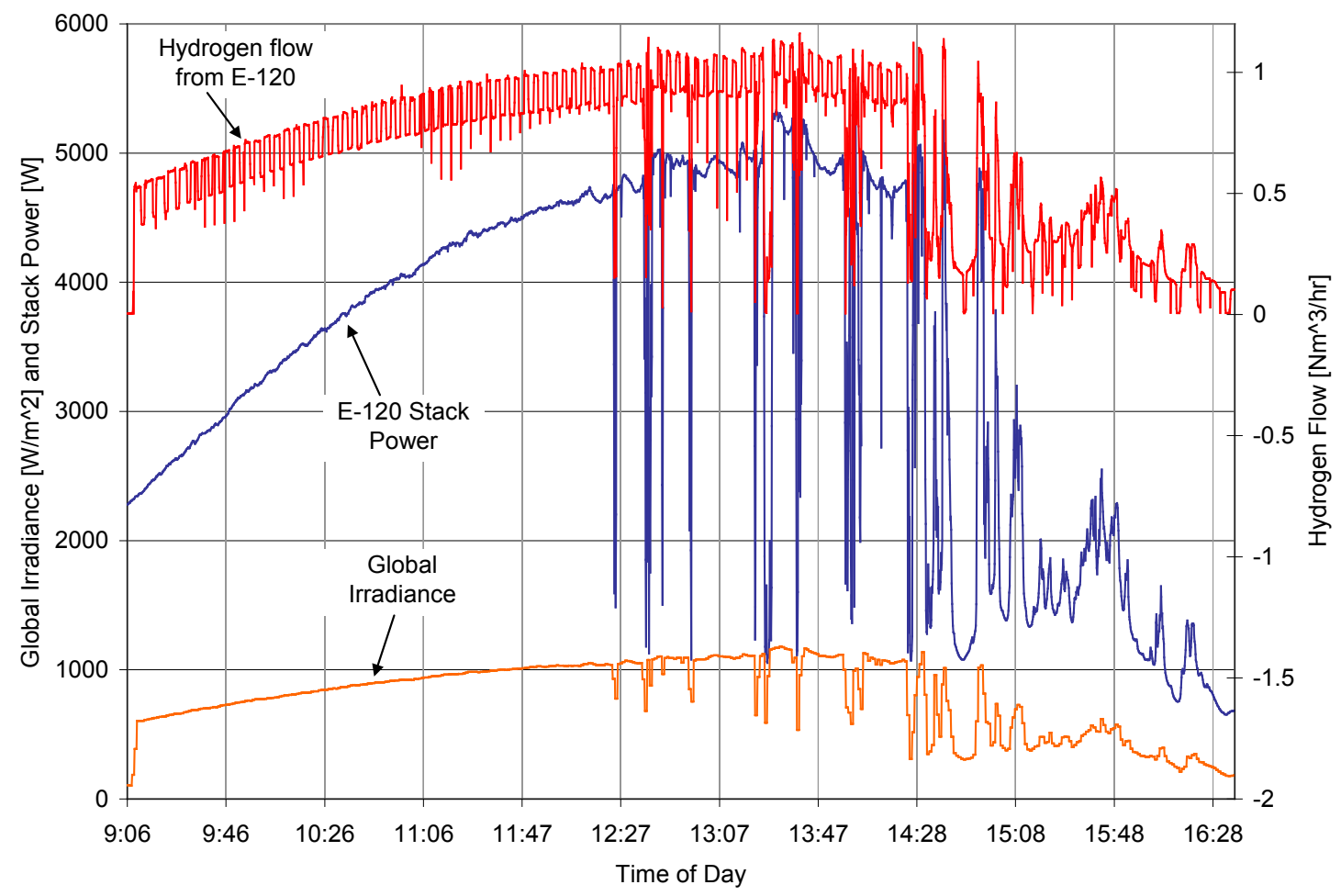

Figure 5-12: Direct connection test results from test 3 (May 12)

Three direct connection tests were run and logged on three different days. Figure 5-12 is an example of these data, representing the typical results of these tests. Notice the varying data in the second half of the day due to cloud cover. For each test, the solar irradiation data are downloaded from NREL's Measurement and Instrumentation Data Center (MIDC) Web site, which samples irradiance data every two seconds and then averages and records on one minute intervals. These irradiance data allow "normalization" of the power data taken when comparing different days. 


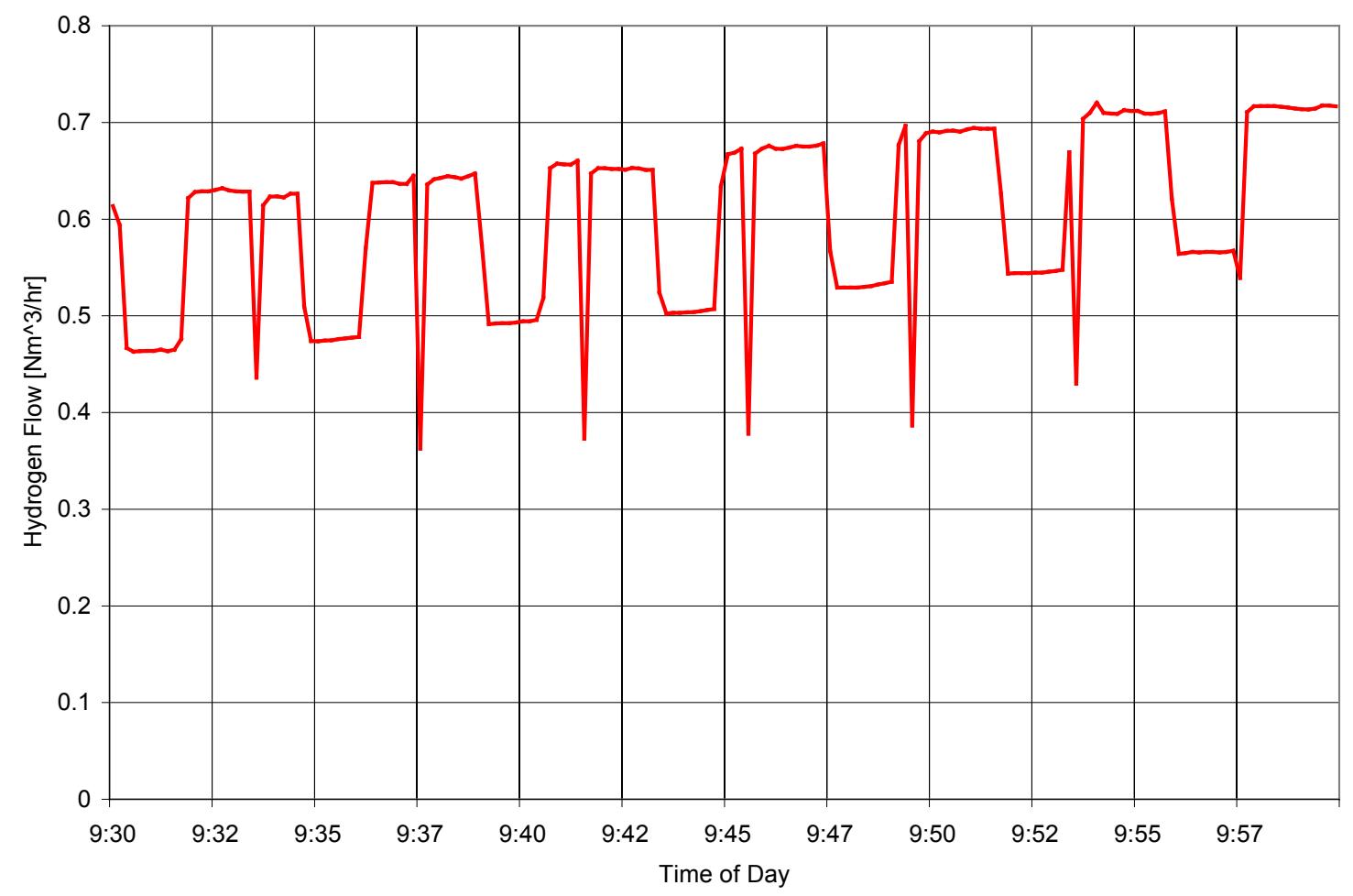

Figure 5-13: Detail of hydrogen flow output cycling from PEM electrolyzer

Also of interest is the periodic cycling of the hydrogen-flow output of the PEM electrolyzer of Figure 5-13. This cyclical characteristic is caused by the electrolyzer high pressure phase separator pumping down the water in the vessel. The shorter spikes are a result of the pressure swing caused by switching desiccant drier tubes.

\subsubsection{Full Array-Power MPPT Electronics (Tests 4-11)}

For this series of tests, the DC/DC MPPT PE converter is inserted between the PV array and the electrolyzer stack.

The tilt of the PV array was adjusted to an $18^{\circ}$ and the PV array maximum power was configured to be the same as in the direct connection tests, $7011 \mathrm{~W}$. Figure 5-14 describes the I-V and power characteristic for the PV array at its $131.2 \mathrm{~V}_{\mathrm{MAX}}$ configuration and Figure 5-15 describes the 262.4 $\mathrm{V}_{\mathrm{MAX}}$ setup. PV configuration A-4 (65.6 V) has the same $\mathrm{I}-\mathrm{V}$ curve as the direct connection tests with the only difference being the tilt of the array. 


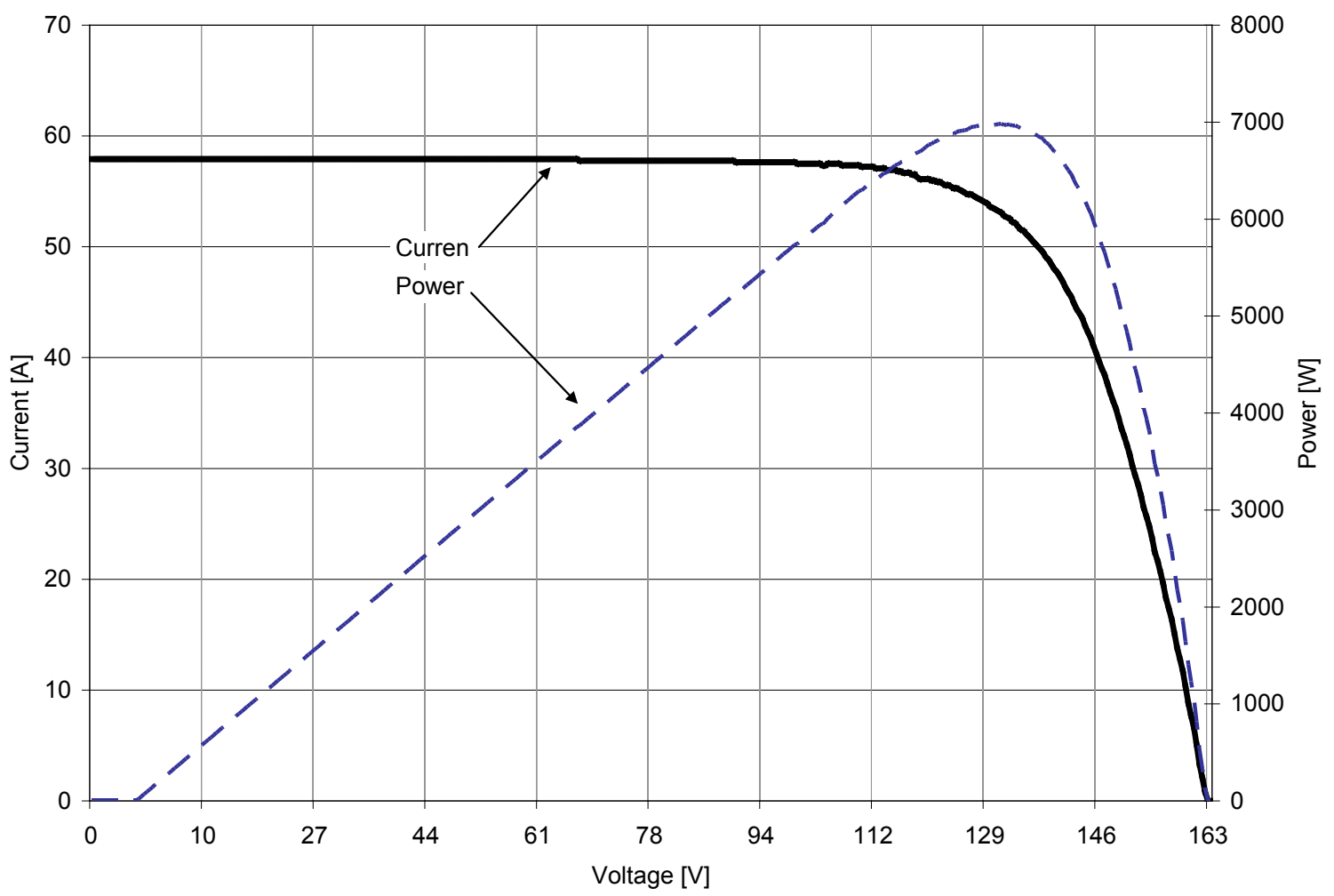

Figure 5-14: PV array I-V characteristic for configuration A-2, 131.2 $\mathrm{V}_{\mathrm{MAX}}$

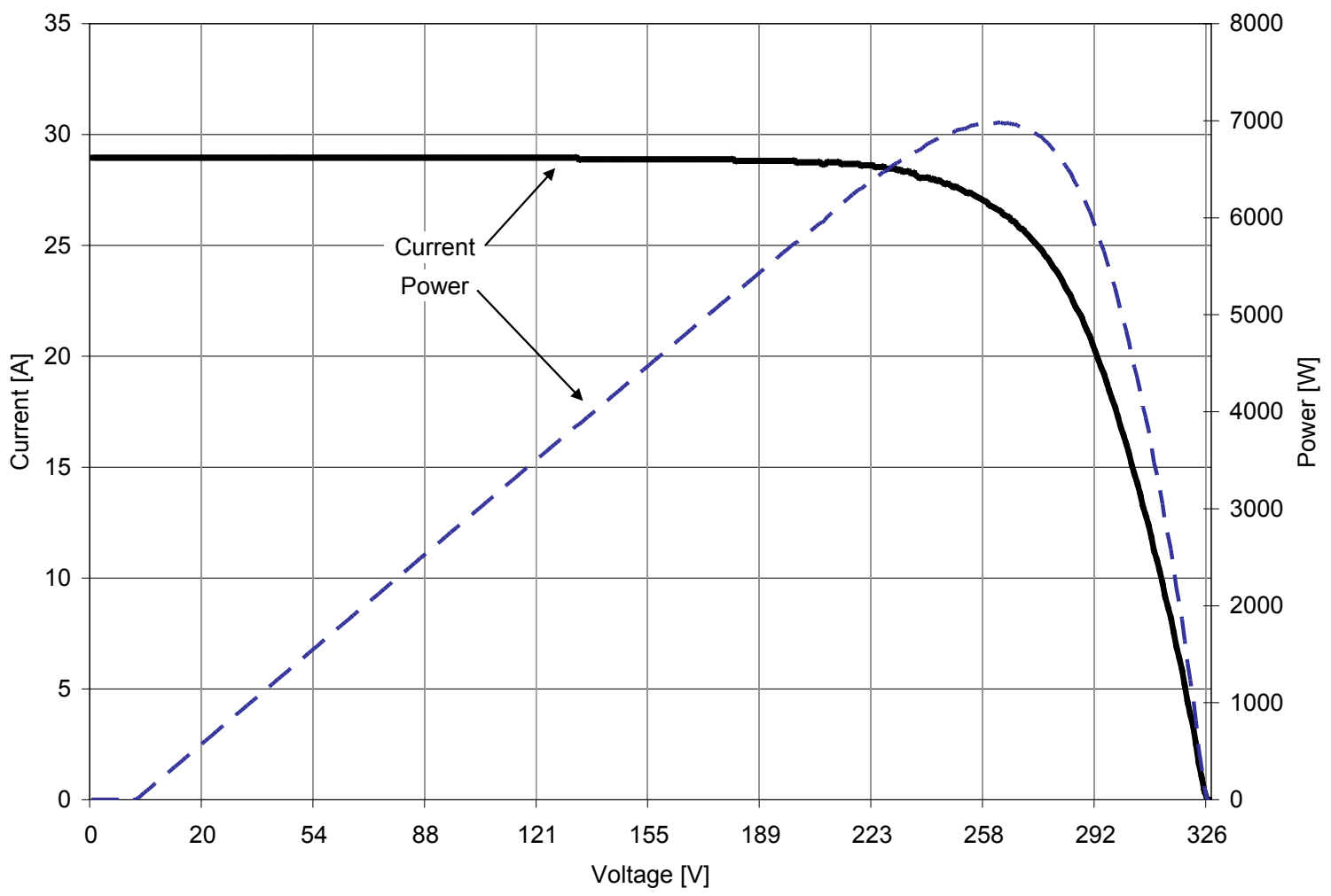

Figure 5-15: PV array I-V characteristic for configuration A-3, 262.4 $\mathrm{V}_{\mathrm{MAX}}$ 


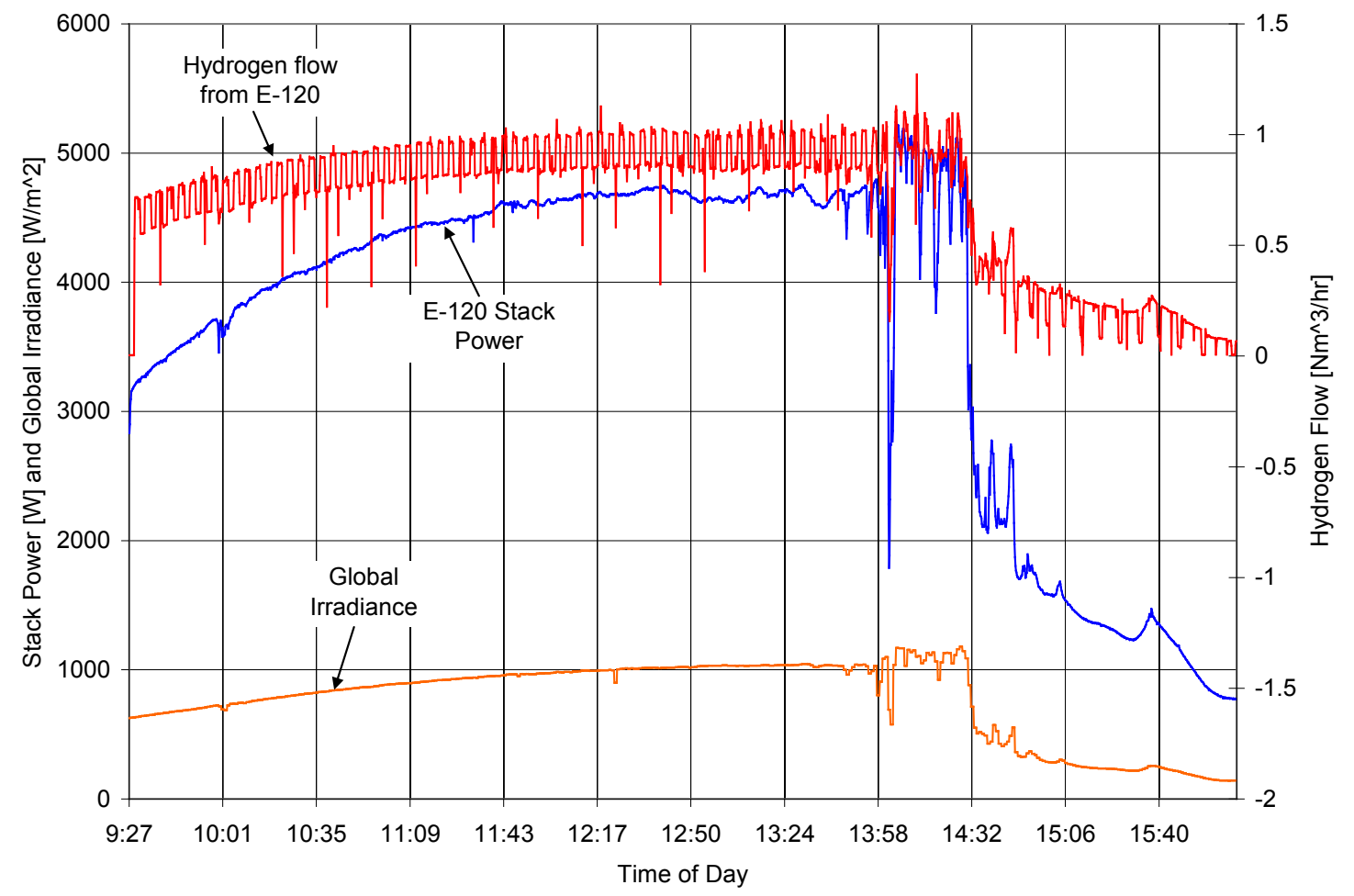

Figure 5-16: MPPT converter test 10 (July 21) with $65.6 \mathrm{~V}_{\text {MAX }}$ PV array voltage

A test of the same PV configuration as the direct connect tests with $\mathrm{V}_{\mathrm{MAX}}=65.6 \mathrm{~V}$ was run, as well as the MPPT converter with medium PV voltage (131.2 $\left.\mathrm{V}_{\mathrm{MAX}}\right)$ and high voltage (262.4 $\left.\mathrm{V}_{\mathrm{MAX}}\right)$. Figure 5-16 includes the July 21 test 10 data from a low voltage (65.6 $\mathrm{V}_{\text {MAX }}$ ) PV array test with the MPPT converter (same array configuration as the direct connect tests). Figure 5-17 is a plot of the test 4 data for the medium voltage PV to MPPT converter test run on July 9, and Figure 5-18 is the high voltage PV array test 6 data from July 11.

In comparing Figure 5-16 with Figure 5-12 (direct connection test), one may note the slightly "flatter" stack power and hydrogen flow curves. This is indicative of more energy extraction in off-peak sun hours. This further reinforces the finding that the MPPT converter transfers more energy to the stack than the direct connection. The Figure 5-17 (medium voltage PV) test has an even flatter production curve than the direct connection test and the tests with low and high voltage PV with a power converter. This result indicates the possible existence of a "sweet spot" in the input voltage level for energy transfer with the MPPT converter. Refer to Table 5-3 for the comparison of the direct connect with the MPPT power converter trials. 


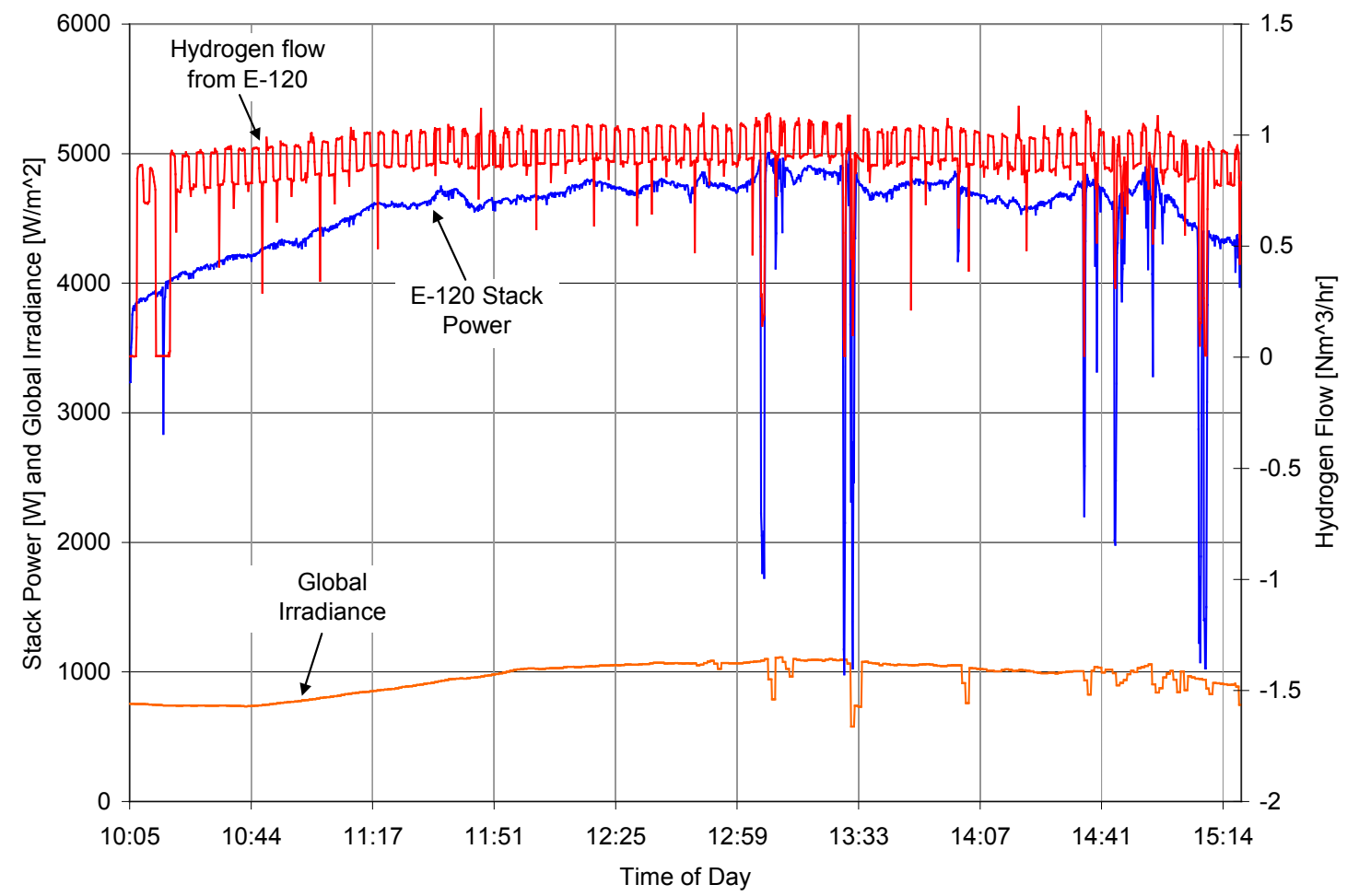

Figure 5-17: Results of MPPT converter test 4 (July 9) with 131.2 $\mathrm{V}_{\mathrm{MAX}}$ PV array voltage

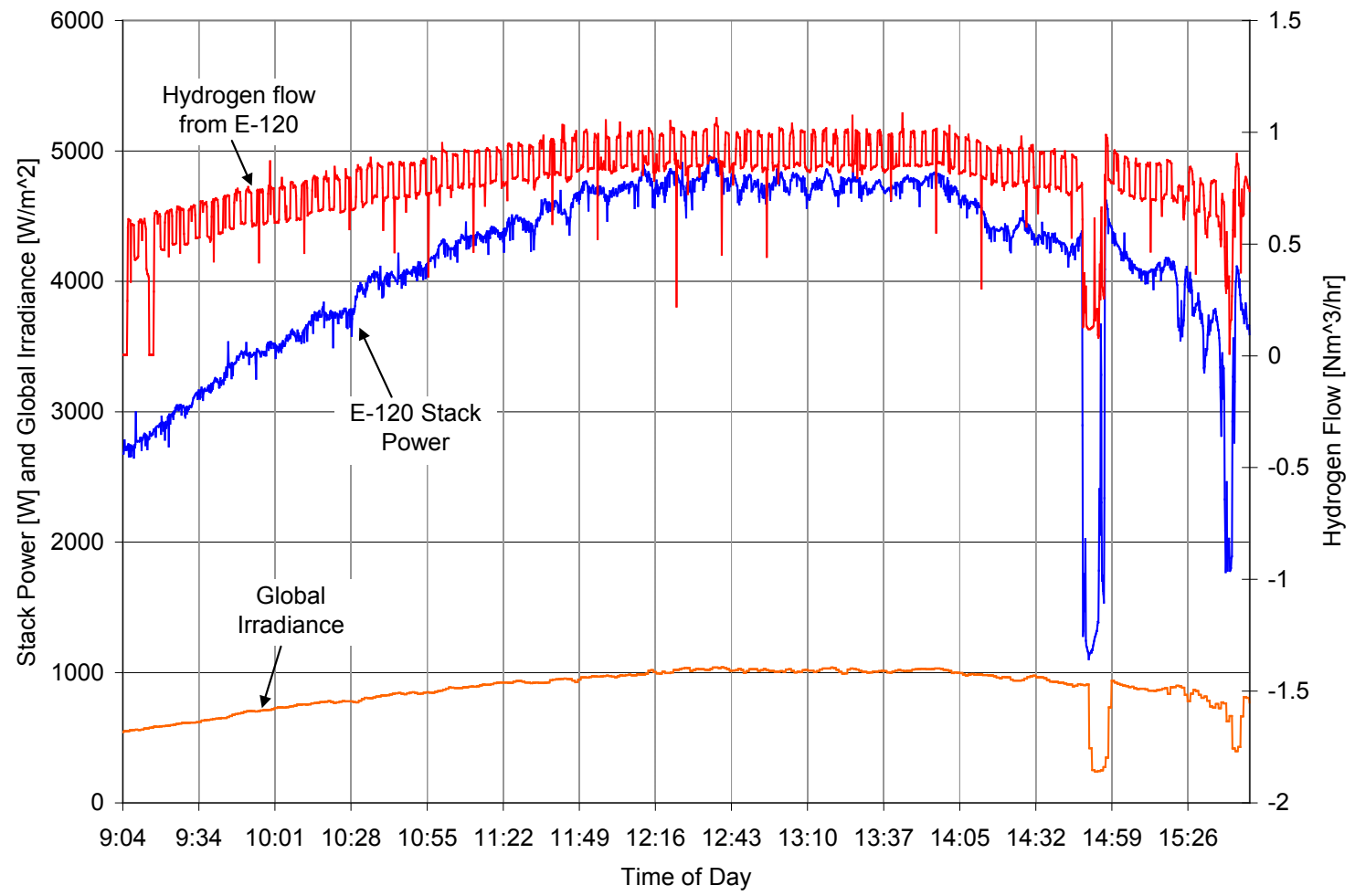

Figure 5-18: Results of MPPT converter test 6 (July 11) with $262.4 \mathrm{~V}_{\mathrm{MAX}} \mathrm{PV}$ array voltage 


\subsubsection{Split Array Direct and MPPT Comparison (Tests 12-15)}

Perhaps the most obvious measure of the MPPT-enhanced performance of the system comes from tests $12-15$. The PV array was configured in two equal partitions, each providing a rated $5258 \mathrm{~W}$ at STC. One partition was connected directly to the stack of one of the PEM electrolyzer stacks, while the other was connected to the other PEM electrolyzer stack through the MPPT power converter. Data were logged concurrently for both systems so direct comparisons could be made. The following four plots show the stack power of each electrolyzer during the trials. It can be easily seen that the power delivered to the stack through the MPPT power converter exceeds that delivered in the direct connection under the same PV irradiance conditions.

Figure 5-19 is a plot of stack power from both PEM electrolyzers energized by a 65.6 $\mathrm{V}_{\text {MAX }}$ array with E-120 connected through the MPPT power converter. Figure 5-20 is the same test as in Figure 5-19 with the electrolyzer stacks swapped (for verification of equal electrolyzer performance). Figure 5-21 connects E-130 directly to the PV array at 65.6 $\mathrm{V}_{\mathrm{MAX}}$, and E-120 connects to the PV array at 131.2 $\mathrm{V}_{\text {MAX }}$ through the MPPT power converter. Finally, Figure 5-22 increases the PV array voltage of the MPPT system to 262.4 V $\mathrm{MAX}$.

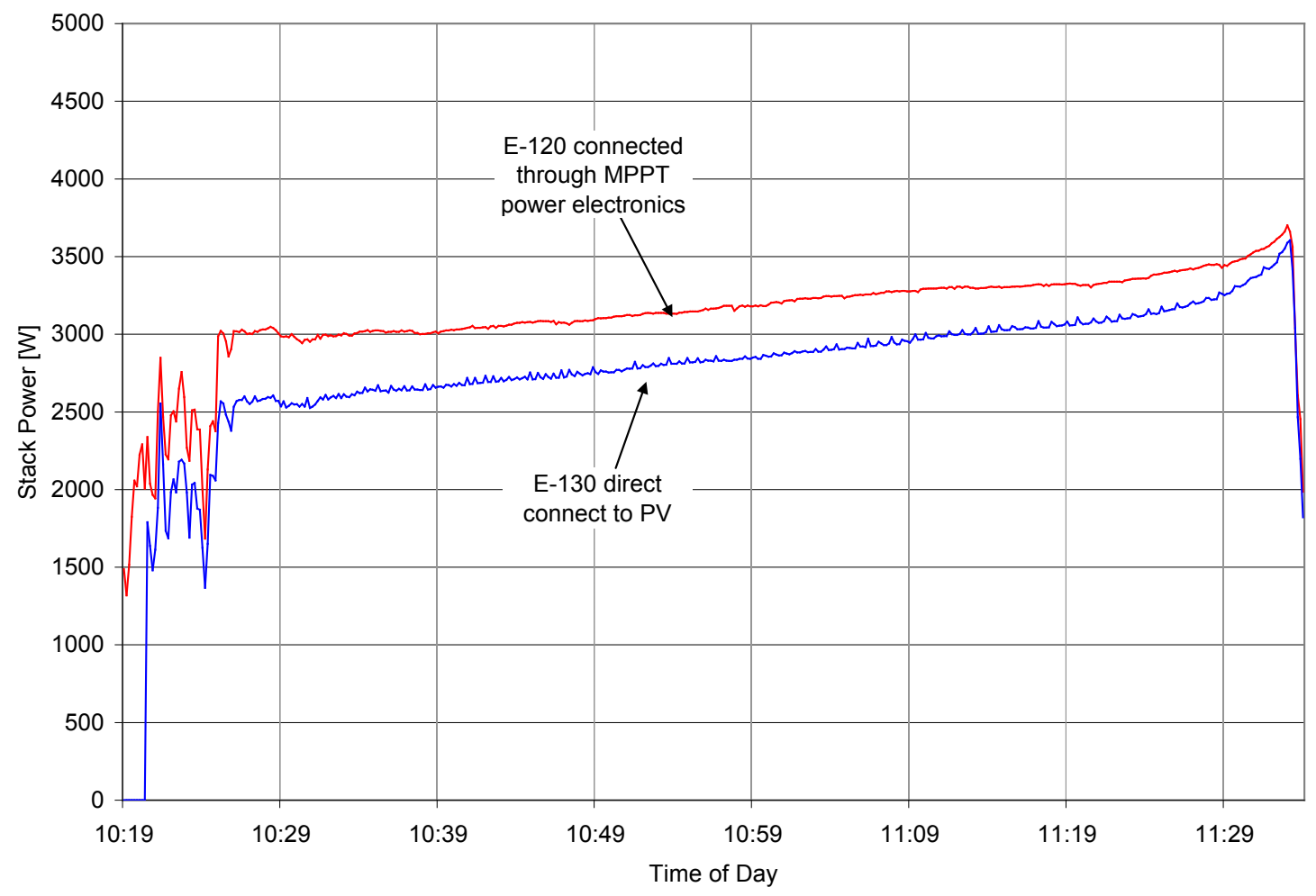

Figure 5-19: Test 12, both PV arrays at $65.6 \mathrm{~V}_{\mathrm{MAX}}$, MPPT powering $\mathrm{E}-120$ 


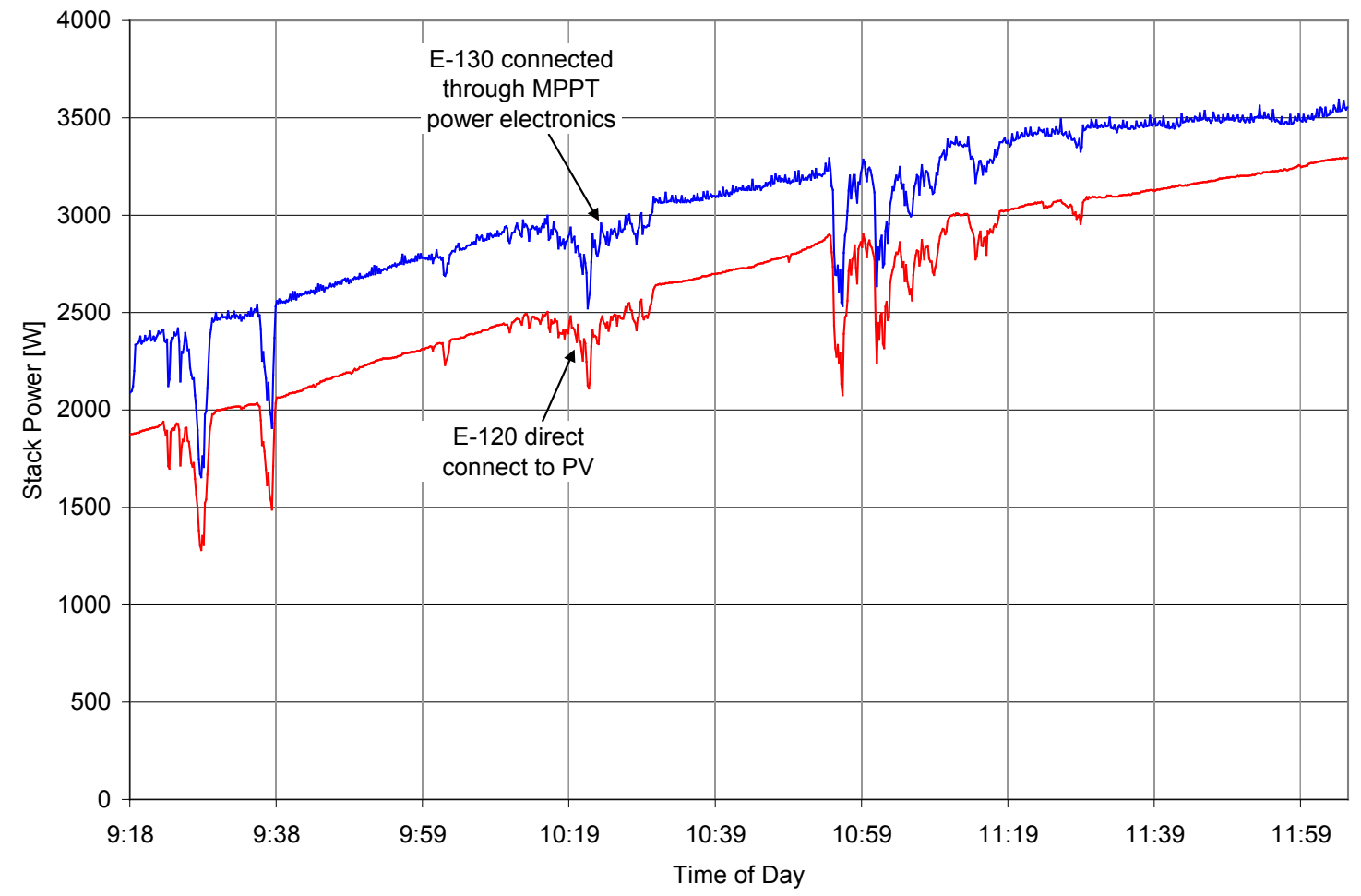

Figure 5-20: Test 13, both PV arrays at 65.6 VMAX, MPPT powering E-130

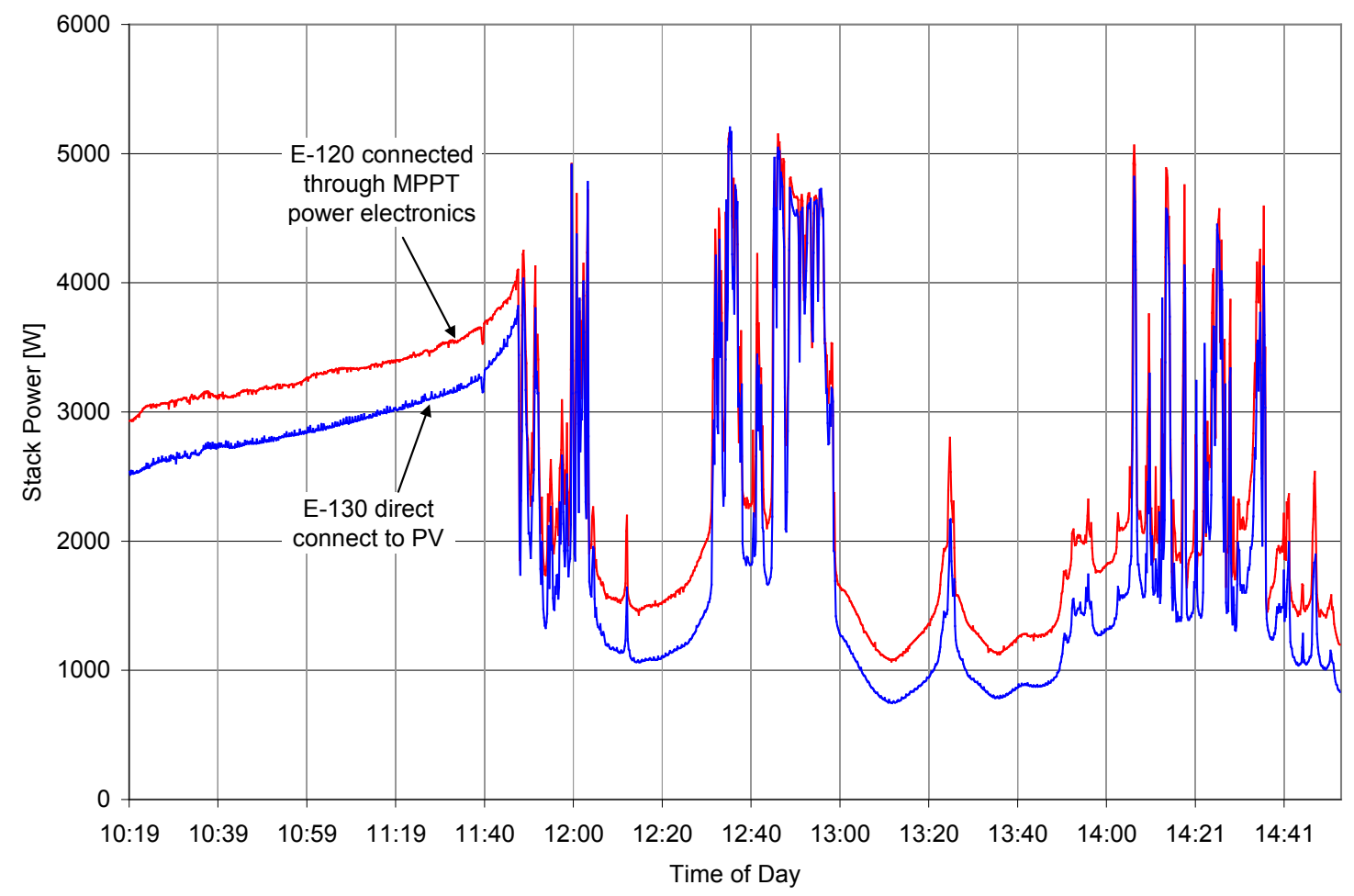

Figure 5-21: Test 14, PV west at $65.6 \mathrm{~V}_{\text {MAX }}$ direct, $P V$ east at 131.2 $\mathrm{V}_{\mathrm{MAX}}$, MPPT powering $\mathrm{E}$ 120 


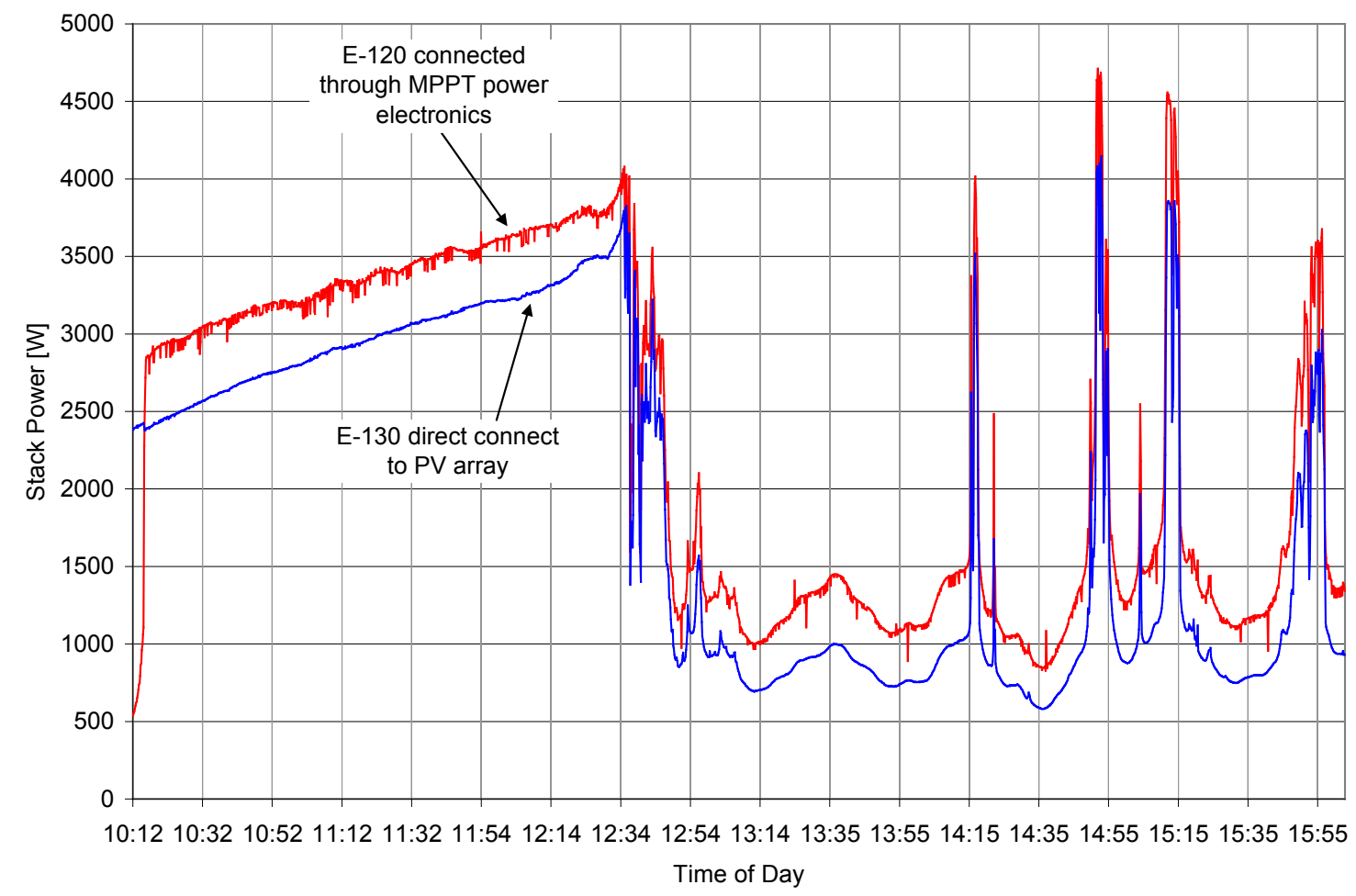

Figure 5-22: Test 15, PV west at $65.6 \mathrm{~V}_{\text {MAX }}$ direct, $P V$ east at $262.4 \mathrm{~V}_{\mathrm{MAX}}, \mathrm{MPPT}$ powering $\mathrm{E}$ 120

The "dither" in the power data for the stack connected through the MPPT power converter, most apparent in Figure 5-22, is a result of the MPPT algorithm constantly searching up and down the operating I-V cure for the maximum power point. The significant variability in the power data in many of the above plots is from variation in the irradiance for that day's test.

\subsection{Large Wind powered Electrolysis}

\subsubsection{Investigation of Close-Coupling Options}

Researchers working on the Wind $2 \mathrm{H} 2$ project have investigated ways to connect the 100 $\mathrm{kW}$ NorthWind 100 wind turbine directly to the stack of the Teledyne electrolyzer. There are several options for extracting power from this turbine to the electrolysis stack, all of which involve different challenges.

The NW100 turbine uses a synchronous, field-controlled generator directly driven by the turbine rotor. The generator windings are Y-connected with the center point of the wye connected to ground. This grounded center-point configuration alleviates electrostatic buildup on the system and holds the $\mathrm{AC}$ output of the generator symmetrical to ground to be compatible with the ground-symmetrical grid voltage. The "wild" AC voltage produced by the variable-speed generator is passed through a passive rectifier that converts the $\mathrm{AC}$ to $\mathrm{DC}$ at approximately $\pm 400 \mathrm{~V}_{\mathrm{DC}}$. Because this conversion occurs with a passive rectifier, the DC link voltage varies slightly with rotor speed and load on the 
system. The power controller monitors this DC link voltage and uses this information to control the generator field, keeping the turbine rotor at the optimal tip-speed ratio for power extraction. This control scheme also varies the load drawn from the DC link by the grid-tie inverter, which exports energy to the utility system. Figure 5-23 is a basic schematic of the wind turbine power system.

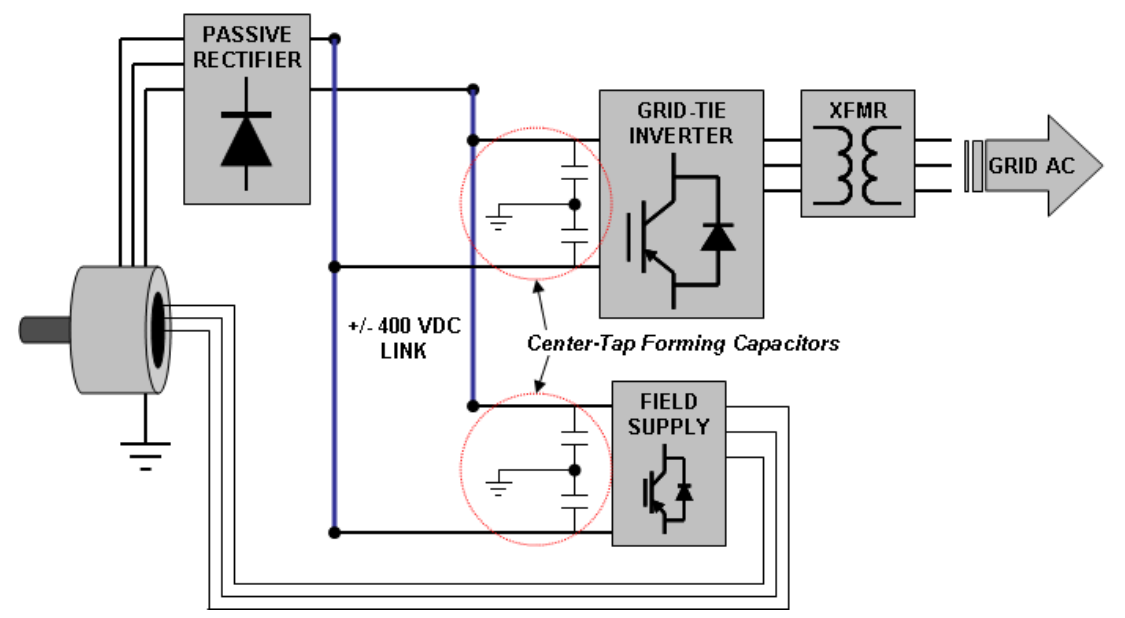

Figure 5-23: NorthWind electrical power system diagram

The first concept studied for connection to the electrolysis system involved tapping the DC link voltage (bipolar $\pm 400 \mathrm{~V}_{\mathrm{DC}}$ ), designing a step-down DC/DC converter (much like the lower power DC/DC unit used for the PV-powered electrolysis testing), and connecting the $\mathrm{DC} / \mathrm{DC}$ output to the electrolyzer stack. The goal for this configuration was to bypass the grid-tie inverter to enable a more-direct connection to the electrolyzer stack. Simulation and further analysis of this system presented a problem: the DC/DC converter operates off a unipolar DC voltage (negative DC link rail tied to ground). The existing NorthWind system is not compatible with the simple DC/DC converter because the $-400 \mathrm{~V}_{\mathrm{DC}}$ leg of the power system would be shorted to ground. This bipolar DC link is created by center-tap-forming capacitors connected to the DC link at the input to the inverter stages (Figure 5-23). A bipolar DC link reduces the voltage stresses experienced by the IGBTs used in the grid-tie inverter. This configuration creates a virtual ground in the system and forces the DC link voltage to $\pm 400 \mathrm{~V}_{\mathrm{DC}}$ rather than the $0 \mathrm{Vdc}$ and 800 $\mathrm{V}_{\mathrm{DC}}$ required for a simple $\mathrm{DC} / \mathrm{DC}$ converter. Connecting the DC/DC converter to only the $+400 \mathrm{~V}_{\mathrm{DC}}$ rail and to ground was considered. This connection would force the return current to go through earth ground back to the source. This is true because in a DC circuit, all load current must be returned to the source to complete the circuit. It would not be viable to design a system that counted on a long current path through the earth as the return current path. In addition, only loading the plus half would imbalance the DC buss.

One way to address this incompatibility is to use an isolated DC/DC step-down converter shown in Figure 5-24. This circuit isolates the source from the load, allowing the load's negative rail to be referenced to ground, creating a unipolar DC circuit for the electrolyzer stack. The bipolar DC source potential would remain on the primary side of 
the transformer. The transformer required to do this job is a specialized, high-frequency, high-power transformer capable of operating at $10,000 \mathrm{~Hz}$ at high-current and power levels $(\sim 50 \mathrm{~kW})$. Perhaps the most challenging aspect of using this circuit is the difficulty in design to achieve reasonable efficiency. For reference, the simple DC/DC, step-down circuit efficiency is in the realm of $85 \%$ to $93 \%$. An isolated converter without advanced control and circuit design may achieve only $50 \%$ efficiency.

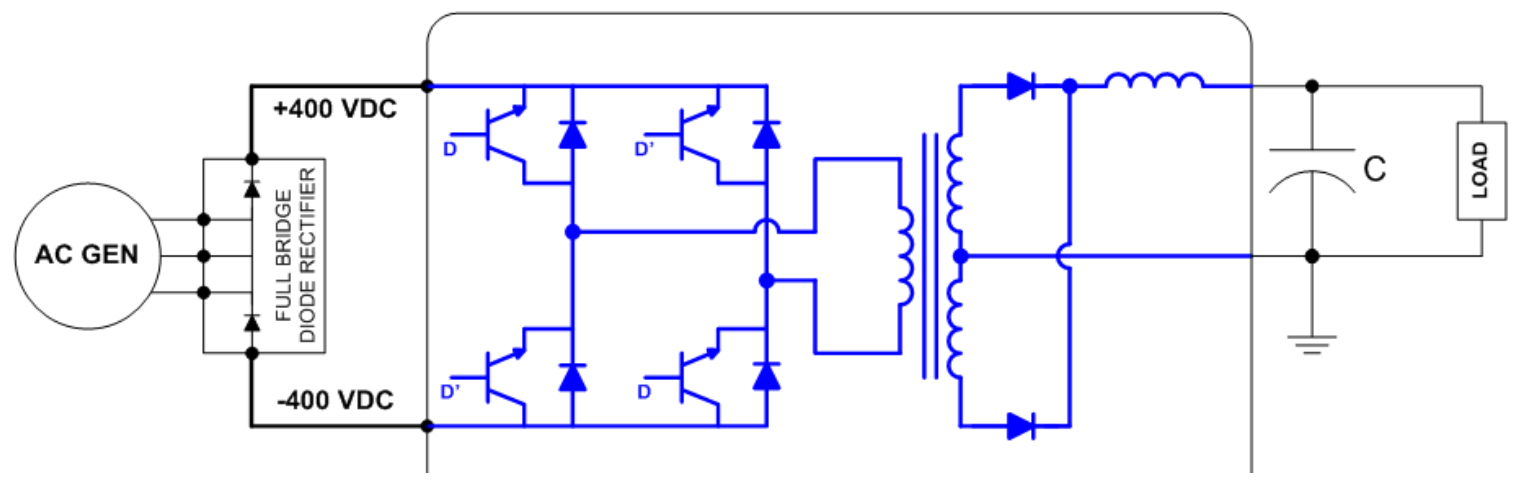

Figure 5-24: Circuit diagram of isolated DC-to-DC, step-down converter

The presence of the high-frequency transformer in the isolated, step-down converter introduces hysteresis in the I-V characteristic experienced by the IGBT and diodes. In addition, the leakage inductance of the transformer must be kept very low to achieve the energy-storage characteristics required in this topology converter.

Overall, a high-efficiency, high-power, isolated DC/DC converter appreciably complicates the design of the transformer and the PE components (including controls), compared to the basic DC/DC buck converter. The design and development of such a converter is not trivial and represents a significant investment of time and capital. Budgetary price quotes for such a high-frequency, low-leakage transformers range from $\$ 8,000$ to $\$ 30,000$. A full converter of the required specifications could potentially be ordered from a PE design and manufacturing firm for an approximate cost of $\$ 150,000$ or more with a lead time of 4-8 months. Generally, a delivered product would incorporate several paralleled, isolated converter stages controlled with tight timing constraints. Due to schedule and budget targets, procurement of such a unit has been suspended pending further study of other potential connection options.

If the bipolar DC links in the NorthWind power system were tapped and loaded externally, the control algorithm for the turbine would have to be updated. The existing system measures the voltage of the DC link and uses this information to control grid loading and turbine-rotor speed. The NorthWind controller adjusts the field current of the synchronous generator to maintain optimal power extraction. A modified control algorithm would be needed to accommodate an additional load on the DC link to ensure stable operation at the maximum power point.

Other options for streamlined connection of the NorthWind turbine to the electrolysis system also have been considered. One of these options is to tap into the "wild" AC 
power coming out of the synchronous generator. This is variable frequency and voltage reaching $575 \mathrm{~V}_{\mathrm{AC}}$ at $100 \mathrm{~kW}$. An AC/DC-controlled rectifier, based on the $10 \mathrm{~kW}$ version already being tested, would be used to convert the varying $\mathrm{AC}$ power to DC power for the electrolyzer stack. Further analysis is required to determine the effects of this method on the existing power system in the NorthWind turbine. In addition, this option poses similar turbine control modifications present with the DC/DC option. The field supply controller would no longer have accurate knowledge of the AC power produced by the generator and could become unstable. The sensing of the power and current in the turbine system would have to be modified as well as the control algorithm to take into account the offset in load created by the electrolyzer stack.

\subsubsection{Real-Time Electrolyzer Operation Linked to Wind Turbine Output}

In Figure 2-5 the electrolyzer is connected to the AC output of the NW100 grid-tie inverter. The Teledyne power supply is used to convert turbine grid $\mathrm{AC}$ power to $\mathrm{DC}$ power for the stack. A signal is routed from the NW100 control system to the Teledyne system that varies stack current based on available wind power. The electrolyzer controller varies the current to the stack based on a 0 to $6 \mathrm{~V}$ signal. This configuration demonstrates a real-time close-coupling of wind power and electrolysis stack.

To accomplish this, the power signal from the NW100 turbine will be networked to the main Wind2H2 system PLC. An analog signal between 0 and $6 \mathrm{~V}$ will be generated in a PLC module and sent to the Teledyne controller to vary stack current. Because of the time required for purging and safety verification when the electrolyzer turns off and on, the electrolyzer is not shut off completely in the absence of wind power. The electrolyzer could remain on until the wind turbine signal indicates the availability of wind power. At that point, the electrolyzer stack current is ramped up to a level corresponding to the amount of wind power available.

\subsection{Summary of Results and Key Findings}

A new AC/DC power converter was designed and tested with the $10 \mathrm{~kW}$ permanentmagnet variable-speed wind turbine. This second generation power converter produced an improved power curve to that determined from testing of the off-the-shelf first generation system. The control algorithm varies the firing angle based on the amount of power that is available from the wind turbine. A hysteresis control was added to the control algorithm so the thyristor bridge shuts off below $10 \mathrm{~Hz}$ and restarts above $20 \mathrm{~Hz}$.

The PV array testing revealed important information about the sizing of the array versus the power requirement of the stack. During testing, the improved MPPT PE package outperformed an unoptimized direct-connect configuration even with power electronics conversion losses between $10 \%$ and $35 \%$ (Table 5-3). The greater the difference between input voltage and output voltage, the greater the internal losses of the PE. Future testing will highlight an optimized stack and PV array versus the same MPPT PE. The new stack-and-a-half will require closer to $10 \mathrm{~kW}$ so concurrent testing of $5 \mathrm{~kW}$ direct versus $5 \mathrm{~kW}$ MPPT PE will no longer be possible.

Overall, a high-efficiency, high-power, isolated DC/DC power converter for the $100 \mathrm{~kW}$ wind turbine requires a highly complex design of the transformer and PE. Further 
research is required to determine the best option for close-coupling of this wind turbine to the alkaline electrolyzer stack using PE solution. This research is underway, and it includes simulation and modeling of the options and consultation with industry experts. In addition, the wind turbine power system industry will be examined to determine what commonalities exist across wind turbine power systems. This knowledge will help to build a converter and system for the NW100 PE that is applicable to as many different manufacturers' turbine power system platforms as possible. In the meantime, real-time control of the alkaline stack will be accomplished with a power signal from the wind turbine controller. Communications will be established between the main Wind2H2 PLC and the turbine controller and an analog signal will drive the alkaline stack current signal.

\section{Future Work}

Operation of the Wind2H2 system will continue with a focus on achieving the project goals laid out in this report. This includes maximizing the transfer of wind and solar energy by better integrating system components and developing optimized PE. From there, improved sequencing of electrolyzer stacks to maximize hydrogen output will be designed, implemented, and tested. These optimized system configurations will be analyzed to determine the performance of the revised systems.

One of the major tasks going forward will be to determine how improvements developed as part of the Wind $2 \mathrm{H} 2$ project can enable the development of better performing, reduced cost renewable electrolysis production systems. The results of system optimization efforts, performance measurements, and evaluation data will be used in economic models to better understand how system improvements developed as part of the Wind $2 \mathrm{H} 2$ project can lower the cost of hydrogen produced via renewable electrolysis.

\subsection{Renewable Electrolysis Cost Analysis and Modeling}

During 2009, economic modeling of renewable wind- and solar-powered electrolysis systems will be conducted based on Wind2H2 system performance data. Testing of improved control strategies and optimized system hardware will be used to provide data for H2A-based cost modeling to better understand the specific cost improvements that might be expected from improvements in system performance and integration. Thus, data from the Wind2H2 project can be used to quantify cost reductions, better illuminating how the DOE cost targets for renewable electrolysis can be met. In this way, actual operational data from the Wind $2 \mathrm{H} 2$ project can be used to inform the modeling parameters used by the $\mathrm{H} 2 \mathrm{~A}$ model.

At the same time, data from the Wind2H2 system will be used to assess the cost of hydrogen produced from a variety of renewable electrolysis scenarios. Such scenarios might include central production of hydrogen at the wind site both from wind-only operation and from grid-assisted operation, and centralized production of hydrogen outside an urban area with energy supplied to the grid from a remote wind farm. This type of modeling will provide context to evaluate the Wind $2 \mathrm{H} 2$ system as a component in the larger energy infrastructure. 
Finally, NREL analysts are modeling the use of hydrogen as an energy storage mechanism. A hydrogen-based energy storage system would include many of the same system elements that are found in the Wind $2 \mathrm{H} 2$ project, namely a renewable energy source, an electrolyzer system, a hydrogen storage system, and a hydrogen genset or fuel cell capable of converting stored hydrogen back to electricity and exported to the electric grid. Data from the Wind2H2 project will be used as part of this modeling effort to better estimate the cost of using hydrogen as an energy storage mechanism.

\subsection{PV-Powered Electrolysis (Phase 2)}

The Wind2H2 project has taken delivery of an additional 10-cell PEM stack cells (Figure 6-1) that will be added in series with the existing E-120 stack. The resulting combined stack will have a total of 30 cells, resulting in operating voltage of $\sim 65 \mathrm{~V}$. The rated current $(135 \mathrm{~A})$ is unchanged, resulting in a stack power rating of $8.8 \mathrm{~kW}$. This upgrade would shift the polarization curve toward the maximum power point of the PV array, as shown in Figure 6-2. This will allow an optimized direct connection to the PV array in which the stack operating voltage closely matches the MPP voltage $\left(\mathrm{V}_{\mathrm{MAX}}=65.6 \mathrm{~V}\right)$ of the solar array. The direct connection tests will be repeated and compared to the performance of the MPPT power converter.

Deionized water flow and temperature sensors will be incorporated in series with the existing DI water supply lines to the full and half stacks. Input and output temperature of the DI water to the stack will be recorded for use in refined stack efficiency calculations.

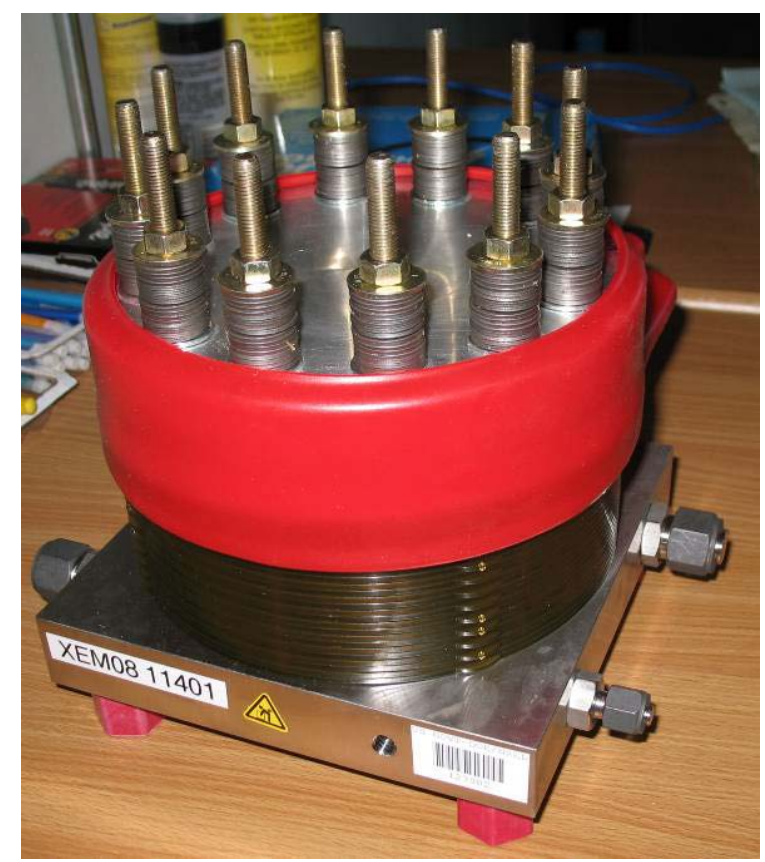

Figure 6-1: Additional 10-cell PEM stack cells to be installed in series with existing 20-cell stack inside E-120 electrolyzer 


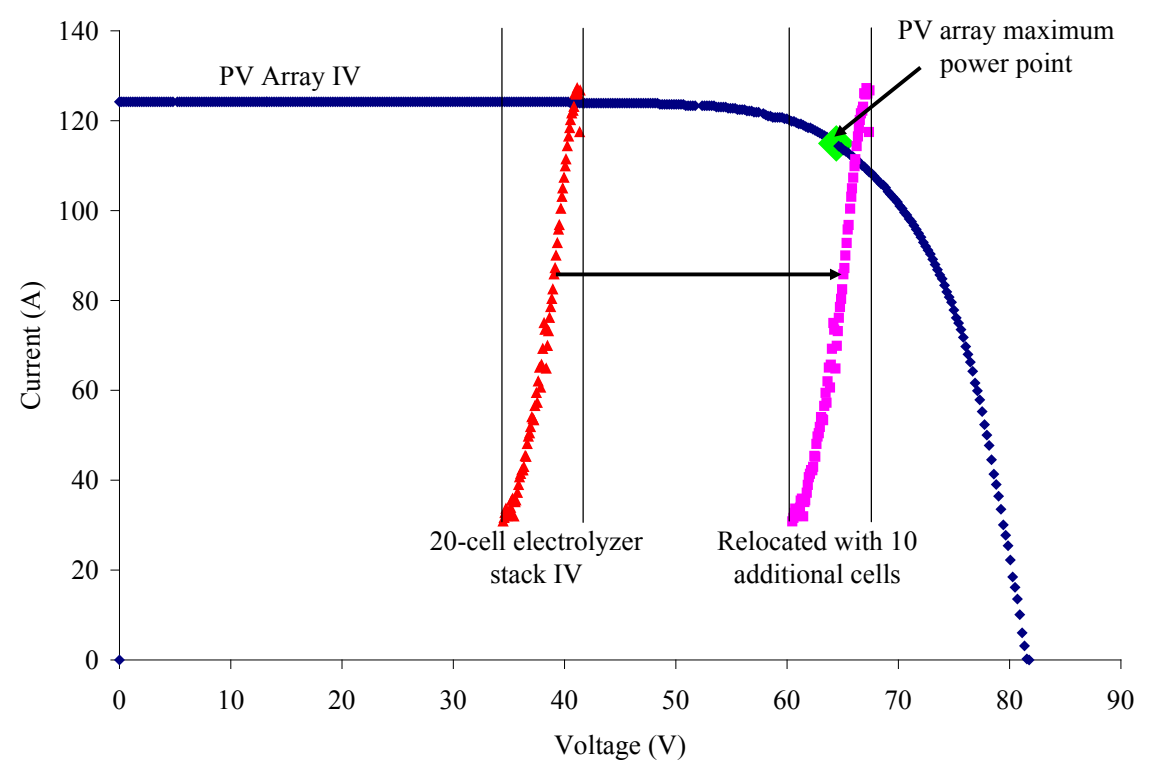

Figure 6-2: Impacts of adding 10 additional electrolyzer cells to the 20 -cell stack

The test setup provides an example of the importance of appropriate sizing considerations and how this affects the most desirable performance for both renewable sources and electrolyzer stacks. An electrolyzer stack with the appropriate number of cells and active area would operate closer to the maximum power point (e.g., knee) of the slightly oversized PV area (Figure 6-2).

To enhance data acquisition of solar irradiance during solar PV testing, the installation of a solar reference cell is underway. The cell is mounted on the PV array rack such that it always has the same tilt as the array panels. The reference cell will provide a precise measurement of the irradiance seen by the PV array. The reference cell provides an open circuit voltage signal and a short circuit current signal that will be monitored by the data acquisition system. From these data, the irradiance value is adjusted for temperature and output to the data collection system. The Unitronix PLC in the DC/DC power converter will sense the voltage and current and calculate the adjusted irradiance and then output these data to the main Wind2H2 PLC in the control building. The use of this reference cell will help to resolve the timing discrepancy between the current PSP data having an averaged sample rate of once per minute and the Wind2H2 PLC sample frequency of 10 $\mathrm{S} / \mathrm{s}$. This will enable a more accurate normalization of the power and energy output of the solar array when comparing PV trials.

\section{$6.310 \mathrm{~kW}$ Wind-Powered Electrolysis}

One of the first priorities in this next phase of testing is to complete the $10 \mathrm{~kW}$ AC/DC converter upgrades. This testing will use new wind-speed data to enhance the MPPT capability of the system. Testing of this next generation of PEM electrolysis powered by a $10 \mathrm{~kW}$ variable output wind turbine is expected to begin in early 2009 . With improved wind speed measurement and power readings, the upgraded variable AC/DC converter will function as a wind turbine MPPT converter supplying an electrolyzer stack. The majority of the work for the third generation converter involved installing the new 
anemometer data acquisition system, mounting the AC/DC PE converter in its permanent location in the DERTF and refining the control programming for the converter.

As of January 2009, all updated hardware is in place for third generation testing. A control algorithm that controls power extraction by maintaining an optimal tip-speed ratio of the turbine is currently in testing. Initial results indicated slightly increased energy capture. The control parameters will be tuned to maximize energy extraction. This revision of this project will demonstrate an important capability of PE converters in renewable energy applications to extract the maximum possible power and to provide regulated output power to the load. The goal of this project is to demonstrate how the maximum amount of hydrogen can be produced from a variable wind source.

Further work will be performed to optimize the share of computing load between the FPGA and the real-time controller. Although converter efficiency is high (better than $90 \%$ ), opportunities for efficiency improvements will be investigated and implemented wherever possible.

Future work will include sensor calibrations and hardware to allow direct communications with the PEM electrolyzer for automated, unattended operation. We will include additional optimization of the control strategy and hardware to maximize the power output to the electrolyzer. The control strategy will utilize optimal control strategies that will operate the electrolyzer at their highest efficiency for a variable wind input. The objective will be to produce as much hydrogen as possible for a given wind profile.

\section{$6.4100 \mathrm{~kW}$ Wind-Powered Electrolysis}

Further research is required to determine the best option for close-coupling of the NorthWind $100 \mathrm{~kW}$ turbine to the Teledyne electrolyzer stack using custom PE. This research is underway and includes simulation and modeling of the electronics topology options and consultation with industry experts. In addition, the wind turbine power system industry will be examined to determine what commonalities exist across windturbine power systems. This research will enable development of a power converter topology that is applicable to as many different manufacturers' turbine power system platforms as possible.

In the meantime, Phase 1 will use a networked power signal from the remotely located (1/4 mile) NorthWind 100 turbine to power the $35 \mathrm{~kW}$ alkaline electrolyzer stack in realtime. Electrolyzer duty cycle and response to the varying wind energy will be analyzed and presented in the next technical report. 


\subsection{Electrolyzer Sequencing and Autonomous Operation}

Electrolyzer stack sequencing in response to varying renewable energy sources will be tested. The goal is to determine a strategy for turning the available electrolyzer stacks on, off, up, or down to maximize the hydrogen production from a given renewable energy input. Included in this set of work is the full automation of the Wind2 2 system. The system will be automated to turn itself on and off at prescheduled times, varying stack current to test different sequencing strategies and maintain all safety functions.

\section{Conclusion}

The Wind2H2 system is fully operational and continues to gather performance data. All hydrogen system components, as well as the control and data acquisition system, are available for testing and are running under daily operations. The Wind $2 \mathrm{H} 2$ system provides an excellent platform to achieve the objectives of this project, namely to demonstrate a renewable energy hydrogen production system, gain operational experience, evaluate system performance and cost, optimize system integration, and explore opportunities for system optimizations resulting in performance increases and cost reductions.

Valuable operational experience in running and managing the Wind2H2 system has been gained through testing, daily operations, and troubleshooting. Streamlining startup procedures, data acquisition, analysis, maintenance, and component tuning have given the NREL system operators expertise in keeping the system functional and optimizing performance.

Stack and system efficiency for PEM electrolyzers were determined by sweeping stack current from rated 135 A down to about 5 A. Stack efficiency increases to over $95 \%$ with roughly $5 \mathrm{~A}$ supplied to the stack. At rated current (135 A), the stack efficiency drops to $\sim 75 \%$. On the other hand, system efficiency reaches a maximum of $57 \%$ at rated current and falls to $0 \%$ at about $15 \mathrm{~A}$. These efficiencies are based on the HHV of hydrogen.

The flexibility of the system and the numerous system configurations that are available has allowed engineers to conduct performance evaluation of system components, including the development of baseline electrolyzer power curves and measurement of electrolyzer efficiency. The alkaline electrolyzer (E-110) stack efficiency was determined to be over $90 \%$ at $30 \mathrm{~A}$, falling to $\sim 70 \%$ at rated current $(220 \mathrm{~A}$ ). Total system efficiency reached a maximum of $41 \%$ at rated current and fell to $0 \%$ at just below $35 \mathrm{~A}$ to the stack. A system efficiency of $50 \%$ would be the result if the rated hydrogen flow from the electrolyzer is realized at $40 \mathrm{~kW}$ system power. These stack and system efficiencies are based on the HHV of hydrogen.

In addition to performance evaluation and measurement, investigations were undertaken to better integrate system components and optimize system performance. An analysis of wind-powered electrolysis production systems found that optimization of the PE section could reduce the overall cost of hydrogen by $7 \%$. Based on this potential cost improvement, an $\mathrm{AC} / \mathrm{DC} \mathrm{PE}$ system was designed and tested in the Wind2H2 system using a $10 \mathrm{~kW}$ wind turbine and PEM electrolyzer stack. Tests show the dynamic 


\section{KEY FINDINGS}

- Efficiency Measurements: Electrolyzer system efficiency was measured for both the polymer electrolyte membrane and alkaline electrolyzer technologies at various stack current levels. At full stack current (135 A), the polymer electrolyte membrane electrolyzer had a system efficiency of 57\% HHV (49\% LHV). At the rated stack current of $220 \mathrm{~A}$, the alkaline system had a system efficiency of $41 \%$ HHV (35\% LHV). Testing at the Wind $2 \mathrm{H} 2$ facility found the hydrogen production flow rate from the alkaline system to be about $20 \%$ lower than the manufacturer's rated flow rate.

- Cost Reductions from Power Electronics Optimization: Analysis showed a potential $7 \%$ reduction in cost per kg of hydrogen based on capital cost improvement by eliminating the inverter from the wind turbine and the AC/DC power electronics in the electrolyzer and replacing them with a DC/DC converter between a wind turbine and electrolyzer stack, with the projected cost of hydrogen falling to $\$ 5.83 / \mathrm{kg}$ from a baseline of $\$ 6.25 / \mathrm{kg}$. Better matching the electrical characteristics of renewable energy sources to the hydrogen-producingstacks would further improve system efficiency and further lower overall cost.

- Energy Transfer Improvements: PV configuration testing compared a suboptimal direct-connect from the PV array to the electrolyzer stack with a connection through a maximum power point tracking power electronics package. Measurements of the power electronics system showed energy conversion losses between $10 \%$ and $35 \%$, depending on PV array input voltage. In all cases however, the MPPT power electronics system captured between $10 \%$ and $20 \%$ more energy than the direct-connect configuration.

\section{LESSONS LEARNED}

- System Integration: Integrated renewable electrolysis systems require that system components from different manufacturers be configured to function smoothly together.

- Implementation of complete renewable electrolysis systems will require systems level design and integration. Until standardized systems with matched system components are developed, systems integrators will need to determine appropriate component sizes to meet the needs of electrolysis-based energy storage projects on a case-by-case basis.

- Development of optimized power electronics packages that can maximize energy transfer, improve overall system efficiency, reduce system complexity, and lower capital costs is a particularly promising area for systems-level improvements. 


\section{Appendices}

\section{Appendix A: Photovoltaic Solar Array Information}

Tables A-1 through A-4 are maximum power point parameters for the solar array.

Table A-1

\section{PV CONFIG A-1}

\begin{tabular}{|c|c|}
\hline \multicolumn{2}{|l|}{ PANEL ARRAY AREA } \\
\hline cell length and width [in] & 4.47 \\
\hline square inch per cell [in $\left.{ }^{2}\right]$ & 19.99 \\
\hline square inch per panel [in'] & 1439.40 \\
\hline number of panels & 64 \\
\hline square inch total $\left[\mathrm{in}^{2}\right]$ & 92121.43 \\
\hline square meter total [ $\left.\mathrm{m}^{2}\right]$ & 59.43 \\
\hline \multicolumn{2}{|l|}{ RATIRGS } \\
\hline mpp voltage [V] & 16.40 \\
\hline mpp current [A] & 6.68 \\
\hline max rated power [M] & 109.55 \\
\hline max open circuit voltage [V] & 20.60 \\
\hline max short circuit current [A] & 7.38 \\
\hline
\end{tabular}

\section{At $800 \mathrm{~W} / \mathrm{m}^{2}$ Irradiance}

\begin{tabular}{|l|r|}
\hline power [M] & 78.30 \\
\hline current [A] & 5.76 \\
\hline voltage [V] & 13.59 \\
\hline \multicolumn{2}{|c|}{} \\
\hline Calculation Values & 16.4 \\
\hline panel voltage [V] & 6.68 \\
\hline panel current [A] &
\end{tabular}

\section{EAST Connection Configuration}

number of panels in series string number of strings used

number of strings in series

number of series strings in parallel

\begin{tabular}{|r|r|}
\hline & 4 \\
\hline & 12 \\
\hline & 12 \\
\hline
\end{tabular}

WEST Connection Configuration

number of panels in series string

number of strings used

number of strings in series

number of series strings in parallel

\begin{tabular}{|l|r|}
\hline & 4 \\
\hline & 4 \\
\hline & 1 \\
\hline
\end{tabular}

\section{EAST ARRAY TOTALS}

MP VOLTAGE [V]

MP CURRENT [A]

MAX POMER [KM]

\section{WEST ARRAY TOTALS}

MP VOLTAGE [V]

MP CURRENT [A]

MAX POMER [KW]

\section{EAST PARALLEL WEST TOTAL}

VOLTAGE [V]

CURRENT [A.

106.9

POMER [KM]
Table A-2

\section{PV CONFIG A-2}

\begin{tabular}{|l|r|}
\hline \multicolumn{2}{|l|}{ PANEL ARRAY AREA } \\
\hline cell length and width [in] & 4.47 \\
\hline square inch per cell $\left[i n^{2}\right]$ & 19.99 \\
\hline square inch per panel [in $\left.{ }^{2}\right]$ & 1439.40 \\
\hline number of panels & 64 \\
\hline Square inch total $\left[\mathrm{in}^{2}\right]$ & 92121.43 \\
\hline square meter total $\left[\mathrm{m}^{2}\right]$ & $\mathbf{5 9 . 4 3}$ \\
\hline
\end{tabular}

\section{RATINGS}

\begin{tabular}{|l|r|}
\hline mpp voltage [V] & 16.40 \\
\hline mpp current [A] & 6.68 \\
\hline max rated power [W] & 109.55 \\
\hline max open circuit voltage [V] & 20.60 \\
\hline max short circuit current $[\mathrm{A}]$ & 7.38 \\
\hline
\end{tabular}

\begin{tabular}{|l|r|}
\hline At $800 \mathbf{~ W / \mathbf { m } ^ { 2 }}$ Irradiance $^{-}$ \\
\hline power $[\mathrm{M}]$ & 78.30 \\
\hline current $[A]$ & 5.76 \\
\hline voltage $[\mathrm{V}]$ & 13.59 \\
\hline
\end{tabular}

\begin{tabular}{|l|r|}
\hline \multicolumn{2}{|l|}{ Calculation Values } \\
\hline panel voltage [V] & 16.4 \\
\hline panel current $[\mathrm{A}$ ] & 6.68 \\
\hline
\end{tabular}

\begin{tabular}{|l|r|}
\hline EAST Connection Configuration \\
\hline number of panels in series string & 4 \\
\hline number of strings used & 12 \\
\hline number of strings in series & 2 \\
\hline number of series strings in parallel & 6 \\
\hline
\end{tabular}

\begin{tabular}{|l|r|}
\hline \multicolumn{2}{|l|}{ WEST Connection Configuration } \\
\hline number of panels in series string & 4 \\
\hline number of strings used & 4 \\
\hline number of strings in series & 2 \\
\hline number of series strings in parallel & 2 \\
\hline
\end{tabular}

\section{EAST ARRAY TOTALS}

\begin{tabular}{|l|r|}
\hline$M P$ VOLTAGE [V] & 131.2 \\
\hline MP CURRENT [A] & 40.1 \\
\hline MAX POMNER [KM] & 5.258 \\
\hline
\end{tabular}

\section{WEST ARRAY TOTALS}

\begin{tabular}{|l|r|}
\hline MP $\vee O L T A G E ~[V]$ & 131.2 \\
\hline MP CURRENT [A] & 13.4 \\
\hline MAX POMER [KM] & 1.753 \\
\hline
\end{tabular}

\section{EAST PARALLEL WEST TOTAL}

\begin{tabular}{|l|r|}
\hline VOLTAGE [V] & 131.2 \\
\hline CURRENT [A] & 53.4 \\
\hline POMER [KN] & 7.011 \\
\hline
\end{tabular}


Table A-3

\section{PV CONFIG A-3}

\begin{tabular}{|c|c|}
\hline $\begin{array}{l}\text { PAREL ARRAY AREA } \\
\text { cell length and width [in] }\end{array}$ & 4.47 \\
\hline square inch per cell $\left[\mathrm{in}^{2}\right]$ & 19.99 \\
\hline square inch per panel $\left[\mathrm{in}^{2}\right]$ & 1439.40 \\
\hline number of panels & 64 \\
\hline square inch total $\left[\mathrm{in}^{2}\right]$ & 92121.43 \\
\hline square meter total $\left[\mathrm{m}^{2}\right]$ & 59.43 \\
\hline \multicolumn{2}{|l|}{ RATINGS } \\
\hline mpp voltage $[\mathrm{V}]$ & 16.40 \\
\hline mpp current $[\hat{A}]$ & 6.68 \\
\hline max rated power [M] & 109.55 \\
\hline max open circuit voltage [ $\mathrm{V}$ ] & 20.60 \\
\hline max short circuit current [A] & 7.38 \\
\hline
\end{tabular}

\begin{tabular}{|l|r|}
\hline At $\mathbf{8 0 0} \mathbf{~ W / \mathbf { m } ^ { 2 }}$ Irradiance \\
\hline power [M] & 78.30 \\
\hline current $[\mathrm{A}]$ & 5.76 \\
\hline voltage [ $\mathrm{V}$ ] & 13.59 \\
\hline
\end{tabular}

\section{Calculation Values}

panel voltage [ $\mathrm{V}$ ]

panel current [A.]

\section{EAST Connection Configuration

\begin{tabular}{|l|r|}
\hline number of panels in series string & 4 \\
\hline
\end{tabular} \\ number of strings used \\ number of strings in series number of series strings in parallel}

\section{WEST Connection Configuration}

number of panels in series string

number of strings used

number of strings in series

number of series strings in parallel

EAST ARRAY TOTALS
\begin{tabular}{|l|r|}
\hline MP $\vee O L T A G E[V]$ & 262.4 \\
\hline MP CURRENT [A] & 20.0 \\
\hline MAX POMVR [KM] & 5.258 \\
\hline
\end{tabular}

\section{WEST ARRAY TOTALS}

\begin{tabular}{|l|r|}
\hline MP VOLTAGE [V] & 262.4 \\
\hline MP CURRENT [A] & 6.7 \\
\hline MAX POMER [KM] & 1.753 \\
\hline
\end{tabular}

\section{EAST PARALLEL WEST TOTAL}

\begin{tabular}{|l|r|}
\hline VOLTAGE [V] & 262.4 \\
\hline CURRENT [A] $]$ & 26.7 \\
\hline PONER [KM] & 7.011 \\
\hline
\end{tabular}

Table A-4

\section{PV CONFIG A-4}

\begin{tabular}{|c|c|}
\hline cell length and width [in] & 4.47 \\
\hline square inch per cell $\left[\mathrm{in}^{2}\right]$ & 19.99 \\
\hline Square inch per panel $\left[i n^{2}\right]$ & 1439.40 \\
\hline number of panels & 64 \\
\hline square inch total $\left[i n^{2}\right]$ & 92121.43 \\
\hline Square meter total [ $\left.\mathrm{m}^{2}\right]$ & 59.43 \\
\hline \multicolumn{2}{|l|}{ RATIIGS } \\
\hline mpp voltage [V] & 16.40 \\
\hline mpp current [A] & 6.68 \\
\hline max rated power [M] & 109.55 \\
\hline max open circuit voltage [V] & 20.60 \\
\hline max short circuit current [A] & 7.38 \\
\hline
\end{tabular}

\begin{tabular}{|c|c|}
\hline power [M] & 78.30 \\
\hline current $[\mathrm{A}]$ & 5.76 \\
\hline voltage [ $\mathrm{V}$ ] & 13.59 \\
\hline
\end{tabular}

\begin{tabular}{|l|r|}
\hline \multicolumn{2}{|l|}{ Calculation Values } \\
\hline panel voltage [V] & 16.4 \\
\hline panel current $[\mathrm{A}]$ & 6.68 \\
\hline \multicolumn{2}{|c|}{} \\
\hline EAST Connection Configuration \\
\hline number of panels in series string & 4 \\
\hline number of strings used & 12 \\
\hline number of strings in series & 1 \\
\hline number of series strings in parallel & 12 \\
\hline
\end{tabular}

\begin{tabular}{|l|r|}
\hline \multicolumn{2}{|l|}{ WEST Connection Configuration } \\
\hline number of panels in series string & 4 \\
\hline number of strings used & 4 \\
\hline number of strings in series & 1 \\
\hline number of series strings in parallel & 4 \\
\hline
\end{tabular}

EAST ARRAY TOTALS
\begin{tabular}{|l|r|}
\hline MP $\vee O L T A G E[V]$ & 65.6 \\
\hline MP CURRENT [A] & 80.2 \\
\hline MAX POMER [KM] & 5.258 \\
\hline
\end{tabular}

\begin{tabular}{|l|r|}
\hline \multicolumn{2}{|l|}{ WEST ARRAY TOTALS } \\
\hline MP $\vee O L T A G E[\vee]$ & 65.6 \\
\hline MP CURRENT [A] & 26.7 \\
\hline MAX POMER [KM] & 1.753 \\
\hline
\end{tabular}

EAST PARALLEL WEST TOTAL
\begin{tabular}{|l|r|}
\hline VOLTAGE $[\vee]$ & 65.6 \\
\hline CURRENT $[A]$ & 106.9 \\
\hline POMVR $[K M]$ & 7.011 \\
\hline
\end{tabular}


Table A-5 shows the calculation for the tilt angle of the PV array.

Table A-5: Solar array tilt angle calculations.

\begin{tabular}{|c|c|c|c|c|c|c|}
\hline \multirow[t]{2}{*}{ panel length } & 57.5 & & & & & \\
\hline & & & $y$ & $\boldsymbol{x}$ & angle (rad) & angle (deg) \\
\hline 4 holes showing & 23.50 & 54.00 & 30.50 & 48.74 & 0.51 & 28.99 \\
\hline 3 holes showing & 24.30 & 52.25 & 27.95 & 50.25 & 0.47 & 26.77 \\
\hline 2 holes showing & 25.00 & 50.25 & 25.25 & 51.66 & 0.43 & 24.36 \\
\hline 1 hole showing & 25.75 & 48.00 & 22.25 & 53.02 & 0.38 & 21.62 \\
\hline last hole & 26.50 & 46.00 & 19.50 & 54.09 & 0.33 & 19.06 \\
\hline lowest & 26.50 & 45.50 & 19.00 & 54.27 & 0.32 & 18.59 \\
\hline
\end{tabular}

\section{Appendix B: Stack and System-Efficiency Calculation Methods Higher Heating Value}

Energy must be provided for the electrochemical process of electrolysis to proceed. The total amount of energy required to decompose water is made up of both electrical and thermal energy known as enthalpy $(\mathrm{H})$. The amount of electrical energy required is known as the Gibbs free energy $(\mathrm{G})$ and corresponds to the maximum amount of useable electrical energy available when hydrogen recombines with oxygen in a fuel cell. Irreversible energy $(\mathrm{S})$ is the "cost of doing business" and is dependent on the temperature at which the reaction takes place. The loss due to entropy $(\mathrm{S})$ is much like the way a bouncing ball loses energy with the floor as friction from the action of bouncing causes a transfer of thermal energy to atoms in the floor. The energy transferred to those floor atoms dissipates and is not recoverable. Consequently, the change $(\Delta)$ in these quantities from a standard set of conditions follows the form of Equation 1.

$$
\Delta \mathrm{H}=\Delta G+T \Delta S \quad \text { (Equation } 1)
$$

It is clear from Equation 1 that the difference between the change in Gibbs free energy and the change in total energy (enthalpy) is accounted for by a change in entropy (S) in the process. Because the change in entropy cannot be delivered as (or converted to) electricity, it must be supplied (or liberated) as heat.

The standard enthalpy, or heat of formation, $\Delta_{\mathrm{f}} \mathrm{H}^{\circ}$, is essentially a constant over a wide range of temperatures and represents the total (thermal and electrical) amount of energy required to dissociate water. The standard enthalpy of formation for liquid water is $-285,840 \mathrm{~J} \mathrm{~mol}^{-1}$. Note that if you burn a mole of hydrogen, you would receive this full amount of heat back. So when hydrogen and oxygen are formed from water, the full $285,840 \mathrm{~J} \mathrm{~mol}^{-1}$ is required in one way or another.

Only a fraction of this energy is available as recoverable (reversible) electrical energy when the hydrogen and oxygen are combined in a fuel cell. The heat of formation 
represented in Joules per mole is easily converted into more common forms of the higher heating value. Signs are dropped from here on, noting that the process of electrolysis requires energy to be added to the system and would therefore be negative.

$$
\begin{aligned}
& 285,840 \frac{\mathrm{J}}{\mathrm{mol}} * \frac{1 \mathrm{~mol} \mathrm{H}_{2}}{2.0158 \mathrm{~g}} * \frac{1000 \mathrm{~g}}{1 \mathrm{~kg}}=141,799,781 \frac{\mathrm{J}}{\mathrm{kg}}=141.8 \frac{\mathrm{MJ}}{\mathrm{kg}} \\
& 141.8 \frac{\mathrm{MJ}}{\mathrm{kg}}=\frac{1 \mathrm{watt}-\mathrm{sec}}{\mathrm{J}} * \frac{1 \mathrm{~kW}}{1000 \mathrm{w}} * \frac{1 \mathrm{hr}}{3600 \mathrm{sec}}=39.4 \frac{\mathrm{kWh}}{\mathrm{kg}}
\end{aligned}
$$

The voltage corresponding to the HHV is $1.48 \mathrm{~V} \mathrm{cell}^{-1}$ as shown in Equation 2. This represents the thermoneutral voltage where hydrogen and oxygen would be produced with $100 \%$ thermal efficiency (i.e., no waste heat produced from the reaction). This is determined by dividing the HHV $\left(285,840 \mathrm{~J} \mathrm{~mol}^{-1}\right)$ by the Faraday constant $(\mathrm{F}=96,485$ coulombs mole $\left.{ }^{-1}\right)$ and the number of electrons needed to create a molecule of $\mathrm{H}_{2}(\mathrm{z}=2)$.

$$
\mathrm{E}_{\mathrm{o}}=\frac{\Delta_{f} H^{\mathrm{o}}}{z F}=\frac{285,840 \frac{\mathrm{J}}{\mathrm{mol}}}{2 * 96,485 \frac{\mathrm{C}}{\mathrm{mol}}}=1.48 \frac{\text { Volts }}{\mathrm{cell}}
$$

The cell voltage corresponding to the (reversible) Gibbs free energy change is calculated the same way as the thermoneutral voltage. Recalling Equation 1 and solving for $\mathrm{G}$, it is clear that only a portion of the enthalpy $(\mathrm{H})$ is available as useable electrical (reversible) energy $(\mathrm{G})$. This portion is represented by $\Delta_{\mathrm{f}} \mathrm{G}^{\circ}$ and is equal to $-237,122$ when the TS term is subtracted from the total enthalpy $(\mathrm{H})$ and is known as the lower heating value (LHV).

The measured entropy values, in Joules per degree Kelvin, for one mole of the reactants and products are provided here.

$$
\mathrm{S}_{\mathrm{H}_{2} 0}=69.9 \frac{\mathrm{J}}{\mathrm{K}} \quad \mathrm{S}_{\mathrm{H}_{2}}=130.7 \frac{\mathrm{J}}{\mathrm{K}} \quad \mathrm{S}_{\mathrm{O}_{2}}=205.1 \frac{\mathrm{J}}{\mathrm{K}}
$$

The "standard" condition, denoted with the superscript $o$, is at $25^{\circ} \mathrm{C}\left(\mathrm{T}_{\mathrm{k}}=298.15\right)$. The change in entropy $(\mathrm{S})$ is used to compensate for the voltage variation due to temperature. Subtracting the entropy of the reactants 69.9 from the products $(130.7+1 / 2205.1)$ the system's entropy is determined to be $163.4 \mathrm{~J} \mathrm{~K}^{-1} \mathrm{~mol}^{-1}$.

$$
\Delta_{f} \mathrm{G}^{\mathrm{o}}=\Delta_{f} \mathrm{H}^{\mathrm{o}}-T \Delta S=-285,840 \frac{\mathrm{J}}{\mathrm{mol}}-(298.15 \mathrm{~K})\left(-163.4 \frac{\mathrm{J}}{\mathrm{mol} \mathrm{K}}\right)=-237,122 \frac{\mathrm{J}}{\mathrm{mol}}
$$

And substituting this into Equation 3 yields a reversible potential of $1.23 \mathrm{~V} \mathrm{cell}^{-1}$. 


$$
\mathrm{E}_{\mathrm{o}}=-\frac{\Delta_{f} G^{\mathrm{o}}}{z F}=-\frac{-237,122 \frac{\mathrm{J}}{\mathrm{mol}}}{2 * 96,485 \frac{\mathrm{C}}{\mathrm{mol}}}=1.23 \frac{\text { Volts }}{\mathrm{cell}}
$$

It is clear that ratio of reversible free energy potential $(1.23 \mathrm{~V})$ over the thermoneutral voltage $(1.48 \mathrm{~V})$ is $83.1 \%$. This represents the highest efficiency attainable when using the LHV to determine stack voltage efficiency. The reporting of efficiencies using the LHV is misleading unless this fact is acknowledged. It is therefore thermodynamically correct to use the HHV because it accounts for the total amount of energy in the electrolysis process.

\section{System Efficiency}

As noted above, the standard enthalpy, or heat of formation, $\Delta_{\mathrm{f}} \mathrm{H}^{\circ}$, represents the total (thermal and electrical) amount of energy required to dissociate water. The standard enthalpy of formation for liquid water is $-285,840 \mathrm{~J} \mathrm{~mol}^{-1}$. This represents the minimum amount of energy required to produce hydrogen from the electrolysis of water. Following the unit conversion calculation above, it can be seen that on a higher heating value basis, it would take a minimum of $39.4 \mathrm{kWh}$ of energy to produce $1 \mathrm{~kg}$ of hydrogen. Thus, a $100 \%$ efficient electrolyzer system would require $39.4 \mathrm{kWh} / \mathrm{kg}$ of hydrogen, with less than perfect efficient systems requiring more energy.

\section{Stack Efficiency}

The stack potential begins at $1.48 \mathrm{~V}$, representing the total amount of energy required to dissociate water. Electrochemical compression of the gasses is not free and therefore is compensated for by using the Nernst potential $\left(\mathrm{V}_{\mathrm{n}}\right)$ to arrive at an "ideal" stack voltage at that pressure.

$$
\mathrm{V}_{\mathrm{n}}=1.48+\frac{\mathrm{RT}}{\mathrm{z} F} \ln \left(\frac{\mathrm{P}_{\mathrm{H}_{2}} \mathrm{P}_{\mathrm{O}_{2}}^{\frac{1}{2}}}{\mathrm{P}_{\mathrm{H}_{2} \mathrm{O}}}\right)
$$

(Equation 4)

Equation 4 shows that $V_{n}$ is composed of the total $(\mathrm{HHV}, 1.48 \mathrm{~V})$ potential. $\mathrm{R}$ is the Universal gas constant $(8.341 \mathrm{~J} / \mathrm{mol}-\mathrm{K}), \mathrm{T}$ is the average operating temperature in Kelvin, $\mathrm{z}$ represents the number of electrons participating in the overall reaction (2), $\mathrm{F}$ is Faraday's constant $(96,485 \mathrm{C} / \mathrm{mol}), \mathrm{P}_{\mathrm{H} 2}$ is the pressure (atm) of the cathode, $\mathrm{P}_{\mathrm{O} 2}$ is the pressure (atm) of the anode, and $\mathrm{P}_{\mathrm{H} 20}$ is the pressure (atm) of the anode feed water.

The Nernst potential $\left(\mathrm{V}_{\mathrm{n}}\right)$ adds an additional term to the voltage (HHV) to account for the electrochemical compression energy that is being delivered to pressurize the cathode (hydrogen) side of the cells. 
This stack efficiency is where the theoretical stack voltage is determined based on stack operating parameters and compared with the actual operating voltage of the stack shown in Equation 5.

$$
\text { Stack Voltage Efficiency }=\frac{\text { Ideal Stack Potential }}{\text { Actual Stack Potential }} \quad \text { (Equation 5) }
$$

Because the ideal stack potential is compared with the actual stack voltage, the stack voltage efficiency represents the degree of departure of the operating stack from the ideal condition. 


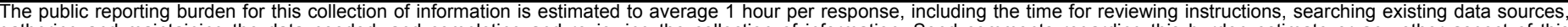

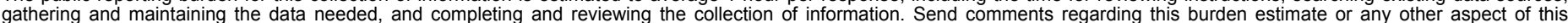

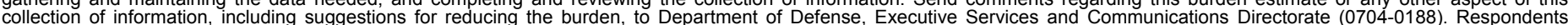

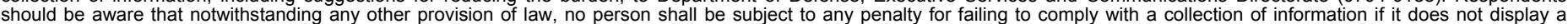

should be aware that notwithstanding

PLEASE DO NOT RETURN YOUR FORM TO THE ABOVE ORGANIZATION.

\begin{tabular}{l|l|l|l} 
1. REPORT DATE (DD-MM-YYYY) & 2. REPORT TYPE & 3. DATES COVERED (FrOm - TO)
\end{tabular} March 2009

Technical Report

4. TITLE AND SUBTITLE

The Wind-to-Hydrogen Project: Operational Experience,

Performance Testing, and Systems Integration 5a. CONTRACT NUMBER

DE-AC36-08-GO28308

5b. GRANT NUMBER

5c. PROGRAM ELEMENT NUMBER

5d. PROJECT NUMBER

NREL/TP-550-44082

5e. TASK NUMBER

$\mathrm{H} 271.3730$

5f. WORK UNIT NUMBER
7. PERFORMING ORGANIZATION NAME(S) AND ADDRESS(ES)

National Renewable Energy Laboratory

1617 Cole Blvd.

Golden, CO 80401-3393
8. PERFORMING ORGANIZATION REPORT NUMBER

NREL/TP-550-44082

9. SPONSORING/MONITORING AGENCY NAME(S) AND ADDRESS(ES)

10. SPONSOR/MONITOR'S ACRONYM(S) NREL

11. SPONSORING/MONITORING AGENCY REPORT NUMBER

12. DISTRIBUTION AVAILABILITY STATEMENT

National Technical Information Service

U.S. Department of Commerce

5285 Port Royal Road

Springfield, VA 22161

13. SUPPLEMENTARY NOTES

14. ABSTRACT (Maximum 200 Words)

The Wind2H2 system is fully functional and continues to gather performance data. In this report, specifications of the Wind2H2 equipment (electrolyzers, compressor, hydrogen storage tanks, and the hydrogen fueled generator) are summarized. System operational experience and lessons learned are discussed. Valuable operational experience is shared through running, testing, daily operations, and troubleshooting the Wind2H2 system and equipment errors are being logged to help evaluate the reliability of the system.

\section{SUBJECT TERMS}

NREL; National Renewable Energy Laboratory; Xcel Energy; maximum power point tracking; MPPT; electrolyzers; electrolysis; wind turbine; photovoltaic array; hydrogen; Wind2H2

\begin{tabular}{|c|c|c|c|c|c|}
\hline 16. SECURITY & CLASSIFICATI & N OF: & 17. LIMITATION & 18. NUMBER & 19a. NAME OF RESPONSIBLE PERSON \\
\hline $\begin{array}{l}\text { a. REPORT } \\
\text { Unclassified }\end{array}$ & $\begin{array}{l}\text { b. ABSTRACT } \\
\text { Unclassified }\end{array}$ & $\begin{array}{l}\text { c. THIS PAGE } \\
\text { Unclassified }\end{array}$ & UL & & 19b. TELEPHONE NUMBER (Include area code) \\
\hline
\end{tabular}

